\title{
The Effects of Environmental Contaminants on Freshwater Cyanobacteria
}

\author{
Jenna Leigh Mumford
}

2020

A thesis submitted in partial fulfilment for the requirements for the degree of Master of Science in Ecology \& Biodiversity

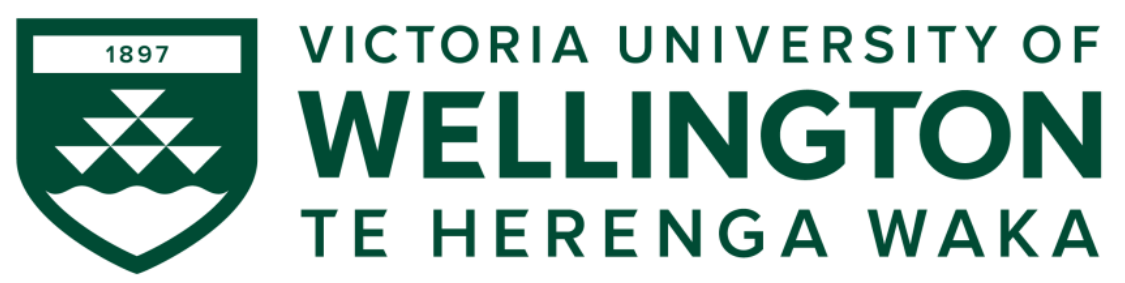


Due to disruptions from the Covid-19 lockdown period, some data analyses were unable to be completed. Notably, some cell enumeration and analyses of toxin samples were not completed in Chapter 2 and Chapter 3. 


\section{Acknowledgements}

First, I would like to thank my supervisors Jonathan Puddick and Ken Ryan. To JP, your support, patience, and guidance throughout my Masters has been of such value. Thank you for hosting me in your lab, always being present, checking up on me, and making sure I was always comfortable and informed. To Ken, thank you for always inspiring and encouraging me, and motivating me to do better with my work and writing. A meeting or phone call with you always left me feeling optimistic and pushed aside any self-doubt. I feel incredibly lucky to have had the opportunity to work under both of you as my supervisors and learn so much.

I am very grateful for scholarship funding for this work from the Marsden Fund of the Royal Society of New Zealand. Thank you for the financial support throughout the "Blooming Buddies" project (CAW1601), awarded to Jonathan Puddick, Cawthron Institute in Nelson.

Many thanks to everyone at Cawthron Institute that made me feel so welcome and helped me to get settled in. It was a great experience to be able to work at Cawthron, meet so many new people and learn so much. Thank you to Georgia Thomson-Laing for putting up with my statistics questions and always taking your time to explain things to me when I needed help.

Thank you to my parents, Grant and Liz Mumford, for your unending love and support. I appreciate everything you have given me and done for me throughout my time at university and my life. Your constant belief in me has always driven me to do my best. Thank you to my siblings, Lauren, Stacey, and Brad for always being there for me and making my laugh.

To my partner, Thomas Powell, thank you for your constant support and for never being more than a phone call away. Thank you for always listening to my woes, being my supplier of tea and coffee, and staying up late with me whilst I was writing.

Thank you to my classmates, the 'Eco Pals', for providing me with entertainment and friendship throughout my Masters, it has been amazing to see everyone finish up and share this achievement. Special thanks to Ronja Hauke and Dayanitha Damodaran for checking in and keeping a smile on my face. Thank you to Victoria Ford for never letting me forget why I chose biology, sharing my excitement about everything, and hyping me up whenever we're together. 


\section{Table of Contents}

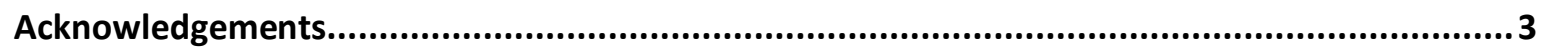

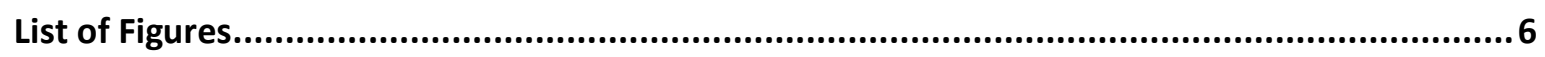

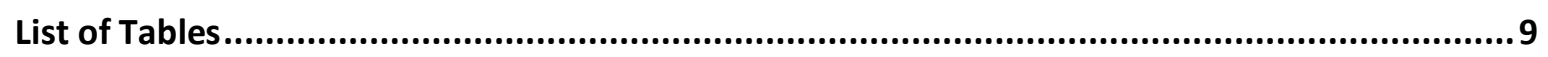

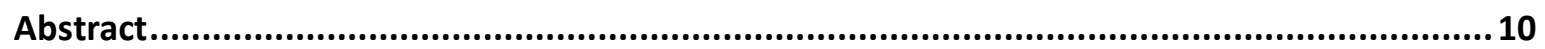

Chapter 1: Introduction .......................................................................................12

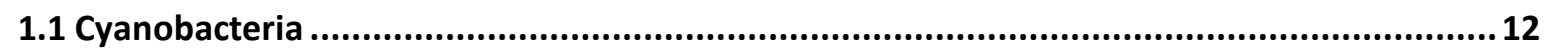

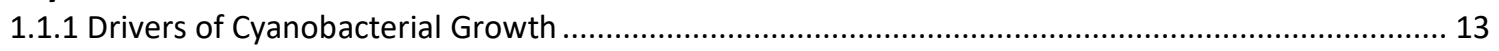

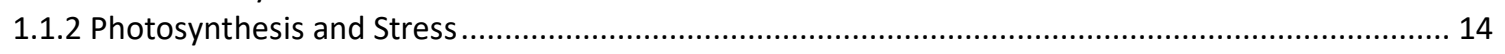

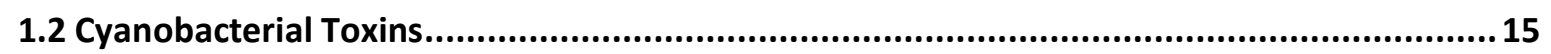

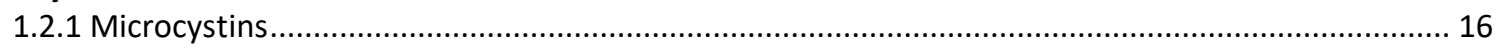

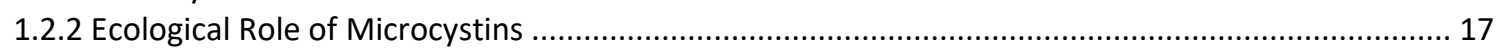

1.2.3 Microcystin Sequestration in Non-Toxic Cyanobacteria .............................................................. 18

1.3 Environmental Effects on Cyanobacteria .......................................................................... 19

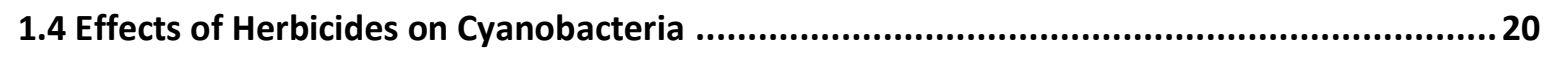

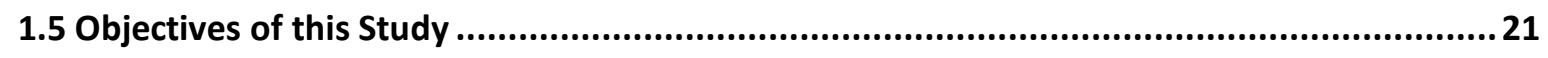

Chapter 2: Effects of the Hepatotoxin Microcystin on Cuspidothrix issatschenkoi .............23

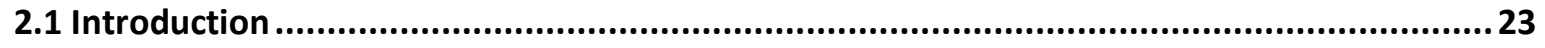

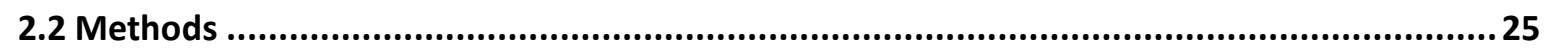

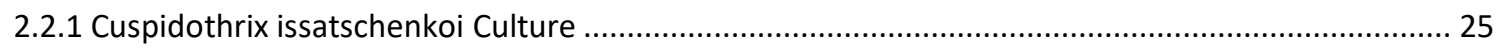

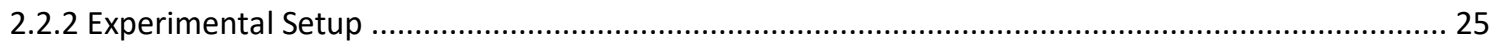

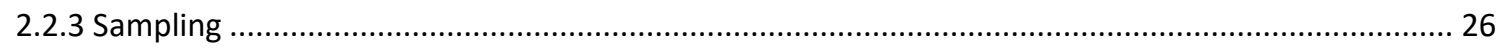

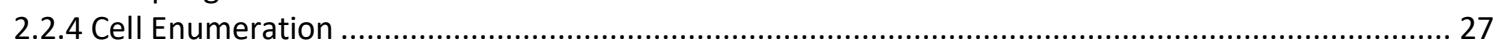

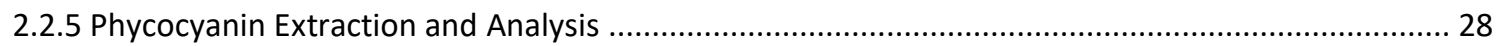

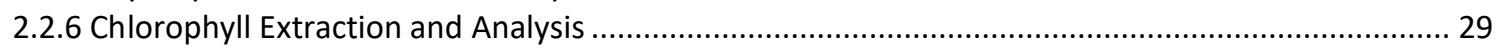

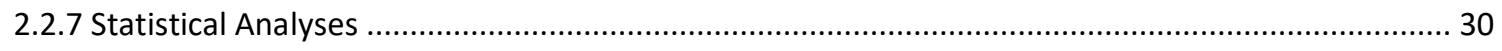

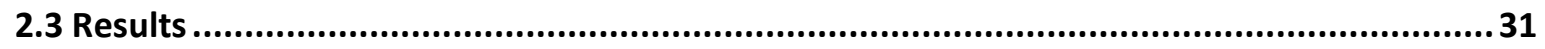

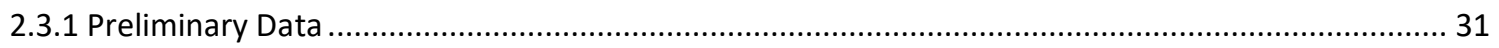

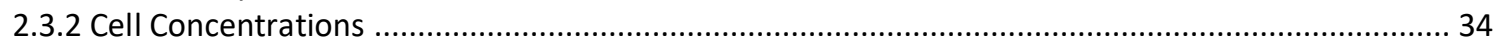

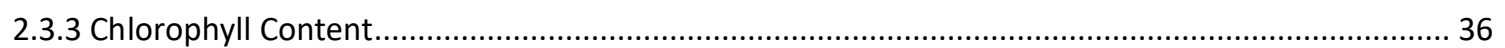

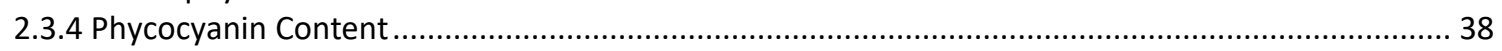

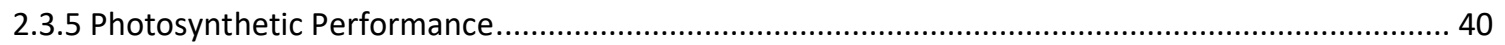

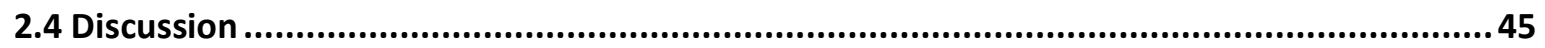

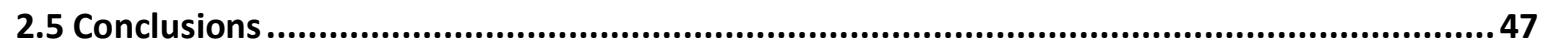

Chapter 3: Effects of Herbicides on New Zealand Cyanobacteria ...................................48

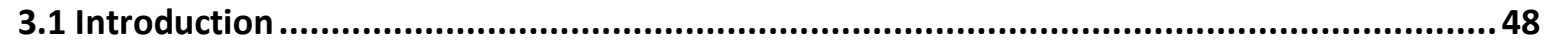

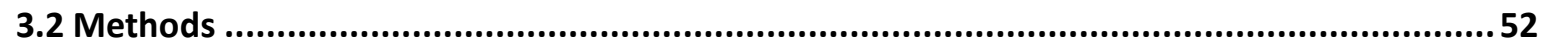

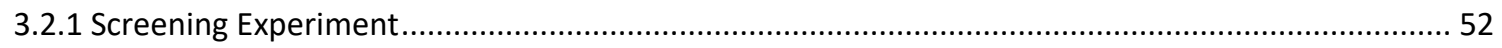

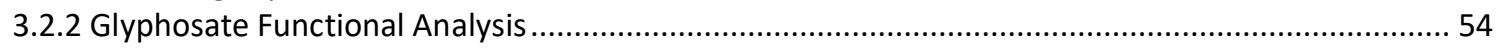

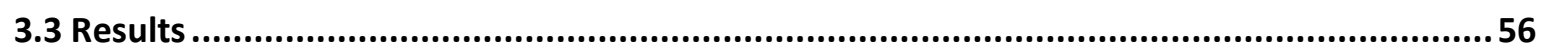

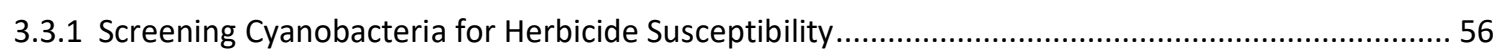

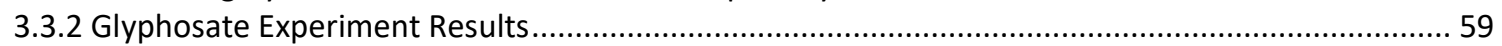




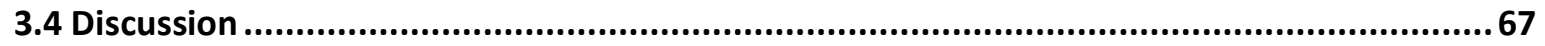

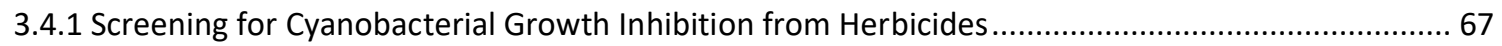

3.4.2 A Functional Analysis of Glyphosate Susceptibility on Selected Species ........................................... 69

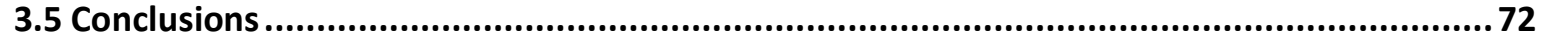

Chapter 4: General Discussion ............................................................................74

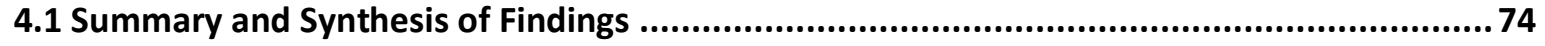

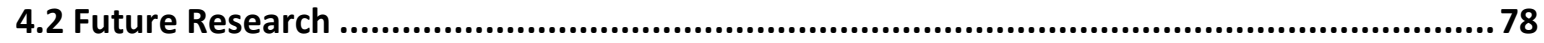

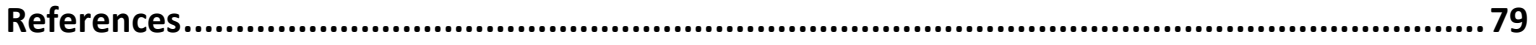

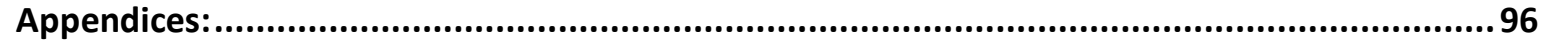




\section{List of Figures}

Figure 1.1: Microcystis surface bloom in a New Zealand lake (Photo credit David Hamilton, University of Waikato; from Berdalet et al. 2017). .14

Figure 1.2: Structures of two common microcystin isoforms, microcystin-RR and microcystinLR (Ozawa et al. 2003)

Figure 2.1: Experimental design for the microcystin supplementation experiment using Cuspidothrix issatschenkoi.

Figure 2.2: Preliminary growth curve of Cuspidothrix issatschenkoi at $18^{\circ} \mathrm{C}, 70 \mu \mathrm{mol} \mathrm{m} \mathrm{m}^{-2} \mathrm{~s}^{-1}$ in MLA media $(n=1)$.

Figure 2.3 A-F: Mean cell concentrations for the experimental control $\left(0 \mu \mathrm{g} \mathrm{L}^{-1}\right)$ and microcystin-supplemented $\left(25 \mu \mathrm{g} \mathrm{L}^{-1}\right)$ Cuspidothrix issatschenkoi cultures in six of the nine different combinations of light level $\left(20,60,100 \mu \mathrm{mol} \mathrm{m}^{-2} \mathrm{~s}^{-1}\right)$, and temperature $\left(15,20^{\circ} \mathrm{C}\right)$. Error bars show \pm one standard deviation. .34

Figure 2.4 A-I: Mean chlorophyll-a (Chl-a) concentrations for the experimental control (0 $\mu \mathrm{g}$ $\left.\mathrm{L}^{-1}\right)$ and microcystin-supplemented $\left(25 \mu \mathrm{g} \mathrm{L}^{-1}\right)$ Cuspidothrix issatschenkoi cultures in nine different combinations of light intensity $\left(20,60,100 \mu \mathrm{mol} \mathrm{m}^{-2} \mathrm{~s}^{-1}\right)$, and temperature $(15,20$, $25^{\circ} \mathrm{C}$ ). Error bars show \pm one standard deviation. 36

Figure 2.5 A-I: Mean phycocyanin (PC) concentrations for the experimental control $\left(0 \mu \mathrm{g} \mathrm{L} \mathrm{L}^{-}\right.$ $\left.{ }^{1}\right)$ and microcystin-supplemented $\left(25 \mu \mathrm{g} \mathrm{L}^{-1}\right)$ Cuspidothrix issatschenkoi cultures in nine different combinations of light level $\left(20,60,100 \mu \mathrm{mol} \mathrm{m}^{-2} \mathrm{~s}^{-1}\right)$, and temperature $\left(15,20,25^{\circ} \mathrm{C}\right)$. Error bars show \pm one standard deviation. 38

Figure 2.6: Mean maximum quantum yield for the experimental control $\left(0 \mu \mathrm{g} \mathrm{L}^{-1}\right)$ and microcystin-supplemented $\left(25 \mu \mathrm{g} \mathrm{L}^{-1}\right)$ Cuspidothrix issatschenkoi cultures in nine different combinations of light level $\left(20,60,100 \mu \mathrm{mol} \mathrm{m}^{-2} \mathrm{~s}^{-1}\right)$, and temperature $\left(15,20,25^{\circ} \mathrm{C}\right)$. Error bars show \pm one standard deviation. $*=$ Significant $\mathrm{p}$ value $<0.05$. 40

Figure 2.7: Mean alpha (slope of the initial linear range of the rapid light curve, photosynthetic efficiency) for the experimental control $\left(0 \mu \mathrm{g} \mathrm{L}^{-1}\right)$ and microcystin-supplemented $\left(25 \mu \mathrm{g} \mathrm{L}^{-1}\right)$ Cuspidothrix issatschenkoi cultures in nine different combinations of light level $(20,60,100$ $\left.\mu \mathrm{mol} \mathrm{m} \mathrm{m}^{-2} \mathrm{~s}^{-1}\right)$, and temperature $\left(15,20,25^{\circ} \mathrm{C}\right)$. Error bars show \pm one standard deviation. $*=$ Significant $p$ value $<0.05$.

Figure 2.8: Mean $\mathrm{ETR}_{\max }$ (maximum electron transport capacity) for the experimental control $\left(0 \mu \mathrm{g} \mathrm{L}^{-1}\right)$ and microcystin-supplemented $\left(25 \mu \mathrm{g} \mathrm{L}^{-1}\right)$ Cuspidothrix issatschenkoi cultures in nine different combinations of light level $\left(20,60,100 \mu \mathrm{mol} \mathrm{m}^{-2} \mathrm{~s}^{-1}\right)$, and temperature $(15,20$, $25^{\circ} \mathrm{C}$ ). Error bars show \pm one standard deviation. 
Figure 2.9: Mean $1_{\mathrm{K}}$ (light saturation parameter) for the experimental control $\left(0 \mu \mathrm{g} \mathrm{L}^{-1}\right)$ and microcystin-supplemented $\left(25 \mu \mathrm{g} \mathrm{L}^{-1}\right)$ Cuspidothrix issatschenkoi cultures in nine different combinations of light level $\left(20,60,100 \mu \mathrm{mol} \mathrm{m}^{-2} \mathrm{~s}^{-1}\right)$, and temperature $\left(15,20,25^{\circ} \mathrm{C}\right)$. Error bars show \pm one standard deviation. $*=$ Significant $\mathrm{p}$ value $<0.05$.

Figure 3.1 A-G: Dose-response curves showing the effect of glyphosate concentration on growth rate (note: only plots where a significant relationship was observed are presented). .57

Figure 3.2: Mean cell concentrations of Dolichospermum lemmermannii treated with glyphosate at $750 \mu \mathrm{g} \mathrm{L}^{-1}$ (IC50 value) and 3,000 $\mu \mathrm{g} \mathrm{L}^{-1}$ (IC75) against the experimental control $\left(0 \mu \mathrm{g} \mathrm{L}^{-1}\right)$. Error bars show \pm one standard deviation. .59

Figure 3.3 A-D: Chlorophyll-a (Chl-a) concentrations for cyanobacteria treated with glyphosate at their $\mathrm{IC}_{50}$ and $\mathrm{IC}_{75}$ values, as well as the corresponding $\mathrm{IC}_{75}$ for the two Microcystis species. Note different scales on y-axes. Error bars show \pm one standard deviation.

Figure 3.4 A-D: Phycocyanin (PC) concentrations all four strains treated with glyphosate at their $\mathrm{IC}_{50}$ and $\mathrm{IC}_{75}$ values, as well as an additional treatment for the two Microcystis species as described in Chapter 3 (Section 3.2.2.2), Table 7. Error bars show \pm one standard deviation.

Figure 3.5: Mean maximum quantum yield for all glyphosate concentrations used (including the experimental control) for all four species. Error bars show \pm one standard deviation. .....63

Figure 3.6: Mean alpha (slope of the initial linear range of the rapid light curve, photosynthetic efficiency) for all glyphosate concentrations used (including the experimental control) for all four species. Error bars show \pm one standard deviation.

Figure 3.7: Mean ETR $\max$ (maximum electron transport capacity) for all glyphosate concentrations used (including the experimental control) for all four species. Error bars show \pm one standard deviation.

Figure 3.8: Mean $\mathrm{l}_{\mathrm{k}}$ (light saturation parameter) for all glyphosate concentrations used (including the experimental control; $0 \mu \mathrm{g} \mathrm{L}^{-1}$ ) for all four species. Error bars show \pm one standard deviation.

Figure A1.1 A-B: Mean maximum quantum yield at $520 \mathrm{~nm}$ (A) and $645 \mathrm{~nm}$ (B) for the experimental control $\left(0 \mu \mathrm{g} \mathrm{L}^{-1}\right)$ and microcystin-supplemented $\left(25 \mu \mathrm{g} \mathrm{L}^{-1}\right)$ Cuspidothrix issatschenkoi cultures in nine different combinations of light level $\left(20,60,100 \mu \mathrm{mol} \mathrm{m} \mathrm{m}^{-2} \mathrm{~s}^{-1}\right)$, and temperature $\left(15,20,25^{\circ} \mathrm{C}\right)$. Error bars show \pm one standard deviation.

Figure A1.2 A-B: Mean alpha at $520 \mathrm{~nm}$ (A) and $645 \mathrm{~nm}$ (B) for the experimental control (0 $\left.\mu \mathrm{g} \mathrm{L}^{-1}\right)$ and microcystin-supplemented $\left(25 \mu \mathrm{g} \mathrm{L}^{-1}\right)$ Cuspidothrix issatschenkoi cultures in nine different combinations of light level $\left(20,60,100 \mu \mathrm{mol} \mathrm{m}^{-2} \mathrm{~s}^{-1}\right)$, and temperature $\left(15,20,25^{\circ} \mathrm{C}\right)$. Error bars show \pm one standard deviation. .98

Figure A1.3 A-B: Mean ETR max $_{\text {ax }}$ at $520 \mathrm{~nm}(\mathrm{~A})$ and $645 \mathrm{~nm}$ (B) for the experimental control $\left(0 \mu \mathrm{g} \mathrm{L}^{-1}\right)$ and microcystin-supplemented $\left(25 \mu \mathrm{g} \mathrm{L}^{-1}\right)$ Cuspidothrix issatschenkoi cultures in 
nine different combinations of light level $\left(20,60,100 \mu \mathrm{mol} \mathrm{m}^{-2} \mathrm{~s}^{-1}\right)$, and temperature $(15,20$, $25^{\circ} \mathrm{C}$ ). Error bars show \pm one standard deviation.

Figure A1.4 A-B: Mean $1_{\mathrm{K}}$ at $520 \mathrm{~nm}(\mathrm{~A})$ and $645 \mathrm{~nm}(\mathrm{~B})$ for the experimental control (0 $\mu \mathrm{g}$ $\left.\mathrm{L}^{-1}\right)$ and microcystin-supplemented $\left(25 \mu \mathrm{g} \mathrm{L}^{-1}\right)$ Cuspidothrix issatschenkoi cultures in nine different combinations of light level $\left(20,60,100 \mu \mathrm{mol} \mathrm{m}^{-2} \mathrm{~s}^{-1}\right)$, and temperature $\left(15,20,25^{\circ} \mathrm{C}\right)$. Error bars show \pm one standard deviation.

Figure A2.1 A-B: Mean maximum quantum yield at $520 \mathrm{~nm}(\mathrm{~A})$ and $645 \mathrm{~nm}$ (B) for each glyphosate concentration (including the experimental control; $0 \mu \mathrm{g} \mathrm{L}^{-1}$ ) for Dolichospermum lemmermannii, Nodularia spumigena, Microcystis aeruginosa, and Microcystis wesenbergii. Error bars show \pm one standard deviation. 103

Figure A2.2 A-B: Mean alpha at $520 \mathrm{~nm}$ (A) and $645 \mathrm{~nm}$ (B) for each glyphosate concentration (including the experimental control; $0 \mu \mathrm{g} \mathrm{L}^{-1}$ ) for Dolichospermum lemmermannii, Nodularia spumigena, Microcystis aeruginosa, and Microcystis wesenbergii. Error bars show \pm one standard deviation. 104

Figure A2.3 A-B: Mean ETR $\max$ at $520 \mathrm{~nm}$ (A) and $645 \mathrm{~nm}$ (B) for each glyphosate concentration (including the experimental control; $0 \mu \mathrm{g} \mathrm{L}^{-1}$ ) for Dolichospermum lemmermannii, Nodularia spumigena, Microcystis aeruginosa, and Microcystis wesenbergii. Error bars show \pm one standard deviation. 105

Figure A2.4 A-B: Mean $l_{k}$ at $520 \mathrm{~nm}(\mathrm{~A})$ and $645 \mathrm{~nm}$ (B) for each glyphosate concentration (including the experimental control; $0 \mu \mathrm{g} \mathrm{L}^{-1}$ ) for Dolichospermum lemmermannii, Nodularia spumigena, Microcystis aeruginosa, and Microcystis wesenbergii. Error bars show \pm one standard deviation. 106 


\section{List of Tables}

Table 2.1: Short-term precision of PAM fluorometry technique on Cuspidothrix issatschenkoi at three light excitation wavelengths (Channels 2-4).

Table 2.2: Statistical results (two sample t-test) for determining if there were significant differences between the cell concentrations of microcystin-supplemented cells and the experimental control.

Table 2.3: Statistical results (two sample t-test) for determining significant differences in chlorophyll-a concentration between microcystin-supplemented cells and the experimental control.

Table 2.4: Statistical results (two sample t-test) for determining significant differences in phycocyanin concentration of microcystin-supplemented cells and the experimental control.

Table 2.5: Statistical results (two sample t-test) for determining significant differences in photosynthetic performance of microcystin-supplemented cells and the experimental control at an excitation wavelength of $665 \mathrm{~nm}$

Table 3.1: Maximum concentrations of glyphosate sampled at sites across the Americas, Asia, and Europe.

Table 3.2: Glyphosate concentrations used on each strain in the functional analysis of glyphosate susceptibility.

Table 3.3: Linear regression p-values for the relationship between glyphosate concentration on growth rate, $\mathrm{IC}_{50}$, and $\mathrm{IC}_{75}$ values for cyanobacteria strains that were affected by glyphosate. $*$ = Significant result $(\mathrm{p}<0.05)$. .58

Table 3.4: Statistical results (ANOVA) for determining significant differences in photosynthetic performance of four cyanobacteria species treated with glyphosate cells and the experimental control.

Table A1.1: Statistical results (two sample t-test) for determining significant differences in photosynthetic performance of microcystin-supplemented cells and the experimental control at 520 and $645 \mathrm{~nm}$

Table A2.1: Linear regression p-values for the relationship between MCPA concentration and growth rate, for all fourteen cyanobacteria strains that were tested in the screening experiment. 101

Table A2.2: Statistical results (ANOVA) for determining significant differences in photosynthetic performance of four cyanobacteria species treated with glyphosate cells and the experimental control at 520 and $645 \mathrm{~nm}$. 


\section{Abstract}

Cyanobacteria are photosynthetic prokaryotes with a cosmopolitan distribution and are key contributors to Earth's primary production. In favourable conditions, some taxa have the ability to form dense algal blooms. When blooms are created by toxin-producing strains they can become a public health threat and may lead to deaths of wild and domestic animals. Different species and strains respond differently to environmental conditions and contaminants, and this thesis investigates the impacts of natural (microcystin, a hepatotoxic cyanotoxin) and anthropogenic (glyphosate) contaminants on cyanobacteria.

Some non-microcystin-producing cyanobacteria have the ability to sequester microcystin, one of them being the strain Cuspidothrix issatschenkoi CAWBG02, and the reason for this ability is unknown. This strain was supplemented with microcystin in a range of environmental conditions (temperature/light intensity combinations) to determine any impacts on fitness by measuring photosynthetic performance, growth, and pigment content (chlorophyll-a and phycocyanin). Microcystin supplementation at a concentration of $25 \mu \mathrm{g} \mathrm{L}^{-1}$ did not have an effect on growth or pigment content in C. issatschenkoi, and photosynthetic performance was also largely unaffected. Based on the results from this thesis, C. issatschenkoi does not acquire competitive advantages from microcystin sequestration due to the lack of effects on growth and photosynthetic functioning. Previous research has suggested that microcystin is used to suppress competitors, and a 33\% decrease in maximum quantum yield was detected in one environmental condition (low temperature, intermediate light), however, there was no significant difference in all of the other conditions used. Therefore, the results from this study do not support the idea that microcystin is used to suppress competitors. Microcystin sequestration may be more beneficial to non-producing-strains within the same species as the toxin-producer (e.g. non-toxic M. aeruginosa).

Glyphosate and MCPA are two of the most commonly used herbicides in New Zealand and globally. These herbicides enter waterways through leaching and come into contact with nontarget species. To determine whether these herbicides have an effect on freshwater cyanobacteria in New Zealand, a screening assay was carried out on fourteen strains. Further, the impacts on pigment content (chlorophyll-a and phycocyanin), growth, and photosynthetic performance in two toxic (Nodularia spumigena, Microcystis aeruginosa) and two non-toxic (Dolichospermum lemmermannii, Microcystis wesenbergii) strains were quantified. Growth rates were not impacted by MCPA in any of the fourteen cyanobacterial strains. Glyphosate 
impacted growth in seven of the fourteen strains, and response differed between strains even within a single species. In general, strains employing a colonial growth strategy were more tolerant to glyphosate in the screening assay. $N$. spumigena and $M$. wesenbergii were unaffected by glyphosate at the concentrations used in the functional analysis, and $D$. lemmermannii had decreased photosynthetic performance from glyphosate. Intermediate concentrations of glyphosate resulted in promotion of PSII functioning in $M$. aeruginosa, and high concentrations inhibited maximum quantum yield. The lack of significant impacts on M. wesenbergii and N. spumigena, as well as negative effects of PSII functioning in D. lemmermannii, suggest that glyphosate contamination in freshwaters may benefit toxic M. aeruginosa more than competing toxic and non-toxic species or strains. 


\section{Chapter 1: Introduction}

\subsection{Cyanobacteria}

Cyanobacteria are photosynthetic prokaryotes that have a worldwide distribution and can be found in most illuminated environments. They are commonly referred to as "blue-green algae" (Paerl and Otten 2013), a name earned by the bluish colour of the cells that can arise from the presence of phycocyanin (a blue light-harvesting phycobiliprotein pigment) and green chlorophyll.

Along with other types of bacteria, they are one of the few prokaryote taxa that carry out oxygenic photosynthesis (Mulkidjanian et al. 2006, Nowicka and Kruk 2016) and have been credited with the oxygenation of the planet. Ultimately, this oxygenation allowed for the evolution of terrestrial animals and plants (Blank et al. 2010, Paerl and Otten 2013) and it has been proposed that the photosynthetic organelle in eukaryotes, the chloroplast, originally arose from cyanobacteria (Sato and Awai 2016, Shih et al. 2012). Cyanobacteria global wet biomass is estimated to be at least one thousand million tons $\left(10^{11} \mathrm{~kg}\right)$, making them one of the most important taxa in the world by biomass (Garcia-Pichel et al. 2003) and thus are a major nutritional component of balanced aquatic food webs (Burkill et al. 1993, Nagarkar et al. 2004). As such, cyanobacteria are a key contributor to Earth's primary production (the rate at which carbon is converted from inorganic to organic forms by photosynthesis; Li 1994) and are especially important in nutrient-limited environments (Garcia-Pichel et al. 2003, Shih et al. 2012). They are also a major contributor to the global nitrogen cycle (Zehr et al. 2008, Paerl and Otten 2013) and produce a range of unique secondary metabolites (Rippka et al. 1979, Dittmann et al. 2001, Rantala et al. 2003).

Cyanobacteria can grow in a diverse range of habitats, but their preference for certain environmental conditions may set them apart from eukaryotic algae. They tend to do better than algal species in warmer climates, due to their affinity for temperatures a few degrees higher than the optimum temperature of these competitors (Kosten et al. 2012). Temperatures above $25^{\circ} \mathrm{C}$ are usually favoured, so a competitive advantage is conferred at elevated temperatures via increased growth rates when compared to diatoms or green algae (Jöhnk et al. 2008, Paerl and Huisman 2008). Their broad distribution is due to the tolerance of certain species for highly saline environments (Dubinin et al. 1992, Talbot et al. 2008) and adaptations to intense ultraviolet (UV) radiation and efficient utilisation of light for photosynthesis at low 
photon flux densities (Quesada and Vincent 1997, Hawes 2001). Some species of cyanobacteria are better able to tolerate high levels of free sulphide than eukaryotic algae, and hydrogen sulphide may sometimes be used as the electron donor for photosynthesis (Cohen et al. 1986). Certain planktonic freshwater species are able to form gas vesicles that aid in buoyancy and can navigate vertically through the water column. This is particularly advantageous in waters lacking vertical mixing, as the buoyant cyanobacteria are able to stay near the surface of the water and exploit the subsequent exposure to light. This ultimately leads to the suppression of competing phytoplankton through shading when they form dense accumulations as surface blooms (Reynolds and Walsby 1975, Paerl and Huisman 2008).

\subsubsection{Drivers of Cyanobacterial Growth}

When environmental conditions are favourable, cyanobacteria can rapidly proliferate to form dense concentrations of cells (Berdalet et al. 2017, Havens et al. 2019; Figure 1.1). When these proliferations are dominated by one or just a few species, they are called cyanobacterial blooms (Scholz et al. 2017). Blooms commonly occur in aquatic ecosystems used for fishing, drinking water, and recreational needs (Van Dolah 2000, Dittmann et al 2001, Paerl and Huisman 2008). Bloom frequency and distribution has increased over the past three decades (Van Dolah 2000, Chia et al. 2019) and is becoming more common due to nutrient enrichment of water bodies by urban, agricultural, and industrial developments (Paerl and Huisman 2008). Blooms decrease aquatic ecosystem water quality by increasing turbidity, and ultimately suppressing aquatic plants and devastating habitats for fish and invertebrates (Paerl and Huisman 2008).

Rising temperatures in lake surface waters strengthens stratification by reducing vertical mixing, and higher water temperatures also allows for cyanobacteria to dominate for longer periods as their optimal growth window expands (Paerl and Huisman 2008). Increased growth windows and warmer waters allow cyanobacteria to grow more prolifically in regions they previously did not. Therefore, climate change is leading to the expansion in bloom distributions and duration globally (Paerl and Huisman 2008, Chapra et al. 2017, Paerl 2018). 
This image has been removed for copyright reasons. Please consult figure legend for further details.

Figure 1.1: Microcystis surface bloom in a New Zealand lake (Photo credit David Hamilton, University of Waikato; from Berdalet et al. 2017).

\subsubsection{Photosynthesis and Stress}

The growth and photosynthesis of different cyanobacteria strains may be affected by environmental conditions in different ways. Zhou et al (2006) showed that the metal cadmium (Cd) inhibits the growth of Microcystis aeruginosa at a concentration of $4 \mu \mathrm{M}$. Different concentrations of $\mathrm{Cd}$ modified the cyanobacterial pigments in different ways. At $0.5 \mu \mathrm{M}$, the concentration of chlorophyll per cell decreased more than the concentrations of phycobiliproteins. However, at higher Cd levels the concentration of phycobiliproteins decreased at a higher rate than chlorophyll. Decreases in either pigment did not always correspond with a decrease in growth, and this illustrates that the way a cyanobacterium is influenced by toxic substances is dependent not only on the type of substance, but also on its concentration and exposure time.

During photosynthesis, chlorophyll reaction centres become chemically excited when absorbing a photon of light, but this makes them unstable. To become stable, the energy will follow one of three pathways. The electron that absorbed the photon in the chlorophyll molecule may be used to drive photosynthesis, in which case it will be transferred to a nearby electron acceptor molecule. The energy of the photon could also be emitted as fluorescence at a lower energy, or follow a third pathway and be released as heat from the chlorophyll 
molecule. These pathways for the utilisation of light energy are in order of preference, although, if the organism/reaction centre is stressed then heat dissipation will be utilised over fluorescence (Ralph and Gademann 2005, Hanelt 2018). When the energy is reemitted as light (chlorophyll fluorescence), it can provide insight into the health of photosynthetic organisms that can be detected non-invasively using fluorometers (Maxwell and Johnson 2000, Baker 2008). Cells are dark-acclimated in an absence of actinic light so they have a non-stressed reference point before exposure to light. Immediately upon exposure, all PSII reaction centres are open and the minimum fluorescence is measured $\left(F_{0}\right)$. A saturating light pulse 'closes' all reaction centres, and the maximal fluorescence level can be attained $\left(\mathrm{F}_{\mathrm{m}}\right)$. The difference between $F_{o}$ and $F_{m}$ is $F_{v}$, which can be used to calculate the maximum quantum yield $\left(F_{v} / F_{m}\right.$; Baker and Rosenqvist 2004). If a photosynthetic organism is more stressed, the maximum quantum yield will be lower due to fewer reaction centres being open/available (Baker and Rosenqvist 2004). ETR $\max$ and alpha are two more photosynthetic parameters that can be measured by fluorometry (Kim Tiam et al. 2015). ETR $\max$ denotes the maximum chlorophyll fluorescence of PSII-based electron transport rate (maximum electron transport rate; Kim Tiam et al. 2015) and alpha is the slope of the initial linear range of a photosynthesis-irradiance curve and indicates photosynthetic efficiency (Gomez and Huovinen 2011). Alpha and maximum quantum yield are related, and alpha has been used to denote maximum quantum yield for some photosynthetic organisms in the past (Saroussi and Beer 2007). However, alpha is defined in terms of ambient light and maximum quantum yield by light absorbed by the phytoplankton (Sakshaug et al. 1997). Fluorometers can also measure the light saturation parameter, the point at which photosynthesis is saturated and an indicator of the photo-acclimation state of phytoplankton (Sakshaug et al. 1997). This is calculated from ETR max/alpha, and indicates when photosynthesis control switches from light absorption and photochemical energy conversion, to reductant utilisation. The light saturation parameter indicates the point at which there is balance between the rate of photo absorption by PSII, and the rate of electron transport from water to carbon dioxide (Sakshaug et al. 1997, Ihnken et al. 2010).

\subsection{Cyanobacterial Toxins}

Cyanobacteria produce a diverse range of secondary metabolites including cyanotoxins that are toxic to humans and animals, and at times other eukaryotes (Sevilla et al. 2011, Li et al. 2017). These toxins can have severe negative impacts on human health and are regarded as a public health threat (World Health Organization 1999, Alexova et al. 2011). Blooms of cyanobacteria often lead to the harming or deaths of domestic and wild animals worldwide 
through liver, digestive, neurological, and skin diseases (Rantala et al. 2003, Paerl and Huisman 2008). In addition, extensive die-offs of fish and shellfish, and the deaths of birds and marine mammals have been attributed to cyanotoxins (Van Dolah 2000). The growing number of blooms dominated by toxic cyanobacteria generates environmental and health problems. Whilst a range of cyanotoxins exist (e.g., anatoxins, microcystins, nodularins), the remainder of this thesis will focus on microcystins.

\subsubsection{Microcystins}

Microcystins are a group of hepatotoxins produced by many cyanobacteria, of which microcystin-LR is the most common variant (Ozawa et al. 2003, Klein et al. 2013; Figure 1.2). It has been extensively investigated due to its widespread distribution and common occurrence.

This image has been removed for copyright reasons. Please consult figure legend for further details.

Figure 1.2: Structures of two common microcystin isoforms, microcystin-RR and microcystinLR (Ozawa et al. 2003).

The toxin is the end product of the microcystin synthase pathway consisting of mixed polyketide synthases and non-ribosomal synthetases (Rantala et al. 2003), and is a potent inhibitor of eukaryotic protein phosphatases 1 and 2A (which modulate the activities of cellular proteins via removal of phosphate groups that regulate protein function and activity; Dittmann et al. 2001). Toxin uptake occurs fastest in liver cells due to the organic anion transporting polypeptide system (OATP system; Runnegar et al. 2001). The inhibition of protein phosphatases in these cells results in over-phosphorylation of hepatocellular cytoskeletal proteins, which leads to the deformation of liver cell structural components and ultimately the whole liver structure (Humpage 2008). Although microcystins are classed as hepatotoxins, they 
can accumulate in, and possibly damage, multiple mammalian organs and tissues including the heart, gonad, kidney, liver, lung, and brain (Wang et al. 2008, Zhao et al 2008). Microcystin intoxication can result in damage to the mitochondrial membrane and electron transport function (Humpage 2008, Zhao et al. 2008) and following intoxication, the majority of the blood in a mammal will remain in the liver and therefore fail to circulate properly throughout the rest of the body. Microcystin has caused hepatotoxicity in humans and animals worldwide (Dittmann et al. 2001). In 1996, microcystins in the water used by a Brazilian haemodialysis clinic resulted in acute liver failure in 100 of their 131 patients (Azevedo et al. 2002). These patients and a further 16 experienced nausea, muscle weakness, vomiting, and visual disturbances, and 52 of the patients died. Examination of the water supply for the clinic along with their water treatment system and liver tissue of patients lead to the diagnosis of microcystin poisoning.

Amongst the toxin-producing cyanobacteria, toxic and non-toxic strains can exist even within a single species (Kardinaal et al. 2007a, Davis et al. 2009). Genera that have microcystinproducing species include; Anabaena, Anabaenopsis, Gloeotrichia, Hapalosiphon, Microcoleus, Nostoc, Oscillatoria (Planktothrix), Plectonema, Rivularia, and Tolypothrix among others, to make up a total of 40 microcystin-producing genera (Dittmann et al. 2001, Quiblier et al 2013, Chaturvedi et al. 2015). The main toxin-producing genera globally are Dolichospermum (previously Anabaena), Microcystis, and Planktothrix (Kardinaal et al. 2007a). The most commonly reported microcystin-producing species is Microcystis aeruginosa (Dittmann et al. 2001, Briand et al. 2008, Klein et al. 2013).

\subsubsection{Ecological Role of Microcystins}

The ecological role of microcystin production is still unclear, although many theories have been proposed. One possible explanation is that the hepatotoxin is a siderophore (a molecule that binds and transports iron; Klein et al. 2013). Iron is essential for primary producers, as it plays a critical role in metabolic processes such as photosynthesis, respiration, and nitrogen fixation, and it also affects biosynthesis of primary and secondary metabolites; e.g., microcystin (Fujii et al. 2011). Zilliges et al. (2011) suggested a protein-modulating role was carried out by microcystin within a toxin-producing cell, as the hepatotoxin binds to proteins and this binding is enhanced under environmental conditions of oxidative stress and high light. The authors found that a microcystin-deficient Microcystis mutant showed significant changes in the accumulation of proteins under high light conditions. Schatz et al 
(2007) proposed that Microcystis cells increase their ability to produce microcystins in response to part of their colony or population dying off. This study found that microcystin production is enhanced and McyB content increased in Microcystis cells following exposure to metabolites released from dead Microcystis cells. Microcystin-LR $\left(50 \mu \mathrm{g} \mathrm{L}^{-1}\right)$ also resulted in increased McyB and microcystins in exposed cells, although not as much as the extract from the lysed cells. The authors noted that microcystins can be passively released and may be actively exported. This may contribute to how Microcystis responds to changing environmental conditions and suggests that microcystins may play a role in intercellular communication.

Exposure to microcystins may promote growth and physiological functioning of cyanobacteria in blooms. Non-toxic Microcystis colonies and toxic Microcystis colonies with naturally low toxin concentrations both significantly increase in size following the addition of microcystins. Following extracellular depletion of the toxin, colony size can decrease (Gan et al. 2012). These authors also suggest that released microcystins are involved with maintaining colony sizes for Microcystis populations and keeping them dominant. However, the non-toxic cyanobacterium Synechococcus elongatus was severely negatively impacted by exposure to high concentrations of microcystin (Hu et al. 2004). Growth was inhibited and the colour of the organism changed, but it was likely that the microcystin concentration used in this study was about $10 \times$ higher than what is expected in the natural environment (Phelan and Downing 2014). Microcystin-LR exposure has been shown to lower photosystem II activity in Anabaena cells, as well as both toxic and non-toxic Microcystis cells (Chia et al. 2019), with maximum quantum efficiency (yield) reduced by up to $37 \%$ in toxic Microcystis at a microcystin-LR concentration of $25 \mu \mathrm{g} \mathrm{L}^{-1}$. If triggers for microcystin production increase in the future, it is possible that these high concentrations of cyanotoxins could be measured in natural environments and have a more serious impact on cyanobacteria.

\subsubsection{Microcystin Sequestration in Non-Toxic Cyanobacteria}

Whilst naturally-occurring contaminants may have negative impacts for some cyanobacteria, some strains have the ability to sequester cyanotoxins and this may be beneficial. Synechocystis strain PCC6803 sequestered exogenous microcystin-LR in culture, and almost half was located in the thylakoid membranes (Phelan and Downing 2014) - the same site as in toxic cyanobacteria (Young et al. 2005). The remainder was found in the cell wall and outer membrane with no known effect. Microcystin sequestration did not reduce cell survival but did cause a decrease in photosystem II activity in the same way that endogenous microcystin does 
in toxic strains (Phelan and Downing 2014). There was no significant difference in PSII activity in the whole cell measurements versus the thylakoid membrane measurements, which suggested that the effects of exogenous microcystin on cyanobacteria were mostly if not all due to the microcystin affecting the thylakoid membrane and specifically PSII. Unpublished work has also demonstrated that microcystin sequestration was observed in a wide array of cyanobacteria genera including; Aphanizomenon, Cuspidothrix, Dolichospermum, Leptolyngbya, Microcoleus, Nostoc, Phormidium, Planktothrix, Scytonema and Synechocystis (unpublished data; Puddick et al. 2020).

If toxin sequestration provides non-toxic cells with an advantage (e.g., increased growth, pigment content, photosynthetic efficiency), mutualism or commensalism could be inferred between toxic and non-toxic strains. Ultimately, this may benefit the entire population in a bloom, if toxic and non-toxic strains both do not experience detrimental effects. A deeper understanding of the role of toxins in non-toxic cells would help us to understand the coexistence of toxic and non-toxic cyanobacterial strains, as environmental conditions can change quickly and drastically and may influence the growth and survival of toxic and nontoxic strains differently. With the anticipated changes to the climate and environment (warming, altered precipitation, environmental contaminants; Allen et al. 2000, Malmqvist and Rundle 2002, Trenberth 2011) and particularly to freshwater ecosystems, it is important to understand their physiological traits for bloom management and health problem avoidance (Mantzouki et al. 2015, Saeudi et al. 2017). With the predicted increases in favourable conditions for cyanobacteria (e.g., global warming), the need to understand the factors controlling community composition is also increasing.

\subsection{Environmental Effects on Cyanobacteria}

The growth and frequency of microcystin-producing and non-microcystin-producing strains is impacted by environmental factors (Kardinaal et al. 2007b, Wang et al. 2015). Although toxic and non-toxic strains may show similar responses to changes in environmental conditions, this can depend on the species being tested and the proportion of toxic vs. non-toxic cells. Nontoxic and toxic strains of Planktothrix agardhii react in similar ways to increased temperatures and phosphorus, but this trend changes when competing against one another (Briand et al 2008). Non-toxic $P$. agardhii cells grow better than toxic $P$. agardhii when grown together in ideal conditions (high light and high temperature). However, growth-limiting conditions favoured toxic strains, suggesting the benefit of toxin production outweighs the cost when the 
environment is stressful. Conversely, an increase in growth rates was seen for toxic Microcystis under high temperatures and increased phosphorus (Davis et al 2009), suggesting that response could be species- or strain-dependent.

Because of these different responses between toxic and non-toxic strains, it is difficult to know the main drivers of blooms. In a natural river study site, toxic Microcystis dominated the Microcystis population during early summer months (May and June) but were mostly replaced by non-toxic strains later on in the season (Davis et al. 2010). However, in a closed eutrophic lake, non-toxic Microcystis dominated throughout the entire sampling season. This could be due to the phosphorus concentration at each site, as under high phosphorus concentrations, toxic Microcystis growth rates are higher than the growth rates of non-toxic Microcystis (Vézie et al. 2002, Davis et al. 2009). Growth of toxic strains of Microcystis was promoted by inorganic nitrogen more frequently than organic nitrogen, even though Microcystis is not a nitrogen fixer and thus lacks the ability to utilise molecular nitrogen. However, the opposite was true for non-toxic strains. Inorganic phosphorus increased abundances of toxic Microcystis strains more frequently than the non-toxic strains, suggesting that the population dynamics and relationships between toxic and non-toxic strains may be influenced by nutrient type and concentrations. Higher levels of inorganic nitrogen and phosphorus may induce high abundance of toxic cells within a Microcystis bloom (Vézie et al. 2002). Kardinaal et al (2007b) noted that successions of dominant phytoplankton may also be true for toxic and non-toxic strains of Microcystis, as succession of different species is common in lake environments. During this study, toxic strains declined compared to non-toxic strains in competition for light, even when toxic strains started with an advantage. This could contribute to the eventual dominance of non-toxic strains when the bloom is peaking in favourable conditions, as they would out-compete the toxic cells.

\subsection{Effects of Herbicides on Cyanobacteria}

Herbicides are frequently used by farmers, landscapers, grounds keepers and domestic households to control unwanted plants. Small amounts of these chemicals may enter waterways and soil (Maule and Wright 1984) where freshwater phytoplankton reside (including cyanobacteria). Glyphosate and 2-methyl-4-chlorophenoxyacetic acid (MCPA) are the two most commonly used herbicides in New Zealand (Manktelow et al. 2005), although both are expected to have low efficacy on microalgae compared to other herbicides (Maule and Wright 1984). Glyphosate, a non-selective broad-spectrum herbicide, has a reputation of being non- 
toxic to animals and is thus a popular product (Helander et al. 2012). Wong (2000) found that whilst low concentrations of herbicides $\left(\leq 200 \mu \mathrm{g} \mathrm{L}^{-1}\right)$ stimulate growth, photosynthesis, and chlorophyll synthesis, high concentrations $\left(\geq 2,000 \mu \mathrm{g} \mathrm{L}^{-1}\right)$ inhibit these functions in the green alga Senedesmus quadricauda. Therefore, it is important to consider different concentrations of commonly used herbicides when determining the effect on cyanobacteria.

Different herbicides impact cyanobacteria in different ways, and other environmental factors such as water $\mathrm{pH}$ and organic carbon sources also influence the toxicity of herbicides in water (Mishra and Pandey 1989). Nostoc linckia, Nostoc calcicola, Nostoc sp., and Anabaena doliolum are all more tolerant of 2,4-dichlorophenoxyacetic acid (2,4-D) compared to two other rice field herbicides Machete (active ingredient 2,4-DB) and Saturn (active ingredient thiobencarb; Mishra and Pandey 1989). Up to 100,000 $\mu \mathrm{g} \mathrm{L}^{-1}$ of 2,4-D stimulated growth and nitrogen fixation of $N$. linckia. The lethal dose of 2,4-D was much higher (250-times) than the other herbicides investigated. Glyphosate may have less of an effect on cyanobacteria than other phytoplankton species (Forlani et al. 2008, Harris \& Smith 2016) as Microcystis aeruginosa utilises the phosphorous bound in glyphosate (Qiu et al. 2013) and this ability may exist in other cyanobacteria. Positive or negative effects to cyanobacteria from herbicides, compared to other phytoplankton, may lead to changes in the community composition of freshwater systems. There is still a lack of data on the effects of herbicides on New Zealand cyanobacteria species, and the ways in which cyanobacteria are physiologically affected (e.g., altered photosynthetic functioning, toxin production). Differential effects on different types of cyanobacteria; i.e., different genera and toxic vs. non-toxic species, may result in changes to freshwater ecosystems.

\subsection{Objectives of this Study}

The overall aim of this thesis is to investigate the impacts of natural and anthropogenic environmental contaminants on planktonic freshwater cyanobacteria.

The first objective was to determine the impact of the cyanotoxin microcystin on the fitness of the filamentous cyanobacterium Cuspidothrix issatschenkoi; by quantifying the effects on growth, pigment content (chlorophyll and phycocyanin) and PSII functioning. Based on previous work (Phelan and Downing 2014, Chia et al. 2019), I hypothesise that microcystin exposure would inhibit PSII functioning in C. issatschenkoi after exposure to the toxin, negatively impacting growth rates. 
The second objective was to determine whether herbicides commonly used in New Zealand and globally (glyphosate and MCPA) have an effect on the growth of a range of New Zealand cyanobacteria. Further, to quantify the impacts on pigment content, growth, and photosynthetic performance in four species of cyanobacteria which encompassed two toxic (Nodularia spumigena, Microcystis aeruginosa) and two non-toxic (Dolichospermum lemmermannii, Microcystis wesenbergii) strains. I hypothesise that MCPA and glyphosate will negatively impact the growth and functioning of cyanobacteria, as MCPA results in abnormal growth (Nielson and Dahllof 2007) and glyphosate has been shown to negatively affect phytoplankton at high concentrations (Ruan and Brown 2008). 


\section{Chapter 2: Effects of the Hepatotoxin Microcystin on Cuspidothrix issatschenkoi}

\subsection{Introduction}

Toxin production may provide a competitive advantage or physiological aid to cyanobacteria in the presence of abiotic stressors (Holland and Kinnear 2013). Toxin evolution and continued retention, despite being an energetically demanding process (Ouellette and Wilhelm 2003), suggests a benefit to the organism producing them (Codd 1995). Although cyanotoxins cause harm to animals and some other organisms, their role for the toxic cyanobacteria themselves may be unrelated to their toxicity (Ouellette and Wilhelm 2003).

Exposure to microcystin can inhibit photosynthesis, alter pigment content, and inhibit growth in terrestrial and aquatic photosynthetic organisms (Chen et al. 2004, Gehringer et al. 2003, Pflugmacher 2002). Interestingly, exogenous microcystin has stimulated growth in a nonmicrocystin-producing strain of Microcystis aeruginosa in low light (Sedmak and Kosi 1998), however, proliferation as a result of microcystin addition is strongly dependent on phytoplankton species and light levels. Under high light, $\mathrm{Hu}$ et al. (2004) reported typical negative effects on non-microcystin-producing cyanobacteria (inhibited photosynthesis, inhibited growth, altered pigment content) following addition of exogenous microcystin. Synechocystis PCC6803, a non-microcystin-producing cyanobacterium, accumulated microcystin in an experiment and almost half of this was located in the thylakoid membranes (Phelan and Downing 2014). The rest was located in the cell wall, which suggests that exogenous microcystin may provide less of an effect than endogenous microcystin at the same concentration, as endogenous microcystin is located primarily in the thylakoid. Previous work has reported complete inhibition of oxygen evolution following the addition of microcystin, however, the microcystin concentrations used were much higher than those seen in the natural environment (Singh et al. 2001). The incomplete inhibition of photosynthesis seen by Phelan and Downing (2014) was likely due to the lower concentration of microcystin used.

Cuspidothrix issatschenkoi (previously classified as Aphanizomenon issatschenkoi; Brient et al. 2009, Ballot et al. 2010) is a filamentous cyanobacterium that can sequester microcystin (unpublished data; Puddick et al. 2020). This species was originally described in 1968 from the Caspian Sea region and has since been observed in a range of freshwater and brackish water bodies around the world including New Zealand (Cirés and Ballot 2016). Competitive 
advantages that could increase the invasiveness of this species include nitrogen fixation, ability to readily disperse under adverse conditions, and ecological plasticity. With predicted global warming, this invasive species could spread further, and increased incidence of algal blooms may result in more shading for low-light-loving $C$. issatschenkoi. However, a lack of knowledge on invasive behaviour and its responses to many environmental variables prevents accurate forecasting of possible expansion (Cirés and Ballot 2016). The C. issatschenkoi CAWBG02 strain used in this study was isolated from an autumn cyanobacterial bloom in the shallow hypertrophic Lake Hakanoa (Waikato region, New Zealand) in 2003 (Wood et al. 2007). It is currently maintained in the Cawthron Institute Culture Collection of Microalgae (CICCM; Nelson, New Zealand).

C. issatschenkoi produces anatoxin-a, which can cause neurotoxic effects in vertebrates and result in gasping, convulsions, muscle overstimulation and twitching, and even death via respiratory arrest immediately after ingestion (Bownik 2010, Colas et al. 2020). Long, straight, almost hair-like filaments of $C$. issatschenkoi are composed of vegetative cells that are cylindrical and elongated (width 4-16 $\mu \mathrm{m}$ long $\times 1.5-4.5 \mu \mathrm{m}$ wide) and narrowed terminal cells (5 - $58 \mu \mathrm{m}$ long, $1-3 \mu \mathrm{m}$ wide) that end the filaments in a point. Akinetes (6-40 $\mu \mathrm{m}$ long, 2-7 $\mu \mathrm{m}$ wide) occur in rows of two to three cells in culture but are rarely seen in samples from the field (Ballot et al. 2010). Positive vegetative growth occurs at $15-30^{\circ} \mathrm{C}$ and low to moderate light intensities of 40-100 $\mu \mathrm{mol} \mathrm{m} \mathrm{m}^{-2} \mathrm{~s}^{-1}$ (Dias et al. 2002, Cirés and Ballot 2016).

To investigate whether sequestered microcystins provide an advantage to the non-microcystinproducing $C$. issatschenkoi, cultures were supplemented with microcystin and growth was measured and compared to non-supplemented control cultures. As previous studies have shown that certain environmental conditions impact toxin production and that growth optima for toxic and non-toxic strains differ (Kaebernick and Neilan 2001, Boopathi and Ki 2014, Rastogi et al. 2014), the experiment was conducted at a range of temperature and light intensity combinations. To understand whether changes in growth were due to modulated photosynthesis, pigment concentrations were measured and photosynthetic performance was assessed by pulse amplitude modulation (PAM) fluorometry. As microcystins can inhibit photosynthesis and growth of non-microcystin-producing cyanobacteria strains, I hypothesise that growth and functioning of $C$. issatschenkoi will be negatively impacted by microcystin supplementation. As $C$. issatschenkoi grows well in lower light and microcystin has stimulated growth in non-microcystin-producing $M$. aeruginosa strains under low light, I hypothesise that 
microcystin will have a greater negative effect on $C$. issatschenkoi when cultured under more stressful conditions (i.e., high light intensity).

\subsection{Methods}

\subsubsection{Cuspidothrix issatschenkoi Culture}

The cyanobacterial strain $C$. issatschenkoi CAWBG02 was sourced from the CICCM. A stock culture was grown and maintained at $18^{\circ} \mathrm{C}\left( \pm 1^{\circ} \mathrm{C}\right)$ with a $12: 12 \mathrm{~h}$ light:dark cycle (photon flux of $70 \mu \mathrm{mol} \mathrm{m} \mathrm{m}^{-2} \mathrm{~s}^{-1}$ ). C. issatschenkoi was grown in MLA media (Bolch and Blackburn 1996) with a reduced sodium bicarbonate concentration $\left(\mathrm{NaHCO}_{3} ; 0.2 \mathrm{mM}\right.$ instead of $\left.2 \mathrm{mM}\right)$, to reduce the initial $\mathrm{pH}$ from 8.55 to 7.85 . This cyanobacterial strain was chosen for its ability to sequester microcystin (unpublished data; Puddick et al. 2020) and its homogenous growth in culture.

\subsubsection{Experimental Setup}

C. issatschenkoi was grown to a cell concentration of $>1.4 \times 10^{6}$ cells $\mathrm{mL}^{-1}$ so it was in the exponential growth phase, and diluted to $\sim 1.4 \times 10^{6}$ cells $\mathrm{mL}^{-1}$ for the experiment . Cells were grown in sterile $60 \mathrm{~mL}$ plastic specimen pottles over nine different combinations of environmental conditions spanning three temperatures $\left(15,20\right.$ and $\left.25^{\circ} \mathrm{C}\right)$ and three light intensities $\left(20,60\right.$ and $\left.100 \mu \mathrm{mol} \mathrm{m}^{-2} \mathrm{~s}^{-1}\right)$. Culturing pottles were kept inside clear plastic trays in temperature-controlled cabinets set at the desired temperatures, and shaded with frost cloth and aluminium foil to provide the desired light levels. Each condition housed six pottles - three treatment replicates each holding $40 \mathrm{~mL}$ of the cyanobacterial culture supplemented with microcystin to a final concentration of $25 \mu \mathrm{g} \mathrm{L}^{-1}$ (in accordance with Chia et al. 2019), and three control replicates each holding $40 \mathrm{~mL}$ of the untreated culture (Figure 2.1). The treatment and control cultures were grown for seven days before measuring the cell concentrations, pigment concentrations, and photosynthetic performance. Setup and sampling of different environmental conditions were staggered so that sampling could occur at the same time in the day (10 am, $2.25 \mathrm{~h}$ after the lights coming on). A $10 \mathrm{~mL}$ sub-sample was taken from the $\sim 500$

$\mathrm{mL}$ stock culture in the exponential growth phase $15 \mathrm{~h}$ before setting up each condition. The sub-sample was preserved with 4 drops of Lugol's iodine solution and stored in the dark overnight at ambient temperature until the following morning when cell enumeration was carried out to dilute the culture to the desired starting concentration. 


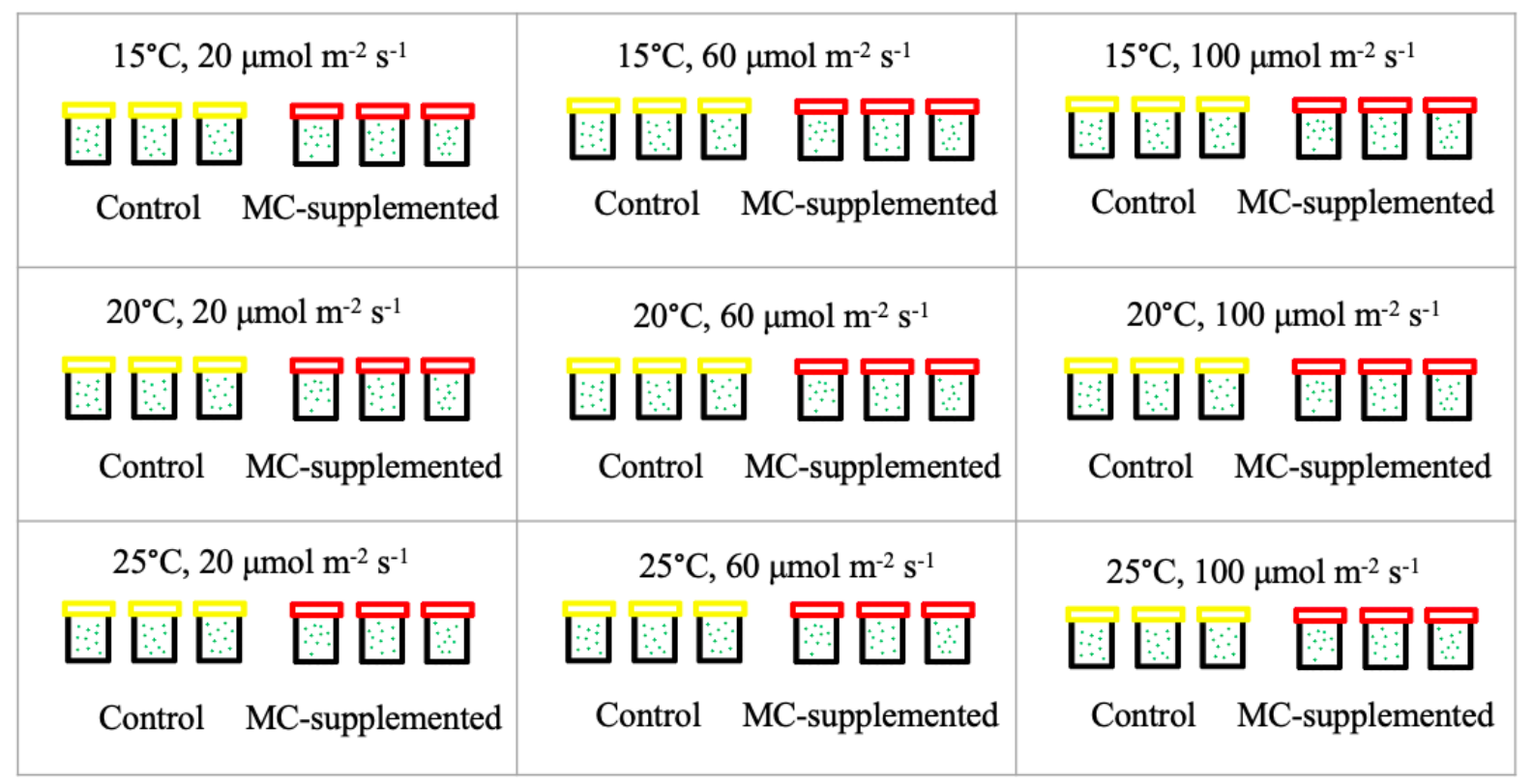

Figure 2.1: Experimental design for the microcystin supplementation experiment using Cuspidothrix issatschenkoi.

\subsubsection{Sampling}

The stock culture used to inoculate pottles when setting up the experiment in each condition was assessed for photosynthetic performance via multi-channel PAM (PHYTO-PAM Phytoplankton Analyzer, Walz, Germany) as per Biessy et al. (2016). The stock culture sampling was carried out six times throughout the experiments to understand the precision of the technique. Six replicate $0.2 \mathrm{~mL}$ samples were taken from the stock culture each time and laid into a black clear-bottom 96-well plate $\left(\right.$ Corning $^{\circledR}$ Costar $\left.^{\circledR}\right)$. As duplicate samples are measured during our conventional PAM analysis (in order to discard an invalid result due to detector saturation), these six samples measured at the same time represented three replicate measurements and were used to determine the short-term precision of the technique. PAM measurements were conducted immediately, as described below.

Experimental pottles were incubated for seven days before sampling. Upon the completion of each experimental period, each pottle was sampled for cell concentration $(10 \mathrm{~mL}$; preserved with four drops of Lugol's iodine solution and stored in the dark at ambient temperature until cell enumeration), chlorophyll and phycocyanin (10 mL each onto GF/C filters; folded and placed in Falcon tubes and stored at $-20^{\circ} \mathrm{C}$ in the dark until pigment extraction and analysis). Photosynthetic performance was also measured by PAM fluorometry, with duplicate samples $(0.2 \mathrm{~mL}$ each) taken from each culturing pottle for analysis. 
Samples for PAM fluorometry analysis were dark acclimated for 20-30 min. Immediately following dark-acclimation, rapid light curves (RLC) were used as a proxy for the rate of photosynthesis (Hofstraat et al. 1994) at chlorophyll excitation wavelengths 470, 520, 645, and $665 \mathrm{~nm}$. An emitter detector fibre-optic measuring head with light emitting diodes was inserted into each well where it delivered $10 \mu$ s light pulses at each wavelength and measured chlorophyll fluorescence at $680 \mathrm{~nm}$ (Schreiber 1998). Auto-gain ensured an optimal gain was set and a RLC was calculated by $10 \mathrm{~s}$ pulses of increasing photon flux density (PAR $=0,1,16$, $32,64,90,120,180,295,405 \mu \mathrm{mol} \mathrm{m} \mathrm{m}^{-2} \mathrm{~s}^{-1}$, which were separated by a saturating light pulse $\left(2,600 \mu \mathrm{mol}\right.$ quanta $\mathrm{m}^{-2} \mathrm{~s}^{-1}$, pulse length $\left.200 \mathrm{~ms}\right)$. Maximum quantum yield (Y), the slope of the initial linear range of the curve (alpha, $\alpha$ ), the maximum electron transport capacity (ETR $\max$ ), and the light saturation parameter $\left(1_{\mathrm{K}}\right)$, which describes the light level of the onset of saturation (often considered the point of $95 \%$ of photosynthesis), were all calculated with the RLC on the PAM instrument. Readings from the $470 \mathrm{~nm}$ PAM excitation wavelength were not recorded, as it is used to measure stimulation via chlorophyll-b, which is not found in cyanobacteria.

\subsubsection{Cell Enumeration}

Cuspidothrix issatschenkoi grows homogenously in culture with individual filaments, thus cell count samples did not require grinding. A subsample $(0.1-1 \mathrm{~mL})$ was placed in a well in a 12well plate (Corning ${ }^{\circledR}$ Costar $^{\circledR}$ ) with milli-Q water (total $4 \mathrm{~mL}$ liquid in each well) and left to settle in the dark overnight. The total filament length in ten random fields of view were measured using an inverted microscope (Olympus CKX41 or IX70 under 400× magnification, Tokyo, Japan) and cellSens Standard micro imaging software. Using a cell enumeration sample prepared on a microscopy slide, the cell length of $C$. issatschenkoi cells $(\mathrm{n}=20)$ were measured on an Olympus BX51 upright microscope (Tokyo, Japan), under oil immersion at 1,000x magnification. The average cell length of $9.61 \mu \mathrm{m}$, field of view area $\left(0.094 \mathrm{~mm}^{2}\right)$ and well area $\left(383.25 \mathrm{~mm}^{2}\right)$ were used to calculate the cell concentration (in cells $\mathrm{mL}^{-1}$ ) using the following formula:

$$
\text { Cells } m L^{-1}=\frac{\frac{\text { Fillength }}{\text { CellLength }} \times \frac{\text { WellArea }}{\text { FoVArea }} \times \text { Dil }}{\text { VolSettled }}
$$

FilLength $=$ Average filament length per field of view $(\mu \mathrm{m})$

CellLength $=$ Average cell length $(\mu \mathrm{m})$ 
WellArea $=$ Well area $\left(\mathrm{mm}^{2}\right)$

FoVArea $=$ Field of view area $\left(\mathrm{mm}^{2}\right)$

Dil $=$ Dilution factor

VolSettled $=$ Volume of sample settled $(\mathrm{mL})$

\subsubsection{Phycocyanin Extraction and Analysis}

Phosphate buffer $(50 \mathrm{mM}$ pH 7.2; $2 \mathrm{~mL}$ ) was added to one of the GF/C filters containing cyanobacteria culture and then frozen at $-20^{\circ} \mathrm{C}$. This was thawed in a bath sonicator with ice (30 min; $52 \mathrm{~Hz}, 100 \%$ power) and blended with an ultra-turrax disperser at 12,000 rpm until relatively homogenous (ca. $30 \mathrm{~s}$ ), before being re-frozen and thawed three more times using the bath sonicator. Following the final thawing cycle, filter debris was pelleted by centrifugation $\left(3,200 \times \mathrm{g}, 10 \mathrm{~min}, 10^{\circ} \mathrm{C}\right)$. The top $1 \mathrm{~mL}$ of liquid was transferred to a microcentrifuge tube and centrifuged $\left(16,000 \times \mathrm{g}, 5 \mathrm{~min}, 10^{\circ} \mathrm{C}\right)$. The clarified extract $(0.8 \mathrm{~mL})$ was transferred to a small-volume disposable spectrophotometer cuvette and the light absorption was measured at 615 and $652 \mathrm{~nm}$ (Eppendorf BioSpectrometer; blanked against phosphate buffer). Light absorption readings were converted to the phycocyanin concentration in the extract (in mg mL $\mathrm{m}^{-1}$ ) using the formula from Bennett and Bogorad (1973):

$$
[P C]=\frac{\mathrm{OD}_{615}-0.474\left(\mathrm{OD}_{652}\right)}{5.34}
$$

$[\mathrm{PC}]=$ Phycocyanin concentration $\left(\mathrm{mg} \mathrm{mL}^{-1}\right)$

OD $_{615}=$ Optical density (light absorption) at $615 \mathrm{~nm}$

$\mathrm{OD}_{652}=$ Optical density (light absorption) at $652 \mathrm{~nm}$

The extract concentration was then converted to a concentration in the culture (in $\mu \mathrm{g} \mathrm{L}^{-1}$ ) using the following formula:

$$
\text { Culture conc }=\frac{[P C] \times \text { ExtractVol }}{\text { FilterVol }} \times 1,000
$$

Culture conc $=$ Phycocyanin concentration in the culture $\left(\mu \mathrm{g} \mathrm{L}^{-1}\right)$

$[\mathrm{PC}]=$ Extract phycocyanin concentration, calculated above $\left(\mathrm{mg} \mathrm{mL}^{-1}\right)$

ExtractVol = Volume of extractant used (phosphate buffer, $\mathrm{mL}$ )

FilterVol $=$ Volume of culture filtered onto GF/C filter (L)

$1,000=$ Conversion from $\mathrm{mg} \mathrm{L}^{-1}$ to $\mu \mathrm{g} \mathrm{\textrm {L } ^ { - 1 }}$ 


\subsubsection{Chlorophyll Extraction and Analysis}

Ethanol (EtOH, $90 \%$ in water; $2 \mathrm{~mL}$ ) was added to the second $\mathrm{GF} / \mathrm{C}$ filter and sonicated in a bath sonicator with ice for $30 \mathrm{~min}(52 \mathrm{~Hz}, 100 \%$ power). Following sonication, the samples were heated at $78^{\circ} \mathrm{C}$ in a water bath for $5 \mathrm{~min}$ and then immediately cooled in an ice bath. The filters were pushed to the bottom of the tube using forceps and centrifuged $(3,000 \times \mathrm{g}, 15 \mathrm{~min}$, $10^{\circ} \mathrm{C}$ ). The top $1 \mathrm{~mL}$ of liquid was transferred to a microcentrifuge tube and clarified by centrifugation $\left(16,000 \times \mathrm{g}, 5 \mathrm{~min}, 10^{\circ} \mathrm{C}\right)$. Chlorophyll extracts were analysed with an EnSpire multimode plate reader (PerkinElmer, USA) and the methodology described by Biggs and Kilroy (2000) and Lorenzen (1967). Four replicate wells (200 $\mu \mathrm{L}$ each) of each sample extract were added to a 96-well plate with control wells of $90 \% \mathrm{EtOH}, 1 \%$ sulphuric acid $\left(\mathrm{H}_{2} \mathrm{SO}_{4}\right)$ and $20 \mathrm{mg} \mathrm{mL}^{-1}$ copper sulphate $\left(\mathrm{CuSO}_{4}\right)$. The light absorption was measured at 665 and $750 \mathrm{~nm}$ using the plate reader (following $30 \mathrm{~s}$ of double-orbital shaking). Hydrochloric acid (1 M; $5 \mu \mathrm{L}$ ) was added to each well using an electronic multichannel auto-pipette. Following acid-addition, the plate was immediately measured again using the EnSpire plate reader where the plate was shaken for $30 \mathrm{~s}$ and the light absorbance was measured at 665 and $750 \mathrm{~nm}$. The shaking and measurement cycle was automatically conducted every $2 \mathrm{~min}$ for $20 \mathrm{~min}$. The absorbance of the $20 \mathrm{mg} \mathrm{mL}^{-1} \mathrm{CuSO}_{4}$ solution was also measured in a 1-cm disposable cuvette (at 665 and $750 \mathrm{~nm}$ with a benchtop Eppendorf BioSpectrometer blanked with $1 \% \mathrm{H}_{2} \mathrm{SO}_{4}$ ) in order to calculate the pathlength of the solutions in the 96-well plate using the formula:

$$
l=\frac{\left[\left(\frac{\left[96-\text { well }_{665}-\text { Blank }_{665}\right]}{1-\mathrm{cm}_{665}}\right)+\left(\frac{\left[96-\text { well }_{750}-\text { Blank }_{750}\right]}{1-\mathrm{cm}_{750}}\right)\right]}{2}
$$

$l=$ Pathlength of extract in 96-well plate $(\mathrm{cm})$

96- well $_{665}=$ Absorbance of the $\mathrm{CuSO}_{4}$ solution at $665 \mathrm{~nm}$ in 96-well plate

Blank $665=$ Absorbance of the $1 \% \mathrm{H}_{2} \mathrm{SO}_{4}$ solution at $665 \mathrm{~nm}$ in 96-well plate

$1-\mathrm{cm}_{665}=$ Absorbance of the $\mathrm{CuSO}_{4}$ solution at $665 \mathrm{~nm}$ in $1 \mathrm{~cm}$ cuvette

96-well $750=$ Absorbance of the $\mathrm{CuSO}_{4}$ solution at $750 \mathrm{~nm}$ in 96-well plate

Blank $750=$ Absorbance of the $1 \% \mathrm{H}_{2} \mathrm{SO}_{4}$ solution at $750 \mathrm{~nm}$ in 96-well plate

$1-\mathrm{cm}_{750}=$ Absorbance of the $\mathrm{CuSO}_{4}$ solution at $750 \mathrm{~nm}$ in $1 \mathrm{~cm}$ cuvette

The chlorophyll concentration was then calculated using the following formula:

Chl-a $\left(m g L^{-1}\right.$ in the culture $)=\frac{\left[\left[\left(\mathrm{B}_{665}-\mathrm{B}_{750}\right)-\left(\mathrm{A}_{665}-\mathrm{A}_{750}\right)\right] \times 28.66 \times 2 \times \text { Dil }\right]}{l \times \text { SampVol }}$ 
$\mathrm{B}_{665}=$ Absorbance at $665 \mathrm{~nm}$ before acid addition

$\mathrm{B}_{750}=$ Absorbance at $750 \mathrm{~nm}$ before acid addition

A $665=$ Absorbance at $665 \mathrm{~nm}$ after acid addition

$\mathrm{A}_{750}=$ Absorbance at 750 after acid addition

28.66 $=$ Absorption coefficient for chlorophyll-a in ethanol

$2=$ Extraction volume (in $\mathrm{mL})$

Dil $=$ Dilution factor $\left(\right.$ if required; Vol $_{\text {Total }} \div$ Volextract $)$

$l=$ Pathlength (in cm; calculated above)

SampVol = Volume of sample filtered (in $\mathrm{mL}$ )

\subsubsection{Statistical Analyses}

Data was analysed in R (version 3.6.3) using R Studio (version 1.2.5033). A two sample t-test was used to determine significant differences in cell concentration, pigment content, and photosynthetic performance parameters between microcystin-treated cultures and the control cultures. The assumption of homogeneity of variances was tested with a Levene's test. If this assumption was violated, a non-parametric Welch's t-test was used to determine any significant differences. 


\subsection{Results}

\subsubsection{Preliminary Data}

A preliminary growth curve was conducted for $C$. issatschenkoi to determine an appropriate starting cell concentration where the culture was in the exponential growth phase (Figure 2.2). The curve shows the exponential growth phase extends from days 4-10, with cell concentrations from $\sim 0.5$ to $3.0 \times 10^{6}$ cells $\mathrm{mL}^{-1}$. A starting concentration of $1.4 \times 10^{6}$ cells $\mathrm{mL}^{-1}$ was selected as a medium density in the exponential growth phase.

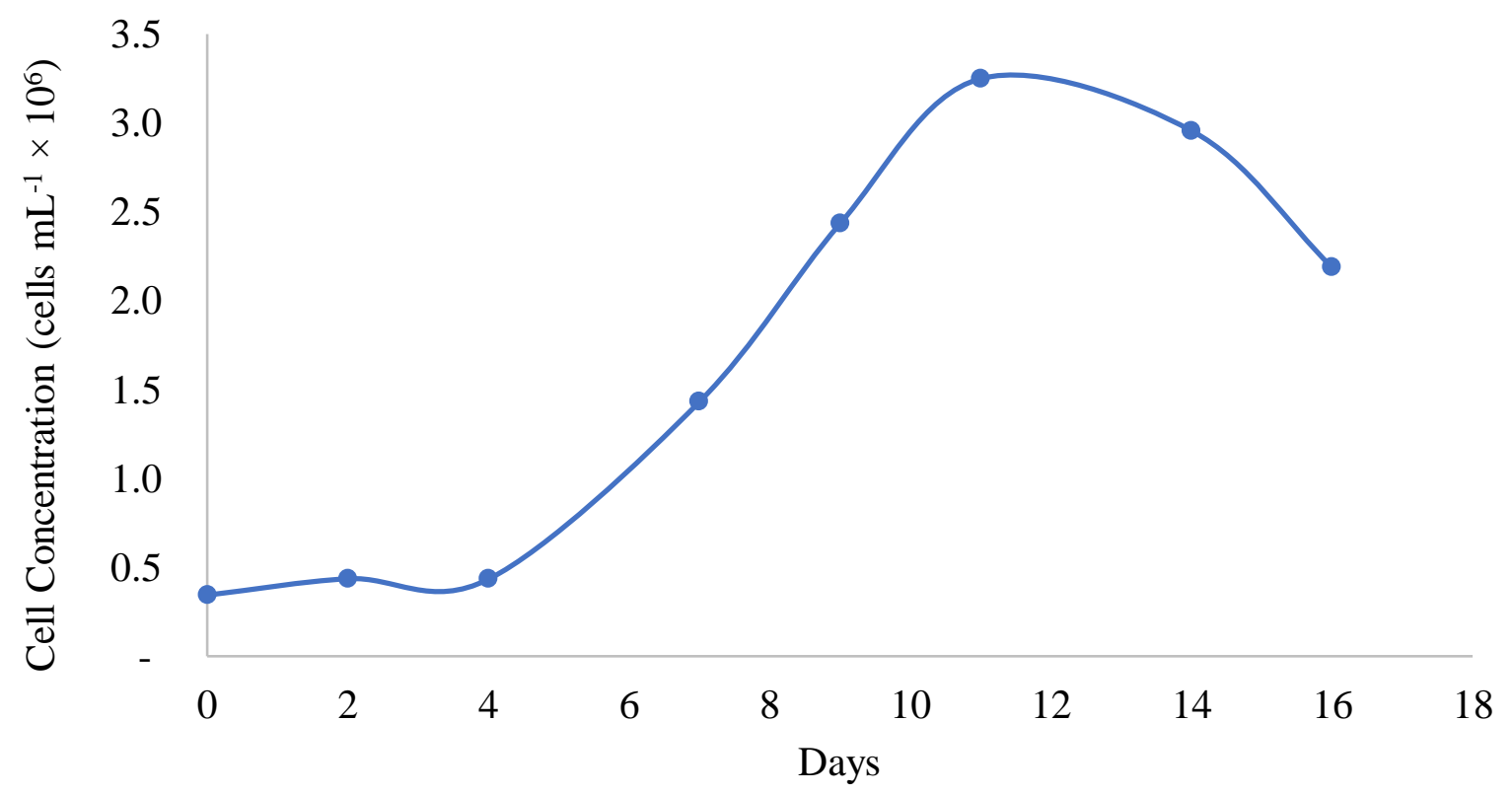

Figure 2.2: Preliminary growth curve of Cuspidothrix issatschenkoi at $18^{\circ} \mathrm{C}, 70 \mu \mathrm{mol} \mathrm{m} \mathrm{m}^{-2} \mathrm{~s}^{-1}$ in MLA media $(n=1)$.

Short-term precision (in one day) of PAM measurements (Table 2.1) were determined using the starting cultures of $C$. issatschenkoi on six separate days. Maximum quantum yield and alpha were fairly consistent across the three channels, however ETR $\max$ and $l_{k}$ were relatively variable in Channel $2(520 \mathrm{~nm})$. Mean light saturation $\left(\mathrm{l}_{\mathrm{k}}\right)$ was higher in Channel $2(129 \%)$ compared to Channel 3 (40\%) and Channel 4 (33\%), and mean ETRmax was also higher in Channel 2 (118\%) compared to Channel 3 (52\%) and Channel 4 (54\%). Channel 4 (665 nm) was chosen for reporting photosynthetic performance results due to the low RSD and high signals on the PAM instrument. 
Table 2.2: Short-term precision of PAM fluorometry technique on Cuspidothrix issatschenkoi at three light excitation wavelengths (Channels 24).

\begin{tabular}{|c|c|c|c|c|c|c|c|c|c|c|}
\hline & \multirow{2}{*}{ Date } & \multicolumn{3}{|c|}{ Channel $2(520 \mathrm{~nm})$} & \multicolumn{3}{|c|}{ Channel $3(645$ nm) } & \multicolumn{3}{|c|}{ Channel $4(665 \mathrm{~nm})$} \\
\hline & & Ave & SD & RSD & Ave & SD & RSD & Ave & SD & RSD \\
\hline \multirow{6}{*}{ Y } & $05 / 11 / 2019$ & 0.30 & 0.01 & $5 \%$ & 0.11 & 0.01 & $11 \%$ & 0.15 & 0.02 & $15 \%$ \\
\hline & $06 / 11 / 2019$ & 0.29 & 0.04 & $15 \%$ & 0.13 & 0.02 & $12 \%$ & 0.17 & 0.01 & $3 \%$ \\
\hline & $15 / 11 / 2019$ & 0.28 & 0.03 & $10 \%$ & 0.14 & 0.02 & $16 \%$ & 0.18 & 0.02 & $14 \%$ \\
\hline & $18 / 11 / 2019$ & 0.32 & 0.02 & $8 \%$ & 0.11 & 0.01 & $5 \%$ & 0.16 & 0.02 & $13 \%$ \\
\hline & $26 / 11 / 2019$ & 0.25 & 0.03 & $12 \%$ & 0.08 & 0.01 & $18 \%$ & 0.12 & 0.01 & $11 \%$ \\
\hline & $27 / 11 / 2019$ & 0.23 & 0.03 & $15 \%$ & 0.09 & 0.01 & $16 \%$ & 0.13 & 0.02 & $13 \%$ \\
\hline \multirow{6}{*}{$\alpha$} & $05 / 11 / 2019$ & 0.12 & 0.02 & $20 \%$ & 0.06 & 0.01 & $12 \%$ & 0.07 & 0.01 & $17 \%$ \\
\hline & $06 / 11 / 2019$ & 0.17 & 0.07 & $41 \%$ & 0.08 & 0.03 & $43 \%$ & 0.10 & 0.04 & $44 \%$ \\
\hline & $15 / 11 / 2019$ & 0.16 & 0.07 & $43 \%$ & 0.06 & 0.03 & $46 \%$ & 0.10 & 0.03 & $32 \%$ \\
\hline & $18 / 11 / 2019$ & 0.17 & 0.08 & $45 \%$ & 0.06 & 0.02 & $28 \%$ & 0.08 & 0.01 & $17 \%$ \\
\hline & $26 / 11 / 2019$ & 0.09 & 0.02 & $26 \%$ & 0.05 & 0.01 & $24 \%$ & 0.05 & 0.01 & $26 \%$ \\
\hline & $27 / 11 / 2019$ & 0.14 & 0.08 & $54 \%$ & 0.06 & 0.01 & $9 \%$ & 0.06 & 0.02 & $39 \%$ \\
\hline \multirow{2}{*}{$\mathrm{ETR}_{\max }$} & $05 / 11 / 2019$ & 57.9 & 65.6 & $113 \%$ & 25.15 & 17.56 & $70 \%$ & 19.53 & 10.52 & $54 \%$ \\
\hline & $06 / 11 / 2019$ & 95.1 & 84.7 & $89 \%$ & 18.32 & 11.20 & $61 \%$ & 22.45 & 14.20 & $63 \%$ \\
\hline
\end{tabular}




\begin{tabular}{|c|c|c|c|c|c|c|c|c|c|c|}
\hline & $15 / 11 / 2019$ & 228.8 & 291.6 & $127 \%$ & 13.0 & 8.43 & $65 \%$ & 22.6 & 12.2 & $54 \%$ \\
\hline & $18 / 11 / 2019$ & 64.2 & 66.3 & $103 \%$ & 21.6 & 15.6 & $72 \%$ & 18.7 & 4.5 & $24 \%$ \\
\hline & $26 / 11 / 2019$ & 1031.7 & 2397.4 & $232 \%$ & 12.9 & 4.3 & $33 \%$ & 10.8 & 7.7 & $71 \%$ \\
\hline & $27 / 11 / 2019$ & 32.3 & 15.3 & $47 \%$ & 13.5 & 1.4 & $10 \%$ & 15.2 & 9.1 & $60 \%$ \\
\hline \multirow{6}{*}{$1_{\mathrm{k}}$} & $05 / 11 / 2019$ & 453.2 & 492.9 & $109 \%$ & 418.7 & 354.6 & $85 \%$ & 264.1 & 113.0 & $43 \%$ \\
\hline & $06 / 11 / 2019$ & 690.5 & 720.3 & $104 \%$ & 239.3 & 111.0 & $46 \%$ & 219.2 & 88.4 & $40 \%$ \\
\hline & $15 / 11 / 2019$ & 1750.2 & 2292.5 & $131 \%$ & 193.7 & 39.6 & $20 \%$ & 227.3 & 51.4 & $23 \%$ \\
\hline & $18 / 11 / 2019$ & 564.4 & 762.6 & $135 \%$ & 332.7 & 175.2 & $53 \%$ & 231.9 & 49.0 & $21 \%$ \\
\hline & $26 / 11 / 2019$ & 10264.1 & 23756.8 & $231 \%$ & 254.2 & 51.7 & $20 \%$ & 213.1 & 92.4 & $43 \%$ \\
\hline & $27 / 11 / 2019$ & 276.5 & 183.8 & $66 \%$ & 230.0 & 28.9 & $13 \%$ & 243.4 & 79.3 & $33 \%$ \\
\hline
\end{tabular}

Ave $=$ Average $; \mathrm{SD}=$ Standard deviation; $\mathrm{RSD}=$ Relative standard deviation $(\mathrm{n}=6) . \mathrm{Y}=$ Maximum quantum yield; $\alpha=$ alpha; ETR $\max =$

Maximum electron transport capacity; $l_{\mathrm{k}}=$ Light saturation parameter. 


\subsubsection{Cell Concentrations}

The growth of $C$. issatschenkoi was not significantly affected by microcystin supplementation (at $25 \mu \mathrm{g} \mathrm{L} \mathrm{L}^{-1}$ ) when grown at $15^{\circ} \mathrm{C}$ and $20^{\circ} \mathrm{C}$ for all three light intensities $(20,60,100 \mu \mathrm{mol} \mathrm{m}$ ${ }^{2} \mathrm{~s}^{-1} ; \mathrm{p} \geq 0.067$; Table 2.2). Cell concentrations appeared to be slightly higher at $15^{\circ} \mathrm{C}$ (Figure 2.3 A-F), although this was not tested statistically due Covid-19 disruptions preventing cell enumeration from starting cultures (needed to convert to growth rates). Cell enumeration for samples from the $25^{\circ} \mathrm{C}$ conditions were also unable to be completed due to the Covid-19 lockdown period.
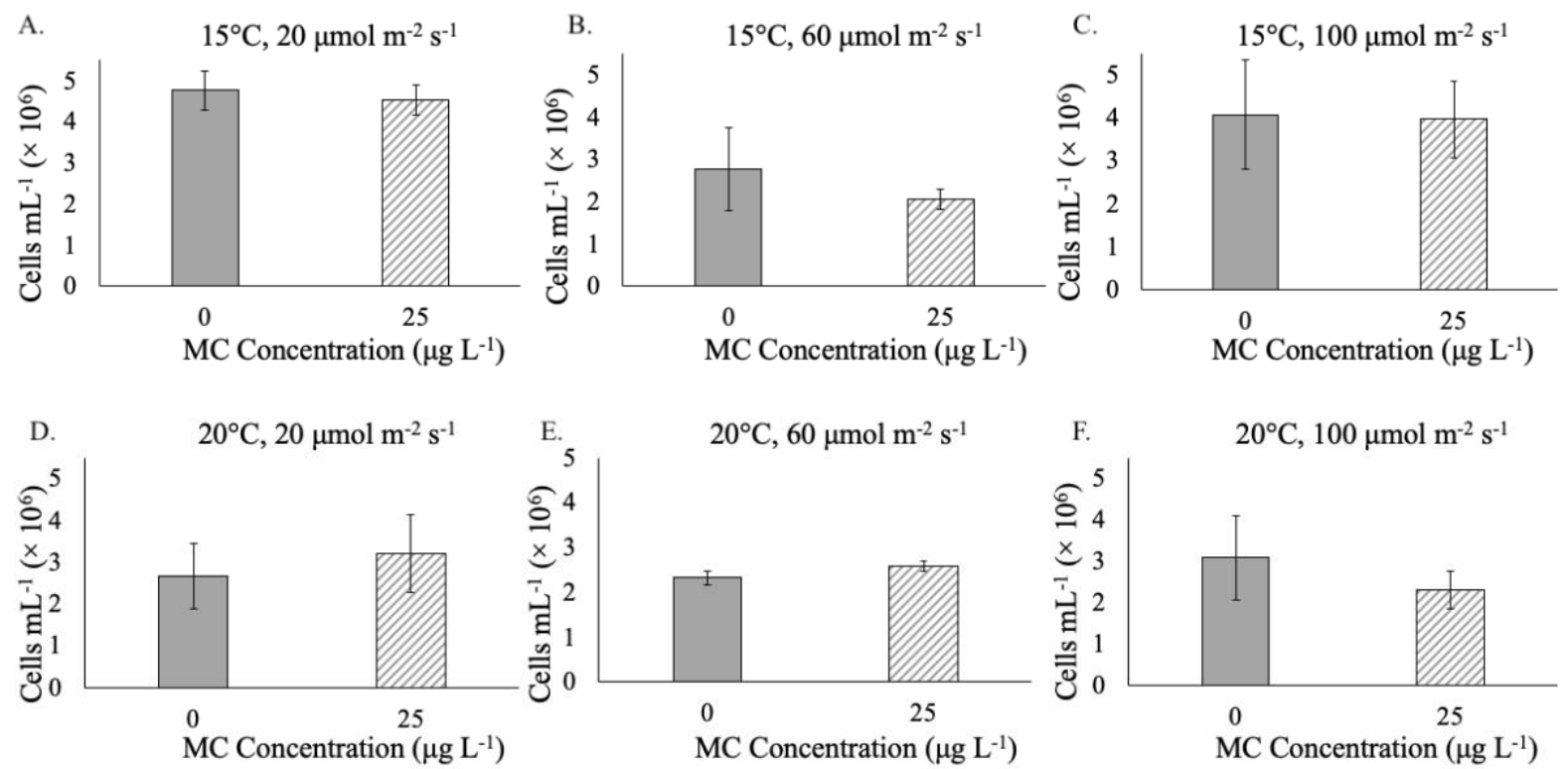

Figure 2.3 A-F: Mean cell concentrations for the experimental control $\left(0 \mu \mathrm{g} \mathrm{L}^{-1}\right)$ and microcystin-supplemented $\left(25 \mu \mathrm{g} \mathrm{L}^{-1}\right)$ Cuspidothrix issatschenkoi cultures in six of the nine different combinations of light level $\left(20,60,100 \mu \mathrm{mol} \mathrm{m}^{-2} \mathrm{~s}^{-1}\right)$, and temperature $\left(15,20^{\circ} \mathrm{C}\right)$. Error bars show \pm one standard deviation. 
Table 2.2: Statistical results (two sample t-test) for determining if there were significant differences between the cell concentrations of microcystin-supplemented cells and the experimental control.

\begin{tabular}{|c|c|c|c|}
\hline \multicolumn{2}{|c|}{ Culturing Condition } & \multirow{2}{*}{$t$-statistic } & \multirow{2}{*}{ p-value } \\
\hline Temp $\left({ }^{\circ} \mathbf{C}\right)$ & Irradiance $\left(\mu \mathrm{mol} \mathrm{m} \mathrm{m}^{-2} \mathrm{~s}^{-1}\right)$ & & \\
\hline \multirow{3}{*}{15} & 20 & 0.695 & 0.525 \\
\hline & 60 & 1.209 & 0.293 \\
\hline & 100 & 0.120 & 0.910 \\
\hline \multirow{3}{*}{20} & 20 & -0.773 & 0.483 \\
\hline & 60 & -2.499 & 0.067 \\
\hline & 100 & 1.227 & 0.287 \\
\hline
\end{tabular}




\subsubsection{Chlorophyll Content}

Microcystin supplementation at a concentration of $25 \mu \mathrm{g} \mathrm{\textrm {L } ^ { - 1 }}$ did not significantly affect the chlorophyll-a content of the $C$. issatschenkoi cultures (Figure 2.4 A-I), under any of the environmental conditions used in these experiments ( $t$-test, $p \geq 0.094$ for all conditions; Table 2.3).
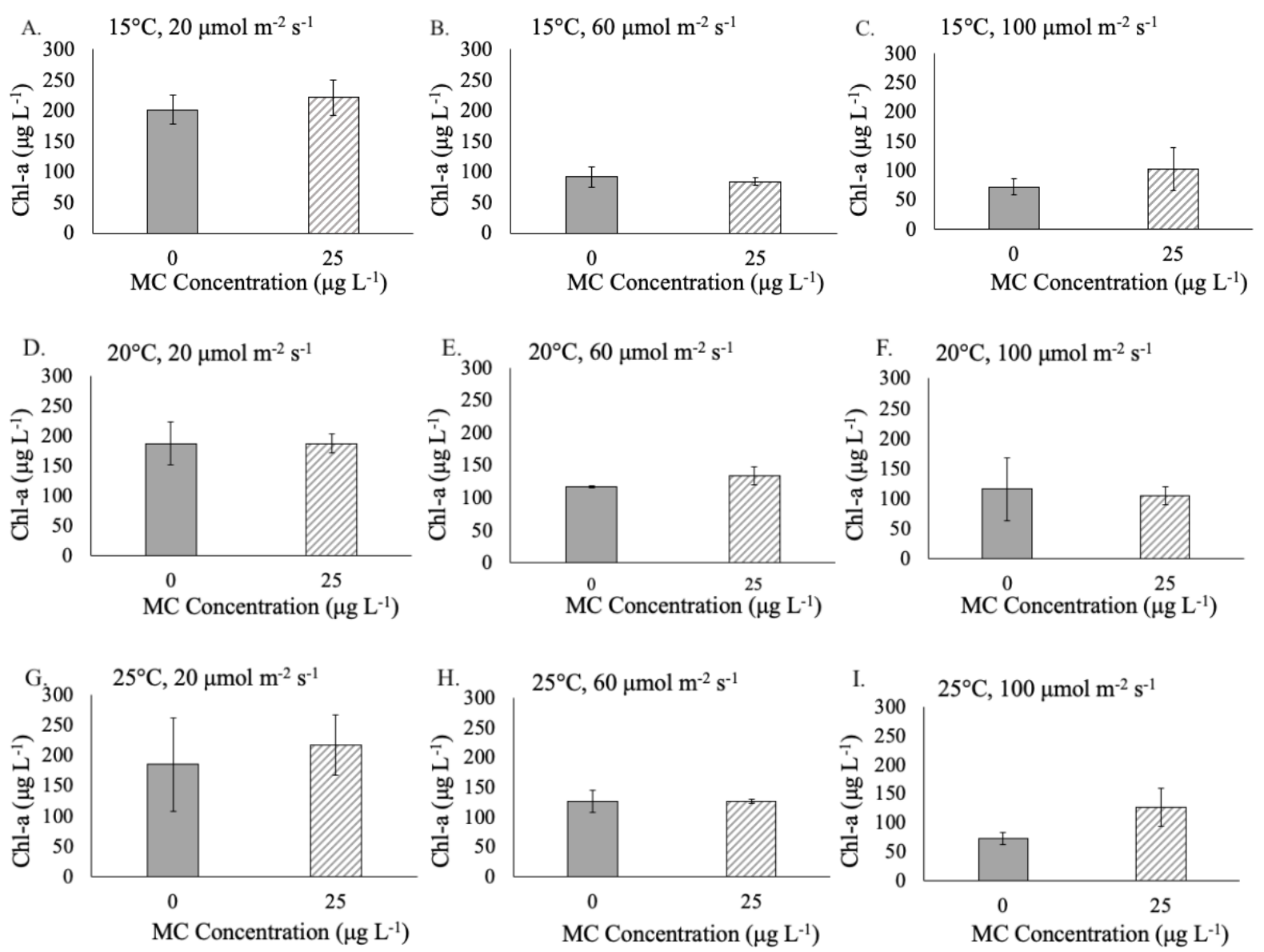

Figure 2.4 A-I: Mean chlorophyll-a (Chl-a) concentrations for the experimental control (0 $\mu \mathrm{g}$ $\left.\mathrm{L}^{-1}\right)$ and microcystin-supplemented $\left(25 \mu \mathrm{g} \mathrm{L}^{-1}\right)$ Cuspidothrix issatschenkoi cultures in nine different combinations of light intensity $\left(20,60,100 \mu \mathrm{mol} \mathrm{m}^{-2} \mathrm{~s}^{-1}\right)$, and temperature $(15,20$, $25^{\circ} \mathrm{C}$ ). Error bars show \pm one standard deviation. 
Table 2.3: Statistical results (two sample t-test) for determining significant differences in chlorophyll-a concentration between microcystin-supplemented cells and the experimental control.

\begin{tabular}{|c|c|c|c|}
\hline \multicolumn{2}{|c|}{ Culturing Condition } & \multirow[b]{2}{*}{$t$-statistic } & \multirow[b]{2}{*}{ p-value } \\
\hline Temp $\left({ }^{\circ} \mathbf{C}\right)$ & Irradiance $\left(\mu \mathrm{mol} \mathrm{m} \mathrm{m}^{-2} \mathrm{~s}^{-1}\right)$ & & \\
\hline & 20 & -0.925 & 0.408 \\
\hline \multirow[t]{3}{*}{15} & 60 & 0.707 & 0.518 \\
\hline & 100 & -1.357 & 0.246 \\
\hline & 20 & -0.0001 & 1.000 \\
\hline \multirow[t]{3}{*}{20} & 60 & -2.183 & 0.094 \\
\hline & 100 & 0.357 & 0.739 \\
\hline & 20 & -0.604 & 0.579 \\
\hline \multirow[t]{2}{*}{25} & 60 & -0.086 & 0.936 \\
\hline & 100 & -2.665 & 0.095 \\
\hline
\end{tabular}




\subsubsection{Phycocyanin Content}

The phycocyanin content of $C$. issatschenkoi was also unaffected by microcystin supplementation $\left(25 \mu \mathrm{g} \mathrm{L}^{-1}\right)$ in all temperature/light level combinations ( $\mathrm{t}$-test, $\mathrm{p} \geq 0.063$ for all conditions; Table 2.4). Some phycocyanin measurements were below the limit of detection and were therefore not recorded. Groups with one of three samples below the limit were: $15^{\circ} \mathrm{C}, 60$ $\mu \mathrm{mol} \mathrm{m} \mathrm{s}^{-2}$ control; $15^{\circ} \mathrm{C}, 100 \mu \mathrm{mol} \mathrm{m}{ }^{-2} \mathrm{~s}^{-1}$ control; $20^{\circ} \mathrm{C}, 20 \mu \mathrm{mol} \mathrm{m}^{-2} \mathrm{~s}^{-1}$ control; $20^{\circ} \mathrm{C}, 20$ $\mu \mathrm{mol} \mathrm{m} \mathrm{m}^{-2} \mathrm{MC} ; 20^{\circ} \mathrm{C}, 100 \mu \mathrm{mol} \mathrm{m} \mathrm{s}^{-1} \mathrm{MC}$; and $25^{\circ} \mathrm{C}, 20 \mu \mathrm{mol} \mathrm{m}{ }^{-2} \mathrm{~s}^{-1}$ control. Groups with two of three measurements below the limit were: $15^{\circ} \mathrm{C}, 60 \mu \mathrm{mol} \mathrm{m} \mathrm{m}^{-2} \mathrm{~s}^{-1} \mathrm{MC}$; and $20^{\circ} \mathrm{C}, 100$ $\mu \mathrm{mol} \mathrm{m} \mathrm{m}^{-2} \mathrm{~s}^{-1} \mathrm{MC}$. Thus, these two groups lack error bars in the bar graphs (Figure $2.5 \mathrm{~A}-\mathrm{I}$ ).
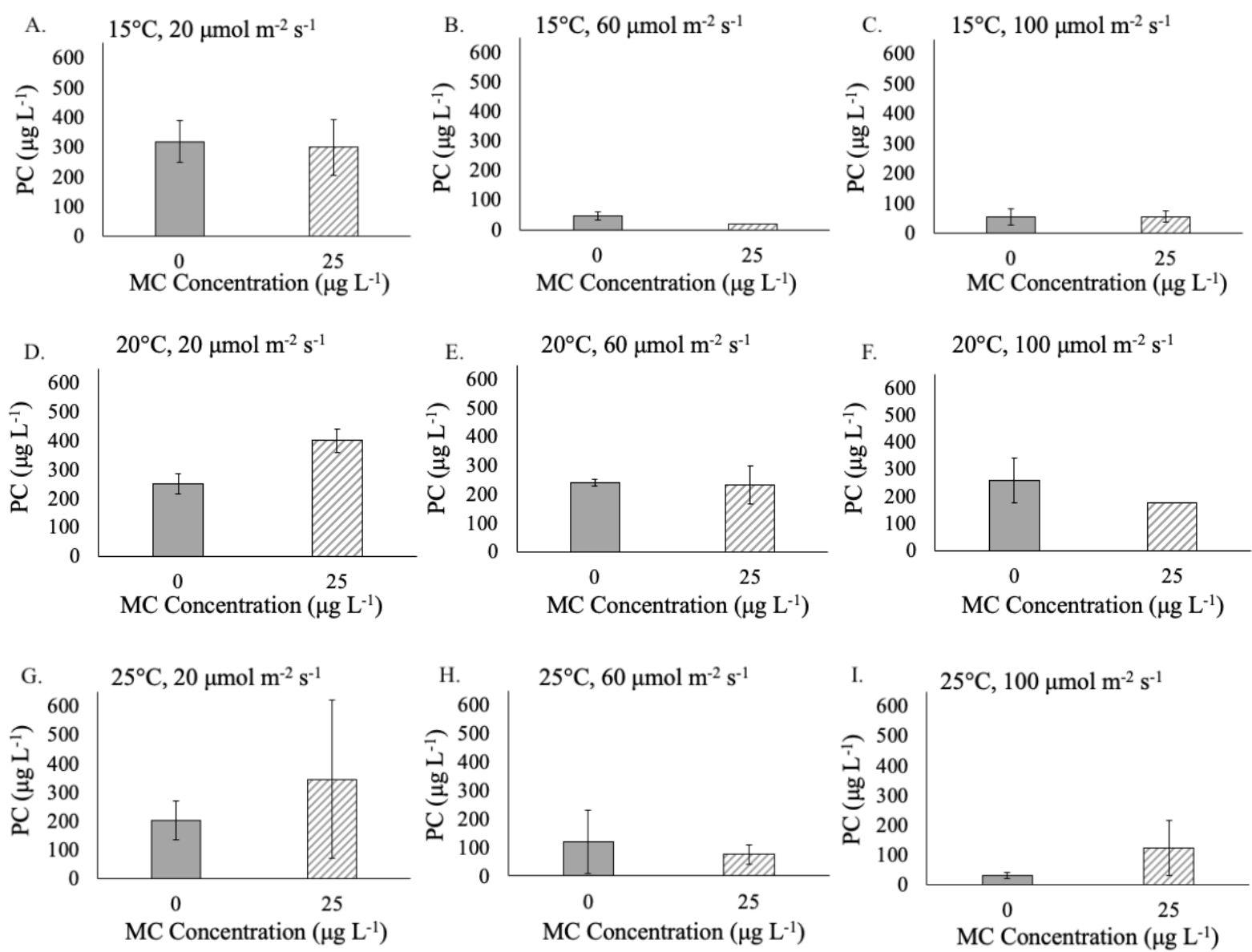

Figure 2.5 A-I: Mean phycocyanin (PC) concentrations for the experimental control $\left(0 \mu \mathrm{g} \mathrm{L}^{-}\right.$ ${ }^{1}$ ) and microcystin-supplemented $\left(25 \mu \mathrm{g} \mathrm{L}^{-1}\right)$ Cuspidothrix issatschenkoi cultures in nine different combinations of light level $\left(20,60,100 \mu \mathrm{mol} \mathrm{m}^{-2} \mathrm{~s}^{-1}\right)$, and temperature $\left(15,20,25^{\circ} \mathrm{C}\right)$. Error bars show \pm one standard deviation. 
Table 2.4: Statistical results (two sample t-test) for determining significant differences in phycocyanin concentration of microcystin-supplemented cells and the experimental control.

\begin{tabular}{|c|c|c|c|}
\hline \multicolumn{2}{|c|}{ Culturing Condition } & \multirow[b]{2}{*}{$t$-statistic } & \multirow[b]{2}{*}{ p-value } \\
\hline $\operatorname{Temp}\left({ }^{\circ} \mathrm{C}\right)$ & Irradiance $\left(\mu \mathrm{mol} \mathrm{m} \mathrm{m}^{-2} \mathrm{~s}^{-1}\right)$ & & \\
\hline & 20 & 0.273 & 0.798 \\
\hline \multirow[t]{3}{*}{15} & 60 & - & - \\
\hline & 100 & 0.048 & 0.965 \\
\hline & 20 & $-3.921 \dagger$ & $0.063 \dagger$ \\
\hline \multirow[t]{3}{*}{20} & 60 & 0.171 & 0.873 \\
\hline & 100 & 0.86 & 0.48 \\
\hline & 20 & -0.684 & 0.543 \\
\hline \multirow[t]{2}{*}{25} & 60 & 0.656 & 0.548 \\
\hline & 100 & $-1.382 \dagger$ & $0.396 \dagger$ \\
\hline \multicolumn{4}{|c|}{$\begin{array}{l}\dagger \text { Levene's test revealed variances were not equal }(\mathrm{p}<0.05) \text {, thus Welch's two sample t-test } \\
\text { was used. The Welch t-test could not be completed at } 15^{\circ} \mathrm{C}, 60 \mu \mathrm{mol} \mathrm{m} \mathrm{m}^{-2} \mathrm{~s}^{-1} \text { due to missing } \\
\text { data as described above. }\end{array}$} \\
\hline
\end{tabular}




\subsubsection{Photosynthetic Performance}

The photosynthetic performance data presented in the results shows readings from Channel 4 of the PAM fluorometer used (light excitation wavelength $665 \mathrm{~nm}$ ). This channel was chosen because it provided consistently high signals when being measured. The precision data (Section 2.3.1; Table 2.1) also shows that this channel had the lowest \% relative standard deviation (RSD). Photosynthetic performance results from Channels $2(520 \mathrm{~nm})$ and $3(645 \mathrm{~nm})$ can be found in Appendix Table A1.1, and Figures A1.1-A1.4.

No significant differences were detected in maximum quantum yield between the control and microcystin-supplemented cells in eight of the environmental conditions (two sample t-test, $p$ $\geq 0.055$; Table 2.5). However, microcystin supplementation resulted in a $33 \%$ decrease when cultured in $15^{\circ} \mathrm{C}, 60 \mu \mathrm{mol} \mathrm{m} \mathrm{m}^{-2} \mathrm{~s}^{-1}$ (two sample $\mathrm{t}$-test; $\mathrm{t}=3.27, \mathrm{p}=0.031$ ).

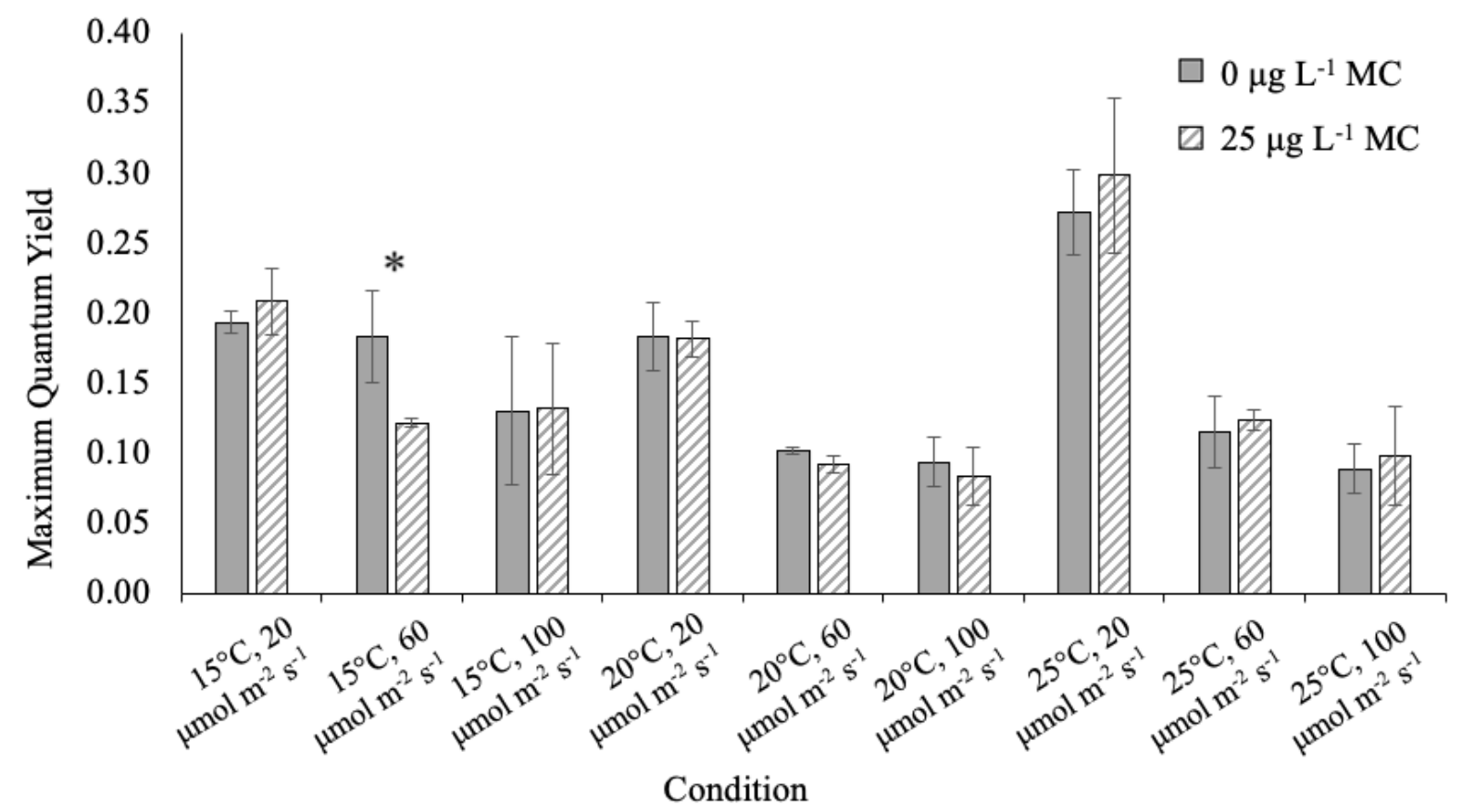

Figure 2.6: Mean maximum quantum yield for the experimental control $\left(0 \mu \mathrm{g} \mathrm{L}^{-1}\right)$ and microcystin-supplemented $\left(25 \mu \mathrm{g} \mathrm{L}^{-1}\right)$ Cuspidothrix issatschenkoi cultures in nine different combinations of light level $\left(20,60,100 \mu \mathrm{mol} \mathrm{m}^{-2} \mathrm{~s}^{-1}\right)$, and temperature $\left(15,20,25^{\circ} \mathrm{C}\right)$. Error bars show \pm one standard deviation. $*=$ Significant $\mathrm{p}$ value $<0.05$.

No significant difference was detected in alpha between the control and microcystinsupplemented cells in seven of the environmental conditions (two sample t-test, $\mathrm{p} \geq 0.189$; Table 2.5). However, microcystin supplementation resulted in a $36 \%$ decrease in alpha at $15^{\circ} \mathrm{C}$, 
$60 \mu \mathrm{mol} \mathrm{m} \mathrm{m}^{-2} \mathrm{~s}^{-1}$ (two sample t-test; $\mathrm{t}=3.287, \mathrm{p}=0.03$ ), and a $25 \%$ increase at $25^{\circ} \mathrm{C}, 100 \mu \mathrm{mol}$ $\mathrm{m}^{-2} \mathrm{~s}^{-1}$ (two sample t-test; $\mathrm{t}=-3.24, \mathrm{p}=0.032$ ).

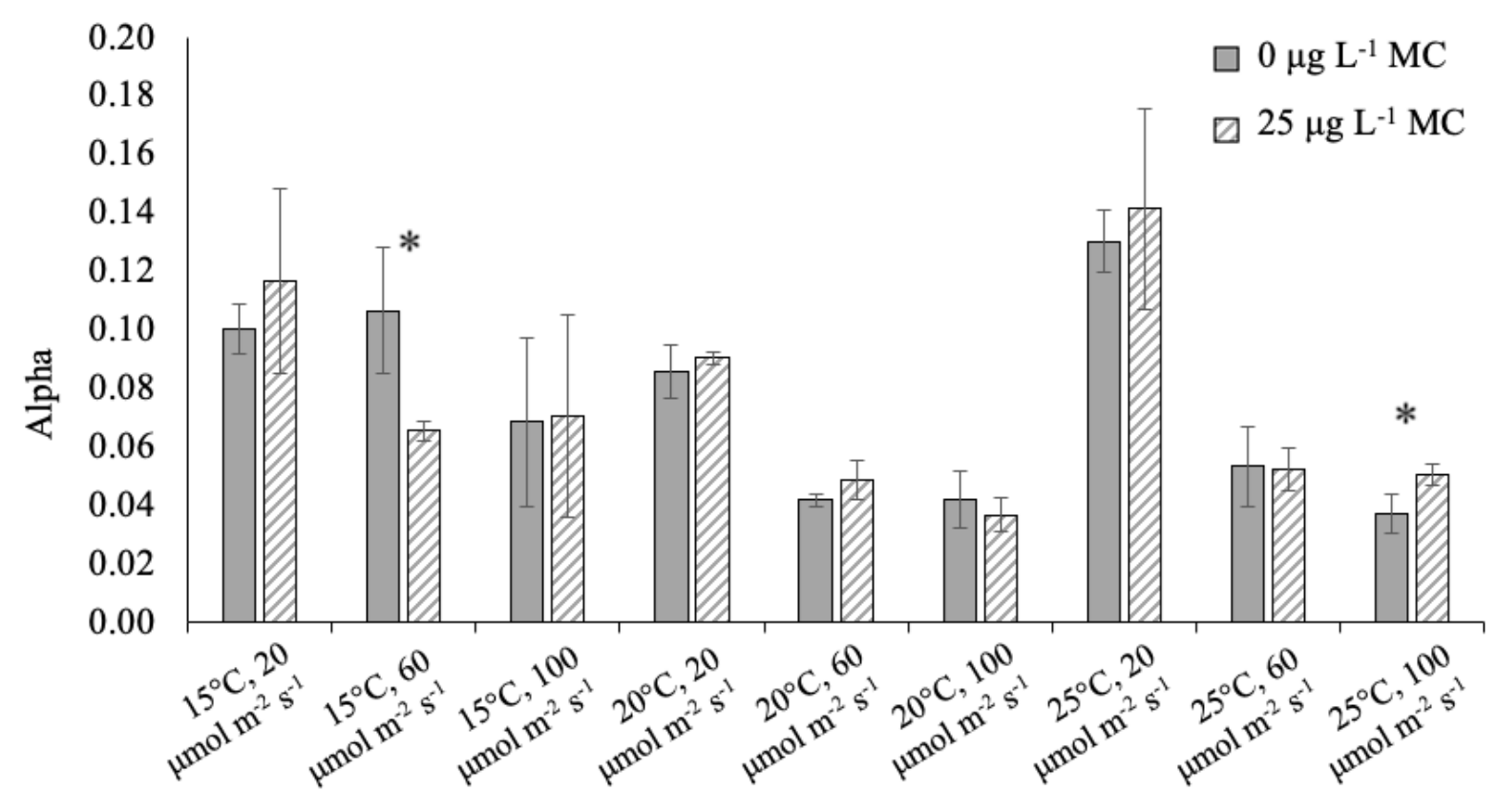

Condition

Figure 2.7: Mean alpha (slope of the initial linear range of the rapid light curve, photosynthetic efficiency) for the experimental control $\left(0 \mu \mathrm{g} \mathrm{L} \mathrm{L}^{-1}\right)$ and microcystin-supplemented $\left(25 \mu \mathrm{g} \mathrm{L}^{-1}\right)$ Cuspidothrix issatschenkoi cultures in nine different combinations of light level (20, 60, 100 $\left.\mu \mathrm{mol} \mathrm{m} \mathrm{m}^{-2} \mathrm{~s}^{-1}\right)$, and temperature $\left(15,20,25^{\circ} \mathrm{C}\right)$. Error bars show \pm one standard deviation. $*=$ Significant $\mathrm{p}$ value $<0.05$.

The ETR $\mathrm{Emax}_{\max }$ of . issatschenkoi was unaffected by microcystin supplementation $\left(25 \mu \mathrm{g} \mathrm{L}^{-1}\right)$ in all temperature/light level combination ( $\mathrm{t}$-test, $\mathrm{p} \geq 0.145$ for all conditions; Table 2.5). 


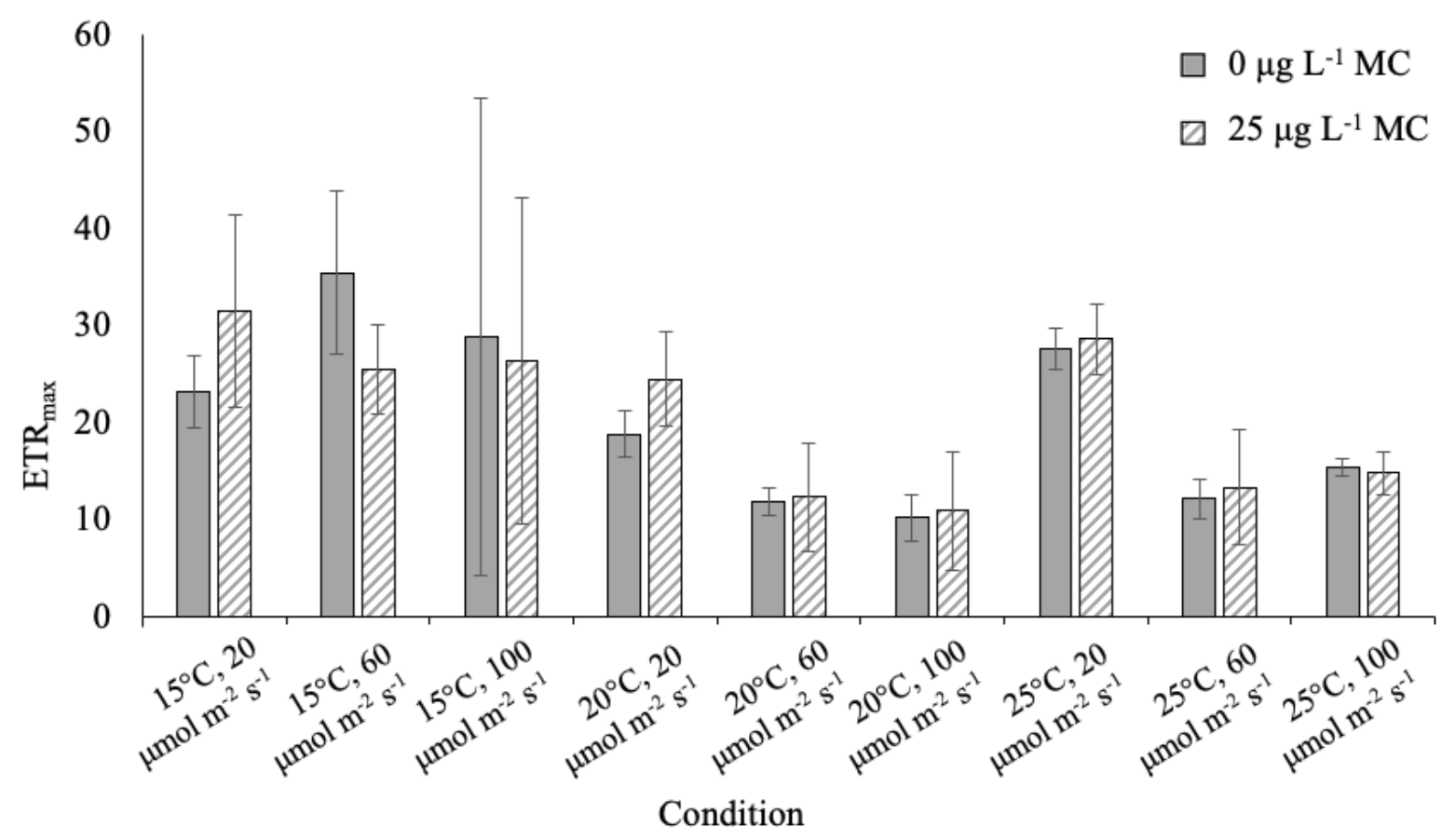

Figure 2.8: Mean ETR $\max$ (maximum electron transport capacity) for the experimental control $\left(0 \mu \mathrm{g} \mathrm{L}^{-1}\right)$ and microcystin-supplemented $\left(25 \mu \mathrm{g} \mathrm{L}^{-1}\right)$ Cuspidothrix issatschenkoi cultures in nine different combinations of light level $\left(20,60,100 \mu \mathrm{mol} \mathrm{m}^{-2} \mathrm{~s}^{-1}\right)$, and temperature $(15,20$, $\left.25^{\circ} \mathrm{C}\right)$. Error bars show \pm one standard deviation.

No significant differences in the light saturation parameter were detected between microcystinsupplemented cells and the control cultures for most of the environmental conditions (t-test, $\mathrm{p}$ $\geq 0.147$; Table 2.5 ). A statistically significant difference in $l_{\mathrm{k}}$ was detected at $25^{\circ} \mathrm{C}, 100 \mu \mathrm{mol}$ $\mathrm{m}^{-2} \mathrm{~s}^{-1}$, with a $26 \%$ decrease in the microcystin-supplemented $C$. issatschenkoi cultures (two sample t-test; $\mathrm{t}=3.347, \mathrm{p}=0.029)$. 


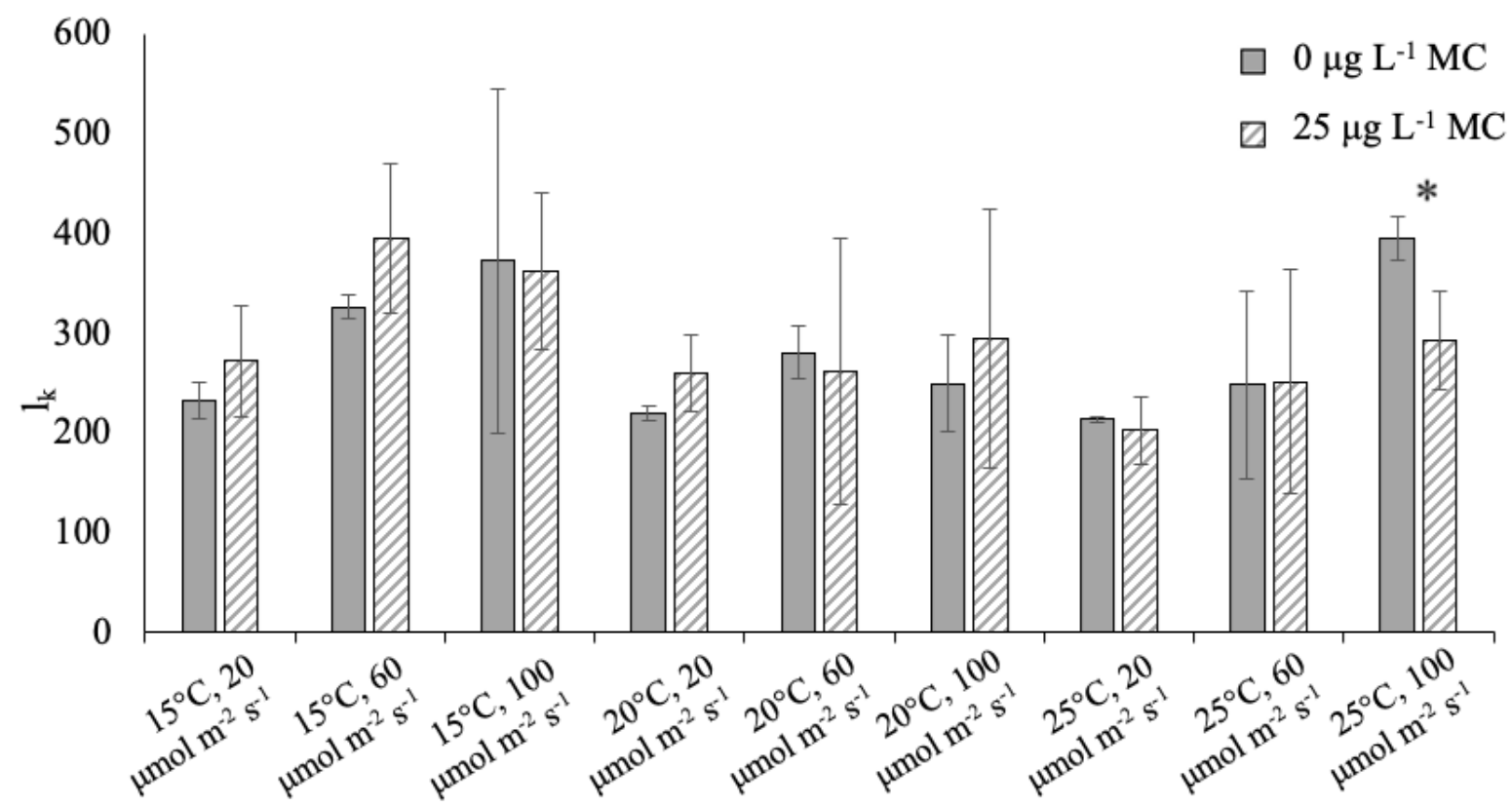

\section{Condition}

Figure 2.9: Mean $1_{\mathrm{K}}$ (light saturation parameter) for the experimental control $\left(0 \mu \mathrm{g} \mathrm{L}^{-1}\right)$ and microcystin-supplemented $\left(25 \mu \mathrm{g} \mathrm{L}^{-1}\right)$ Cuspidothrix issatschenkoi cultures in nine different combinations of light level $\left(20,60,100 \mu \mathrm{mol} \mathrm{m}^{-2} \mathrm{~s}^{-1}\right)$, and temperature $\left(15,20,25^{\circ} \mathrm{C}\right)$. Error bars show \pm one standard deviation. $*=$ Significant $\mathrm{p}$ value $<0.05$. 
Table 2.5: Statistical results (two sample t-test) for determining significant differences in photosynthetic performance of microcystinsupplemented cells and the experimental control at an excitation wavelength of $665 \mathrm{~nm}$.

\begin{tabular}{|c|c|c|c|c|c|c|c|c|c|}
\hline \multicolumn{2}{|c|}{ Condition } & \multicolumn{2}{|c|}{$\mathrm{Y}$} & \multicolumn{2}{|c|}{ Alpha } & \multicolumn{2}{|c|}{$\mathrm{ETR}_{\max }$} & \multicolumn{2}{|c|}{$\mathrm{l}_{\mathrm{K}}$} \\
\hline Temp $\left({ }^{\circ} \mathbf{C}\right)$ & 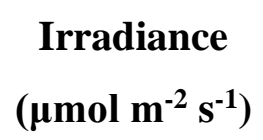 & t-statistic & p-value & t-statistic & p-value & t-statistic & p-value & t-statistic & p-value \\
\hline & 20 & -1.046 & 0.355 & -0.857 & 0.440 & -1.357 & 0.246 & -1.166 & 0.308 \\
\hline \multirow[t]{3}{*}{15} & 60 & 3.270 & $0.031 *$ & 3.287 & $0.030^{*}$ & 1.787 & 0.149 & -1.575 & 0.190 \\
\hline & 100 & -0.041 & 0.969 & -0.077 & 0.943 & 0.146 & 0.891 & 0.095 & 0.929 \\
\hline & 20 & 0.104 & 0.922 & -0.794 & 0.472 & -1.805 & 0.145 & -1.796 & 0.147 \\
\hline \multirow[t]{3}{*}{20} & 60 & 0.055 & 0.055 & -1.581 & 0.189 & -0.130 & 0.903 & 0.240 & 0.822 \\
\hline & 100 & 0.647 & 0.553 & 0.765 & 0.486 & -0.181 & 0.865 & -0.564 & 0.603 \\
\hline & 20 & -0.733 & 0.504 & -0.534 & 0.622 & -0.404 & 0.707 & 0.562 & 0.604 \\
\hline \multirow[t]{2}{*}{25} & 60 & -0.552 & 0.610 & 0.073 & 0.945 & -0.326 & 0.761 & -0.044 & 0.968 \\
\hline & 100 & -0.441 & 0.682 & -3.240 & $0.032 *$ & 0.449 & 0.677 & 3.347 & $0.029 *$ \\
\hline
\end{tabular}




\subsection{Discussion}

Cuspidothrix issatschenkoi is a non-microcystin-producing cyanobacterium capable of sequestering microcystin. This is the first study investigating the effects of microcystin supplementation on this species, and possible effects were examined under nine different irradiance and temperature combinations. Microcystin supplementation did not affect chlorophyll-a or phycocyanin concentration in C. issatschenkoi over the nine environmental conditions tested, or cell concentration in the $15^{\circ} \mathrm{C}$ and $20^{\circ} \mathrm{C}$ conditions. Cell concentrations overall were slightly higher in cultures kept in $15^{\circ} \mathrm{C}$ compared to $20^{\circ} \mathrm{C}$, although the response was not statistically comparable between conditions without the data being converted into a growth rate (due to the Covid-19 lockdown, cell concentrations of the starting cultures have not yet been determined). Chlorophyll-a and phycocyanin content in C. issatschenkoi was also higher in low light conditions. Visually, cultures grown at high light intensities were light green/yellow rather than their usual bluish-green colour. Increasing pigment content in low light is a common response to maximise photosynthesis as it increases the light-harvesting efficiency (Foy and Gibson 1982). It is more difficult to understand the trend in phycocyanin content in this experiment due to some of the samples being below the limit of detection. Bhandari and Sharma (2006) found that high light $\left(500 \mu \mathrm{mol} \mathrm{m} \mathrm{m}^{-2} \mathrm{~s}^{-1}\right)$ considerably decreased chlorophyll-a and phycocyanin content in Nostoc spongiaeforme, with phycocyanin by up to 93\% after six hours. High levels of photosynthetic active radiation can lead to photobleaching of pigments and inhibit photosynthesis.

Cell enumeration could not be completed for cultures kept in $25^{\circ} \mathrm{C}$ due to Covid-19 lockdown disruptions, however because the chlorophyll-a and phycocyanin content was not significantly altered by the addition of microcystin at this temperature, it is likely that no change in cell concentration would have occurred from microcystin supplementation. Many cyanobacteria prefer temperatures of $\geq 25^{\circ} \mathrm{C}$ (Konopka and Brock 1978, Robarts and Zohary 1987), and cyanobacteria may respond differently to contaminants in conditions that are stressful compared to those that are not (Hu et al. 2004, Zilliges et al. 2011).

In general, photosynthetic performance was not different between microcystin-supplemented cultures and the controls. Maximum quantum yield in the $20^{\circ} \mathrm{C}, 25 \mu \mathrm{mol} \mathrm{m} \mathrm{m}^{-2} \mathrm{~s}^{-1}$ condition was comparatively high for both the control and the microcystin-supplemented cultures, compared to all other conditions. At $15^{\circ} \mathrm{C}, 60 \mu \mathrm{mol} \mathrm{m} \mathrm{m}^{-2} \mathrm{~s}^{-1}$, the maximum quantum yield and alpha of microcystin-supplemented $C$. issatschenkoi significantly decreased by approximately one third 
compared to the control in the same environmental condition. ETR $\max$ was also lower in microcystin-supplemented cells. This response indicates that microcystin supplementation causes stress in this condition and reduces photosynthetic performance, which was unexpected as these conditions are considered favorable for $C$. issatschenkoi (Dias et al. 2002, Cirés and Ballot 2016). In $25^{\circ} \mathrm{C}, 100 \mu \mathrm{mol} \mathrm{m} \mathrm{m}^{-2} \mathrm{~s}^{-1}$, alpha increased by a quarter and $\mathrm{l}_{\mathrm{k}}$ decreased by a quarter. A decrease in $l_{\mathrm{k}}$ in high light indicates that the cells are stressed and suggests that $C$. issatschenkoi does not survive well under high light and high temperatures. C. issatschenkoi has been previously described as preferring low to moderate light, however positive vegetative growth for this species is a relatively a wide temperature range $\left(15-30^{\circ} \mathrm{C}\right.$; Cirés and Ballot 2016). Although the chlorophyll-a content did not differ significantly at this temperature/light intensity combination, the average concentration was higher in the microcystin-supplemented cells. Interestingly, the increase in alpha in this condition contradicts the result for $l_{k}$, as a higher alpha indicates increased photosynthetic efficiency. The combination of high light and high temperature may have induced stress in $C$. issatschenkoi, and the increased photosynthetic efficiency may be compensation when the samples were dark-acclimated. In nature, fast changing abiotic and biotic factors means that phytoplankton can experience rapid fluctuations in light intensity (Dubinsky and Stambler 2009). Cyanobacteria have preferred depths in the water column for this reason among others (Karlsson-Elfgren et al. 2004, Kutser et al. 2008), however when grown in culture they are unable to escape high light.

Microcystin $\left(10 \mu \mathrm{g} \mathrm{L}^{-1}\right)$ sequestration in Synechocystis PCC6803 caused a significant decrease in PSII activity measured by oxygen evolution (Phelan and Downing 2014). This Synechocystis strain was cultured at $20^{\circ} \mathrm{C}, 100 \mu \mathrm{mol} \mathrm{m} \mathrm{m}^{-2} \mathrm{~s}^{-1}$ - one of the conditions used in this study. However, microcystin supplementation resulted in only a slight decrease in Y and alpha, and a slight increase in ETR max and $l_{k}$ in the present study for this temperature and light combination, although, not enough to be significantly different from the control and the same result was true for most of the environmental conditions used. Chia et al (2019) also found that microcystin $\left(25 \mu \mathrm{g} \mathrm{L}^{-1}\right)$ decreased the maximum quantum efficiency of PSII in two Microcystis strains at $23^{\circ} \mathrm{C}, 40 \mu \mathrm{mol} \mathrm{m} \mathrm{m}^{-2} \mathrm{~s}^{-1}$. Microcystis is a successful bloom-forming species and often outcompetes competitors (Yamamoto and Nakahara 2005), but this genus has many other traits (excluding microcystin production) that make it a good competitor. Suppression of competitors through PSII inhibition may provide advantages to microcystin-producers. However, the results from the present study suggest that other biotic and abiotic factors play a role in the 
toxicity of microcystin to other cyanobacteria, as $C$. issatschenkoi was largely unaffected by microcystin, and pigment content and cell concentration was also unaffected.

\subsection{Conclusions}

To better understand the role of microcystins and investigate whether microcystin sequestration increases fitness in $C$. issatschenkoi, a non-microcystin-producing species, cultures were supplemented with microcystin in a range of environmental conditions. I hypothesised that microcystin would negatively impact the growth and photosynthetic performance of $C$. issatschenkoi and this effect would be greater in high light. The reason this species has the ability to sequester the toxin is still unknown, but previous studies (Phelan and Downing 2014, Chia et al. 2019) have shown that microcystin causes a decrease in PSII functioning in nonproducing strains. However, the lack of negative impact on $C$. issatschenkoi supports the idea that microcystin is not used to suppress competing phytoplankton. This is the first study investigating the effects of microcystin supplementation, on non-microcystin-producing species with the ability to sequester the toxin, in a range of environmental conditions. The use of different temperature/light intensity combinations determined whether any benefits of sequestration were niche-specific. Based on the findings in this study, I conclude that microcystin has no effect on growth and fitness of $C$. issatschenkoi, and is unlikely to play a role in suppressing competing phytoplankton growth. 


\section{Chapter 3: Effects of Herbicides on New Zealand Cyanobacteria}

\subsection{Introduction}

Due to their cosmopolitan distribution, cyanobacteria are useful indicators of pollution and environmental contamination (Zhou et al. 2006). Many aquatic organisms depend on clean freshwater to live (Baillie and Neary 2015), and research on water quality and environmental inputs is important for understanding how species survive and thrive under different conditions. Herbicides and other pesticides are a common contaminant of aquatic ecosystems (Relyea 2008) and have a known mode of action against photosynthetic organisms (Harris and Smith 2016). Their use is an integral part of the management and production of forests and agriculture in New Zealand (Manktelow et al. 2005, Baillie 2016), with control of competing weeds being one of the most important treatments for crop and tree growth in the country and worldwide (Rolando et al. 2013). Before the introduction of herbicides, weed removal was more difficult and very labour-intensive (Délye et al. 2013).

The classification of herbicides is determined by the mechanism/mode of action, or how they inhibit plant survival. This could involve photosynthesis inhibition, disruption of cell division, or inhibition of lipid or amino acid biosynthesis (Duke 1990). Phenoxy hormone herbicides are the most commonly used herbicides in New Zealand, making up 25\% of all pesticide active ingredient use per year (1,081 tonnes), mostly being used by the arable and pastoral farming sectors ( 137 tonnes and $~ 914$ tonnes respectively). 2-Methyl-4-chlorophenoxyacetic acid (MCPA) dominates this category at 447 tonnes, which alone accounts for $10.5 \%$ of all pesticide use (Manktelow et al 2005). It is a selective post-emergence herbicide, and has been popular for control of broad leaf weeds since the 1950s (Bourdot et al 1996, Chouhan et al 2016).

The phosphonyl herbicide $N$-(phosphonomethyl)glycine (glyphosate; Vivancos et al. 2011, Harris \& Smith 2016), is the second most commonly used herbicide in New Zealand. The phosphonyls account for $8.4 \%$ of pesticide use, and glyphosate makes up $~ 97 \%$ of that - this chemical is used across the horticulture (100 tonnes year $\left.{ }^{-1}\right)$, pastoral farming (100 tonnes year $^{-1}$ ) and forestry (140 tonnes year ${ }^{-1}$ ) sectors. Glyphosate was created in 1950 and patented as a metal binding agent (Richmond 2018). It inhibits a plant enzyme responsible for biosynthesis of the amino acids tryptophan, phenylalanine, and tyrosine by binding to manganese (Vivancos et al. 2011, Harris \& Smith 2016, Richmond 2018), and was first sold 
commercially by Monsanto in 1974 in their product 'RoundUp' (Benbrook 2016, Richmond 2018). The herbicide is absorbed through foliage of growing plants and non-selectively kills all vegetation, which restricted the amount that could be used. It was initially used around power lines and train tracks and for specific landscaping and farming (Richmond 2018). However, genetically-engineered glyphosate-tolerant crops were developed and planted in the United States in the mid-1990s, and consequently the use of glyphosate increased as farmers could spray fields indiscriminately to remove unwanted weeds (Woodburn 2000, Benbrook 2016).

Liquid pesticide-use tripled between 1993 and 2001 on farms, with herbicides topping fungicides and insecticides as the most used type of pesticide in New Zealand (MacLeod and Moller 2006). Due to the worldwide increases in herbicide use, herbicide resistance is becoming more common in targeted weed species and threatening food production (Délye et al. 2013). This had led to a cocktail approach, in which multiple herbicides are often used together to eliminate unwanted plants. The mixtures of ingredients added to the environment results in more non-target species and ecosystems inevitably being exposed to a range of contaminants, which can have drastic direct and indirect effects (Relyea 2008).

Different herbicides impact cyanobacteria in different ways, and other environmental factors such as water $\mathrm{pH}$ and organic carbon sources also influence the toxicity of herbicides that leach into waterways (Mishra and Pandey 1989). Glyphosate has less of an effect on cyanobacteria than other phytoplankton species (Forlani et al. 2008, Harris \& Smith 2016). Microcystis aeruginosa can utilise the phosphorous bound in glyphosate (Qiu et al. 2013) and this ability may exist in other species. The advantage conferred to cyanobacteria over other phytoplankton in the presence of herbicides may lead to changes in the community composition of freshwater systems. Maule and Wright (1984) showed that MCPA and glyphosate were the least inhibitory of six herbicides for cyanobacteria. Because MCPA and glyphosate are frequently used in New Zealand, cyanobacteria domination may become more common among phytoplankton communities in New Zealand than in countries favouring other active ingredients.

It is disturbing to note that microcystin production in $M$. aeruginosa may be promoted in the presence of metolachlor. This herbicide upregulates the expression of $m c y H$ transporter genes in the microcystin gene cluster, as well as $m c y D$ - a polyketide synthase involved in the synthesis of the Adda amino acid (Chen et al. 2019). These genes code for microcystins in cyanobacteria (Rouhiainen et al. 2004). Intracellular microcystin also increased in 
M. aeruginosa after treatment with the herbicides acetochlor and napropamide in a time dependent manner, before decreasing back to levels similar to the control. This could be due to decreased pigment content (Xie et al. 2018). Increased microcystin production was seen in M. aeruginosa following exposure to 2,4-D (Martínez-Jerónimo and Martínez-Jerónimo 2018), and fenoxaprop-p-ethyl (FPE) impacted toxin amount in two different Microcystis species differently (Du et al. 2017). In this study, intracellular microcystin increased by over $200 \%$ in M. aeruginosa three days following FPE exposure, and both intracellular and extracellular microcystin increased by day six (> 100\% intracellular increase with FPE treatment of 2 and $10 \mathrm{mg} \mathrm{L}^{-1}$ ). Similarly, intracellular microcystin in $M$. viridis increased by over $50 \%$ at high FPE concentrations (10 $\mathrm{mg} \mathrm{L}^{-1}$ ), but no significant difference was measured for extracellular microcystin. After six days, the intracellular microcystin had significantly increased but the extracellular was still relatively low except for at a high FPE concentration of $10 \mathrm{mg} \mathrm{L}^{-1}$. The treatment of a high herbicide concentration resulted in a microcystin increase of over $100 \%$. It is vital to understand how cyanobacteria, notably toxic strains, respond to differing amounts of herbicides entering waterways.

Glyphosate has long been regarded as a safe choice due to its low toxicity to animals, however, leaching into waterways can result in exposure to non-target species. Not only could herbicides impact other species directly, but killing plant species that make up the habitat could negatively affect vertebrates and invertebrates in waterways that rely on plants for shelter. Glyphosate has been measured in a range of freshwater systems including lakes, rivers, and wetlands as shown in Table 3.1. Concentrations in water runoff may be as high as 5,200 $\mu \mathrm{g} \mathrm{L}^{-1}$ (Edwards et al 1980) but are commonly much lower (Hébert et al 2018). 
Table 3.1: Maximum concentrations of glyphosate sampled at sites across the Americas, Asia, and Europe.

\begin{tabular}{|c|c|c|c|}
\hline Location & $\operatorname{Max}\left(\mu g L^{-1}\right)$ & Water Body & Reference \\
\hline \multirow[t]{4}{*}{ USA } & 3.08 & Large rivers & Battaglin et al. 2014 \\
\hline & 73 & Streams & \\
\hline & 427 & Ditch, tile, or surface & \\
\hline & 301 & $\begin{array}{l}\text { Lakes, ponds, } \\
\text { wetlands }\end{array}$ & \\
\hline \multirow[t]{3}{*}{ Mississippi, USA } & 73 & Basin/sub basin & Coupe et al. 2012 \\
\hline & 6.2 & Basin/sub basin & \\
\hline & 41 & Basin/sub basin & \\
\hline \multirow[t]{2}{*}{ Iowa, USA } & 290 & Subsurface drain & \\
\hline & 1.6 & Basin/sub basin & \\
\hline \multirow[t]{7}{*}{ Indiana, USA } & 5.7 & Basin/sub basin & \\
\hline & 430 & Overland flow site & \\
\hline & 49 & Overland flow site & \\
\hline & 2.1 & Basin/sub basin & \\
\hline & 1 & Basin/sub basin & \\
\hline & 1.6 & Basin/sub basin & \\
\hline & 5.5 & Basin/sub basin & \\
\hline France & 86 & Basin/sub basin & \\
\hline Ohio, USA & 5,200 & Runoff & Edwards et al. 1980 \\
\hline \multirow[t]{2}{*}{ Canada } & 12.5 & Groundwater & Crowe et al. 2011 \\
\hline & 0.286 & Lake surface water & \\
\hline \multirow[t]{4}{*}{ Canada } & 40.8 & Brook & Struger et al. 2008 \\
\hline & 30.5 & Creek & \\
\hline & 18.6 & River & \\
\hline & 3.17 & Lake & \\
\hline \multirow[t]{6}{*}{ Argentina } & 370 & Wetland & Peruzzo et al. 2008 \\
\hline & 660 & Wetland & \\
\hline & 330 & Surface stream & \\
\hline & 560 & Surface stream & \\
\hline & 280 & Surface stream & \\
\hline & 370 & Surface stream & \\
\hline Argentina & 4.52 & Lakes & $\begin{array}{l}\text { Castro Berman et al. } \\
2018\end{array}$ \\
\hline Argentina & 7.6 & Stream & Aparicio et al. 2013 \\
\hline Switzerland & 4.97 & Catchment & Daouk et al. 2013 \\
\hline Sri Lanka & 45 & Lakes & $\begin{array}{l}\text { Gunarathna et al. } \\
2018\end{array}$ \\
\hline
\end{tabular}

To investigate the susceptibility of cyanobacteria to glyphosate and MCPA, 14 strains of cyanobacteria spanning seven species in four genera were treated with the herbicides 


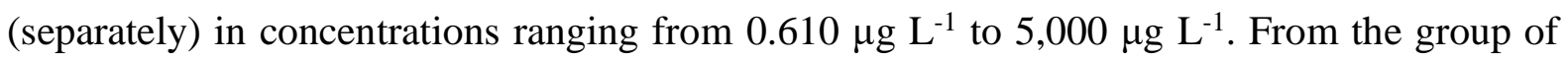
strains that were shown to be affected, four were selected for a functional analysis investigating the impacts of glyphosate on growth, photosynthetic performance, and pigment content (chlorophyll-a and phycocyanin). Glyphosate can negatively impact growth and functioning of cyanobacteria (Ruan and Brown 2008) and MCPA causes abnormal growth (Nielson and Dahllof 2007), thus, I hypothesise that both herbicides will have a negative effect on growth and photosynthetic performance on the cyanobacteria used.

\subsection{Methods}

\subsubsection{Screening Experiment}

\subsubsection{Cyanobacterial Cultures}

Cyanobacterial cultures were sourced from the Cawthron Institute Culture Collection of Microalgae (CICCM). Fourteen isolates of planktonic cyanobacteria spanning four genera and different morphologies were used including filamentous, single-celled, and colonial forms; Cuspidothrix issatschenkoi (CAWBG02), Dolichospermum circinale (CAWBG663), Dolichospermum lemmermannii (CAWBG567, CAWBG680), Dolichospermum planctonicum (CAWBG651), Microcystis aeruginosa (CAWBG11, CAWBG563, CAWBG570, CAWBG617, CAWBG624, CAWBG706), Microcystis wesenbergii (CAWBG647), and Nodularia spumigena (CAWBG21, CAWBG704). To avoid discrepancies due to sample heterogeneity, cultures employing benthic growth strategies were not assessed. Stock cultures were maintained at $18^{\circ} \mathrm{C}\left( \pm 1^{\circ} \mathrm{C}\right)$ with a $12: 12 \mathrm{~h}$ light:dark cycle (photon flux of $70 \mu \mathrm{mol} \mathrm{m}{ }^{-2}$ $\left.\mathrm{s}^{-1}\right)$.

\subsubsection{Experimental Design}

Herbicide screening experiments were set up in clear 96-well plates (Corning ${ }^{\circledR}$ Costar $^{\circledR}$, USA). The effects of glyphosate and MCPA from low $\left(0.610 \mu \mathrm{g} \mathrm{L}^{-1}\right)$ to high $\left(5,000 \mu \mathrm{g} \mathrm{L}^{-1}\right)$ concentrations were determined in triplicate wells. A negative control (cyanobacteria in MLA media) and a blank (only MLA media) were also included in triplicate wells. Cultures in the exponential growth phase were grown to a cell concentration of $>50,000$ cells $\mathrm{mL}^{-1}$ in sterile MLA medium, enumerated by light microscopy (described below) and diluted to $~ 50,000$ cells $\mathrm{mL}^{-1}$ in MLA (or 100,000 cells $\mathrm{mL}^{-1}$ for $C$. issatschenkoi) for application into the wells. The optical density of $C$. issatschenkoi could not be measured at a density of 50,000 cells $\mathrm{mL}^{-1}$ due to its thin filaments, so the starting concentration was doubled for that strain. When a culture 
was diluted to the desired starting concentration, it was added to each well in the 96-well plate except the blank MLA wells. They were then supplemented with final in-well concentrations of herbicide (in triplicate) ranging from 0.610 to $5,000 \mu \mathrm{g} \mathrm{L}^{-1}$. Cyanobacteria in the 96-well plates were grown at $18^{\circ} \mathrm{C}\left( \pm 1^{\circ} \mathrm{C}\right)$ with a $12: 12 \mathrm{~h}$ light:dark cycle (photon flux of $70 \mu \mathrm{mol} \mathrm{m} \mathrm{m}^{-2}$ $\mathrm{s}^{-1}$; i.e., the same conditions as the stock cultures). The 96-well plates were measured using an EnSpire multimode plate reader (PerkinElmer, USA) every two days for up to twelve days. The plate was shaken for $60 \mathrm{~s}$ using a double orbital shake mode (50 rpm, $5 \mathrm{~mm}$ diameter) before the optical density was measured at $750 \mathrm{~nm}$ as a proxy for cell density.

\subsubsection{Cell Enumeration}

A $5 \mathrm{~mL}$ sample was taken from the exponential-phase culture before setting up the experiment for each strain, and diluted to the desired starting concentration of 50,000 cells $\mathrm{mL}^{-1}(100,000$ cells $\mathrm{mL}^{-1}$ for $C$. issatschenkoi). Each sample was preserved with two drops of Lugol's iodine solution in $15 \mathrm{~mL}$ Falcon tubes. A mortar and pestle was used to break apart visible clumps in colonial strains and strains in which cells may stick together (all except $C$. issatschenkoi CAWBG02). Sub-samples of the ground cells $(0.1-1 \mathrm{~mL})$ were placed in 12-well plates with milli-Q water so that each well held a total of $4 \mathrm{~mL}$, and left to settle in the dark for $\geq 3 \mathrm{~h}$.

Concentrations of spherical-celled strains and filamentous strains with cells easily distinguishable (all except CAWBG02) were determined by counting the number of cells in random fields of view. An inverted microscope (Olympus CKX41 or IX70) at a magnification of $400 \times$ or $800 \times$ was used to count the numbers of cells in ten random fields of view for each well and cell concentrations were calculated using the equation below:

$$
\text { Cells } m L^{-1}=\frac{\text { AveCells } \times \text { Dil } \times \frac{\text { WellArea }}{\text { FoVArea }}}{\text { VolSettled }}
$$

AveCells $=$ Average number of cells in a field of view (from ten fields of view)

Dil $=$ Dilution factor

WellArea $=$ Well area $\left(\mathrm{mm}^{2}\right)$

FoVArea $=$ Field of view area $\left(\mathrm{mm}^{2}\right)$

VolSettled $=$ Volume of cyanobacterial culture settled $(\mathrm{mL})$

The concentration of $C$. issatschenkoi CAWBG02 was determined by measuring filament lengths as described in Chapter 2 (Section 2.2.4). 


\subsubsection{Screening Statistical Analyses}

Data was analysed in R (version 3.6.3) using R Studio (version 1.2.5033). The average optical density for each strain was used to determine the growth rate, as the gradient of the linear regression equation for time vs. OD 750 . The linear regression between herbicide concentration vs. growth rate was used to determine if any growth impairment had occurred. When growth was statistically significantly negatively impacted $(\mathrm{p}<0.05$ and a negative gradient for the regression equation), $\mathrm{IC}_{50}$ and $\mathrm{IC}_{75}$ values were determined using the 'drc' package (Ritz et al. 2016). Growth rates were plotted against glyphosate concentration, and dose-response models were fitted to each strain with model W1.4.

\subsubsection{Glyphosate Functional Analysis}

\subsubsection{Cyanobacteria Strains}

Dolichospermum lemmermannii CAWBG567, Microcystis aeruginosa CAWBG617, Microcystis wesenbergii CAWBG647, and Nodularia spumigena CAWBG703 were sourced from the CICCM. These strains were chosen for this experiment based on the preliminary screening results, in which the growth of all four were impacted by the herbicide glyphosate in the tested range of concentrations $\left(0.610-5,000 \mu \mathrm{g} \mathrm{L}^{-1}\right)$. Stock cultures were maintained at $18^{\circ} \mathrm{C}$ $\left( \pm 1^{\circ} \mathrm{C}\right)$ with a 12:12-hour light:dark cycle (photon flux of $70 \mu \mathrm{mol} \mathrm{m}^{-2} \mathrm{~s}^{-1}$ ).

\subsubsection{Experimental Setup}

The experiment was carried out in sterile $60 \mathrm{~mL}$ plastic specimen pottles. Staggered setup and sampling allowed for PAM fluorometry measurements to be taken at the same time of day for each strain. Samples were set up on consecutive days and sampled four days later. Each pottle was rinsed with the experiment solution before cyanobacteria culture $(40 \mathrm{~mL})$ was added. All four strains had triplicate pottles of a negative control $\left(0 \mu \mathrm{g} \mathrm{L}^{-1}\right.$ glyphosate), triplicate pottles of their $\mathrm{IC}_{50}$ value, and triplicate pottles of their $\mathrm{IC}_{75}$ value. Thus, $D$. lemmermannii was set up with treatments of 750 and 3,000 $\mu \mathrm{g} \mathrm{L}^{-1}$ respectively, $N$. spumigena with 50 and 1,500 $\mu \mathrm{g} \mathrm{L}^{-1}$

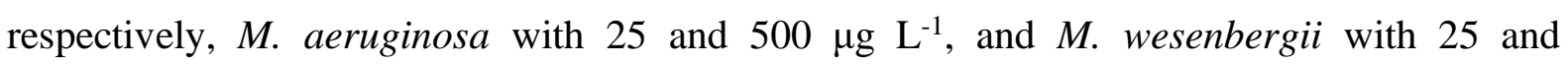
2,000 $\mu \mathrm{g} \mathrm{L}^{-1}$. Both Microcystis species had an additional treatment with the $\mathrm{IC}_{75}$ value of the corresponding species, to allow for direct comparison between toxic and non-toxic Microcystis (as shown below in Table 3.2). Samples were taken at the start of each strain set-up to measure the initial chlorophyll-a and phycocyanin concentration, the cell concentration, and the photosynthetic performance (by PAM fluorometry; as described below). 
Table 3.2: Glyphosate concentrations used on each strain in the functional analysis of glyphosate susceptibility.

\begin{tabular}{lcccc}
\hline \multicolumn{1}{c}{ Species } & Culture Code & $\begin{array}{c}\mathbf{I C}_{\mathbf{5 0}} \\
\left(\boldsymbol{\mu g} \mathbf{~ L}^{-\mathbf{1}}\right)\end{array}$ & $\begin{array}{c}\mathbf{I C}_{\mathbf{7 5}} \\
\left(\boldsymbol{\mu g} \mathbf{~ L}^{-\mathbf{1}}\right)\end{array}$ & $\begin{array}{c}\text { Additional } \\
\text { Treatment }\end{array}$ \\
\hline Dolichospermum lemmermannii & CAWBG567 & 750 & 3,000 & - \\
Nodularia spumigena & CAWBG704 & 50 & 1,500 & - \\
Microcystis aeruginosa & CAWBG617 & 25 & 500 & 2,000 \\
Microcystis wesenbergii & CAWBG647 & 25 & 2,000 & 500 \\
\hline
\end{tabular}

\subsubsection{Sampling}

PAM fluorometry was carried out as described in Chapter 2 (Section 2.2.3) immediately upon sampling at the end of the experiment, with duplicate $0.2 \mathrm{~mL}$ samples taken from each pottle. Staggered set-up allowed for PAM sampling to be undertaken at the same time of the day for each strain (10:00 am; $3 \mathrm{~h}$ after the lights were turned on). Cell enumeration was carried out by light microscopy and cell concentration was calculated as described above (Section 3.2.1.3). All four strains were lightly ground with a mortar and pestle to break apart any large cell colonies. Chlorophyll-a and phycocyanin extraction and analyses were carried out as described in Chapter 2 (Sections 2.2.5-2.2.6).

Extracellular and cellular microcystin samples were collected for $M$. aeruginosa and $N$. spumigena at the end of the four day experiment. For each pottle, $2 \mathrm{~mL}$ of culture was filtered onto a $\mathrm{GF} / \mathrm{C}$ filter and stored in the dark at $-20^{\circ} \mathrm{C}$ until analysis for cellular toxin. A $1 \mathrm{~mL}$ sample was collected from the liquid filtered through the GF/C filter to measure extracellular toxin. The extractions and analyses for toxin samples were unable to be completed due to disruptions from the Covid-19 lockdown period.

\subsubsection{Statistical Analyses}

Data was analysed in R (version 3.6.3) using R Studio (version 1.2.5033). A one-way analysis of variance (ANOVA) was used to determine significant differences in cell concentration, pigment content, and photosynthetic performance parameters between glyphosate concentrations (including the experimental control) for all four species assessed. Levene's test for homogeneity of variances was used to test the assumption of equal variances. A nonparametric Kruskal-Wallis test was used if this assumption was violated. If a significant 
difference was detected, a post-hoc Tukey HSD test was used to determine which means were significantly different from each other.

\subsection{Results}

\subsubsection{Screening Cyanobacteria for Herbicide Susceptibility}

MCPA did not have a significant negative effect on the growth rate (determined by absorbance at $750 \mathrm{~nm} ; \mathrm{p}>0.05$; Appendix Table A2.1) on any of the fourteen strains tested in the screening experiment. A significant negative effect of glyphosate concentration on growth rate was detected for seven of the strains assessed; D. lemmermannii (CAWBG567, CAWBG680); D. planctonicum (CAWBG651); M. aeruginosa (CAWBG617, CAWBG706); $M$. wesenbergii (CAWBG647) and N. spumigena (CAWBG704). IC 50 and $\mathrm{IC}_{75}$ values were calculated for these strains (Figure 3.1 A-G, Table 3.3). Calculated values for D. planctonicum were high and both the $\mathrm{IC}_{50}$ and $\mathrm{IC}_{75}$ value were above the concentration range used $\left(>5,000 \mu \mathrm{g} \mathrm{L}^{-1}\right)$. Even within a species, results varied substantially. The two strains of $M$. aeruginosa (CAWBG617 and CAWBG706) had relatively similar IC 50 and $\mathrm{IC}_{75}$ values ( $\mathrm{IC}_{75}$ of 295 and $652 \mu \mathrm{g} \mathrm{L}^{-1}$ ). $M$. wesenbergii, from the same genus, had a much higher IC75 value of 2,140 $\mu \mathrm{g} \mathrm{L}^{-1}$. However the $\mathrm{IC}_{50}$ values of $M$. wesenbergii CAWBG647 and $M$. aeruginosa CAWBG617 were very similar at 27 and $35 \mu \mathrm{g} \mathrm{L}^{-1}$ respectively. 
A.

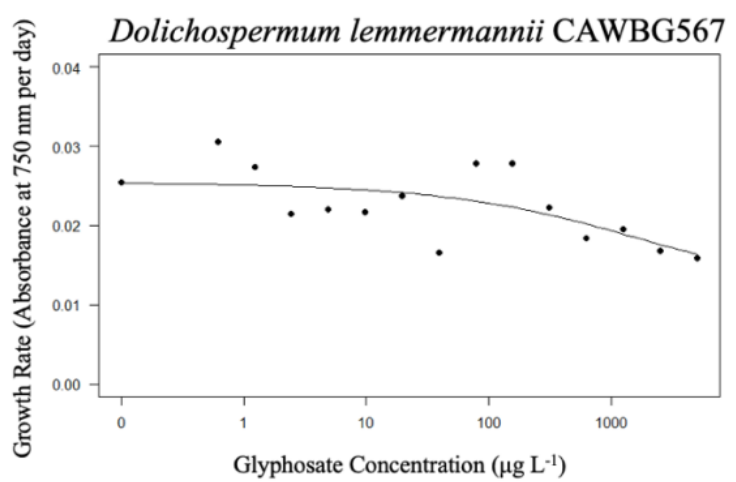

C.

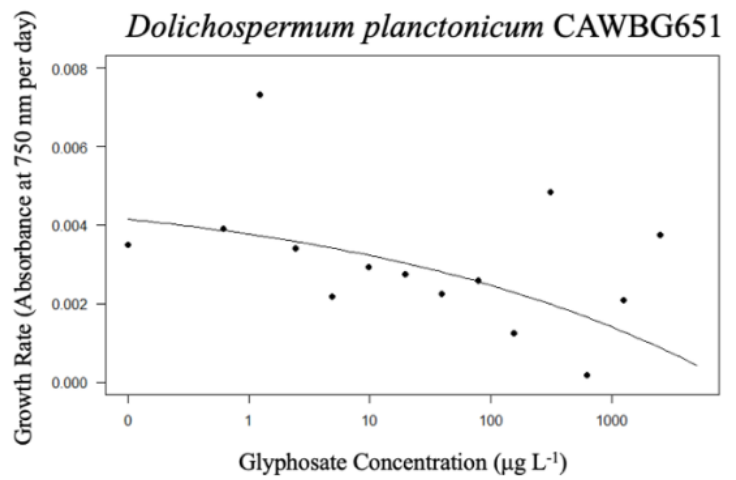

E.

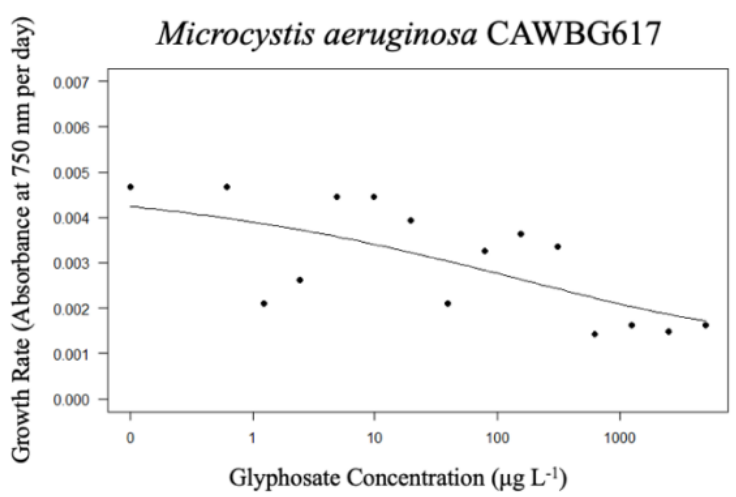

G.

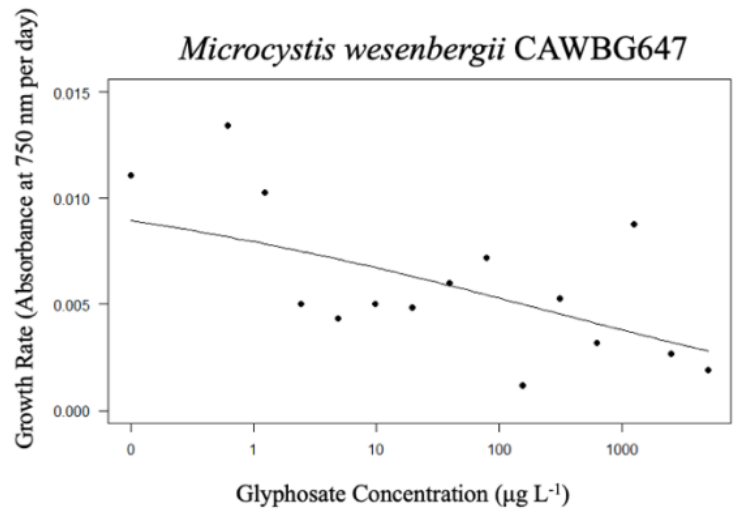

B.

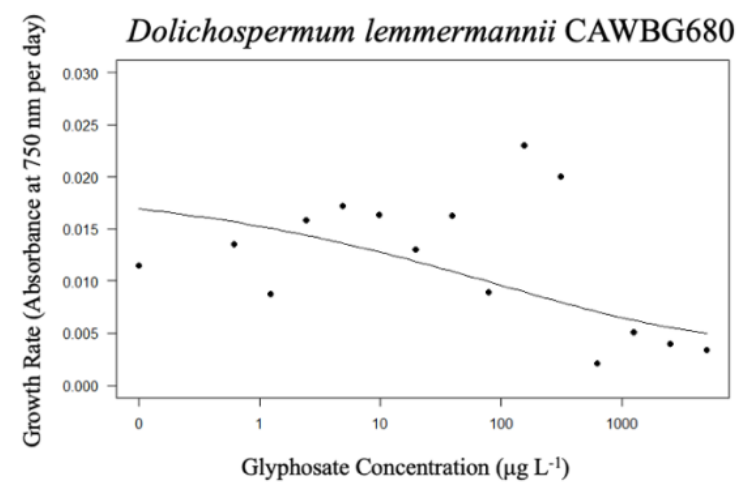

D.

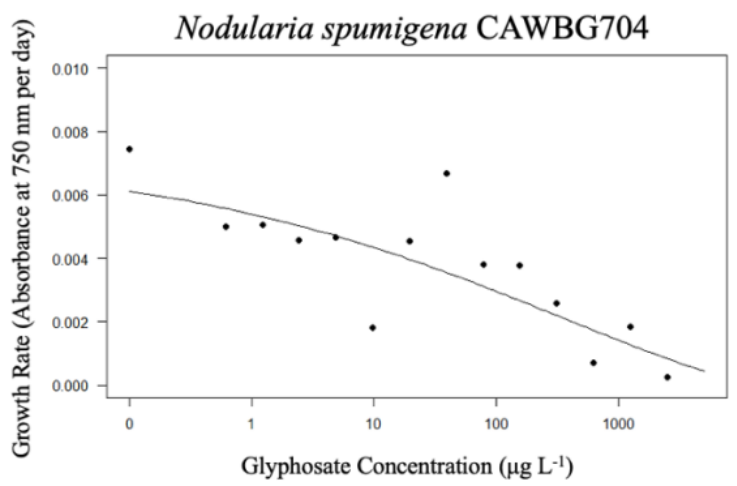

F.

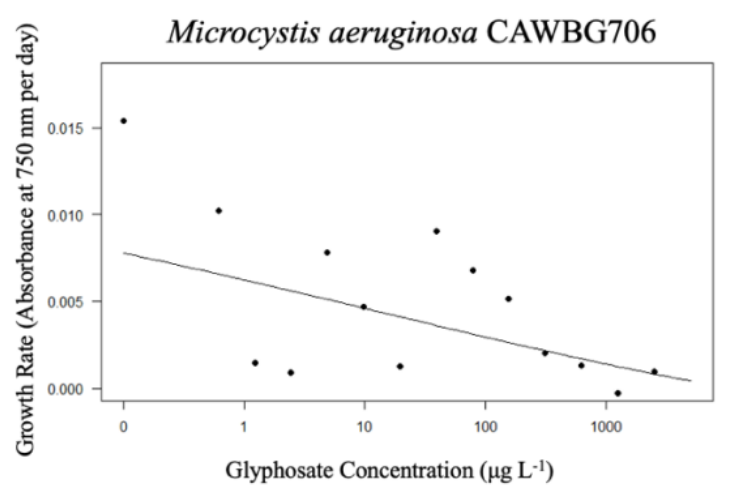

Figure 3.1 A-G: Dose-response curves showing the effect of glyphosate concentration on growth rate (note: only plots where a significant relationship was observed are presented). 
Table 3.3: Linear regression $p$-values for the relationship between glyphosate concentration on growth rate, $\mathrm{IC}_{50}$, and $\mathrm{IC}_{75}$ values for cyanobacteria strains that were affected by glyphosate. $*=$ Significant result $(\mathrm{p}<0.05)$.

\begin{tabular}{|c|c|c|c|c|}
\hline Species & Culture Code & p-value & $\mathrm{IC}_{50}\left(\mu \mathrm{g} \mathrm{L}^{-1}\right)$ & $\mathrm{IC}_{75}\left(\mu \mathrm{g} \mathrm{\textrm {L } ^ { - 1 }}\right)$ \\
\hline C. issatschenkoi & CAWBG02 & 0.942 & - & - \\
\hline D. circinale & CAWBG663 & 0.894 & - & - \\
\hline D. lemmermannii & CAWBG567 & $0.017 *$ & 715 & 3,061 \\
\hline D. lemmermannii & CAWBG680 & $0.002^{*}$ & 19 & 381 \\
\hline D. planctonicum & CAWBG651 & $0.01 *$ & $>5,000$ & $>5,000$ \\
\hline M. aeruginosa & CAWBG011 & 0.625 & - & - \\
\hline M. aeruginosa & CAWBG563 & 0.425 & - & - \\
\hline M. aeruginosa & CAWBG570 & 0.456 & - & - \\
\hline M. aeruginosa & CAWBG617 & $0.0004 *$ & 35 & 652 \\
\hline M. aeruginosa & CAWBG624 & 0.064 & - & - \\
\hline M. aeruginosa & CAWBG706 & $0.016^{*}$ & 0.05 & 295 \\
\hline M. wesenbergii & CAWBG647 & $0.038^{*}$ & 27 & 2,140 \\
\hline N. spumigena & CAWBG704 & $0.0007^{*}$ & 64 & 1,363 \\
\hline N. spumigena & CAWBG021 & 0.626 & - & - \\
\hline
\end{tabular}

$N$. spumigena and $M$. wesenbergii were chosen for further testing, as well as one $M$. aeruginosa strain (CAWBG617) and one D. lemmermannii strain (CAWBG567). These cyanobacteria strains were chosen to compare in a functional analysis between the three different genera that were significantly impacted by glyphosate. $N$ spumigena CAWBG704 was the only Nodularia strain with significant results, so it was selected. D. planctonicum was ruled out due to the calculated $\mathrm{IC}_{50}$ and $\mathrm{IC}_{75}$ values being out of the chosen herbicide concentration range and much higher than all other strains, and D. lemmermannii CAWBG567 was chosen due to the $\mathrm{IC}_{50}$ and $\mathrm{IC}_{75}$ values being closer to the other strains to allow for a more accurate comparison (notably the $\mathrm{IC}_{75}$ value, compared to CAWBG680). Two Microcystis strains were chosen to allow a direct comparison between a toxic and non-toxic species of the same genus, $M$. aeruginosa CAWBG617 and $M$. wesenbergii CAWBG647. 


\subsubsection{Glyphosate Experiment Results}

\subsubsection{Glyphosate Impact on Cyanobacterial Growth}

A significant difference in cell concentration with glyphosate treatment was detected for D. lemmermannii (ANOVA; $\mathrm{F}=7.29, \mathrm{p}=0.024$ ). A post hoc Tukey test between the cultures treated revealed a significant difference between 750 and 3,000 $\mathrm{g} \mathrm{L} \mathrm{L}^{-1}$ (Tukey HSD; $\mathrm{p}=0.021$ ), with an $83 \%$ increase in cell density measured between them (Figure 3.2). No statistically significant difference was seen between the control and 750 (Tukey HSD; $\mathrm{p}=0.304$ ) or the control and 3,000 $\mu \mathrm{g} \mathrm{L}^{-1}$ (Tukey HSD; $\mathrm{p}=0.155$ ). Cell enumeration for $N$. spumigena, $M$. aeruginosa, and $M$. wesenbergii were unable to be completed due to the Covid-19 lockdown.

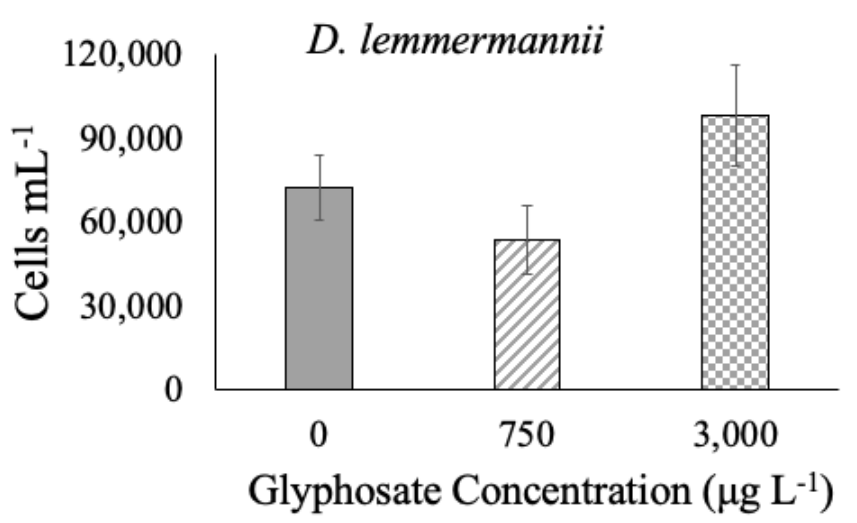

Figure 3.2: Mean cell concentrations of Dolichospermum lemmermannii treated with glyphosate at $750 \mu \mathrm{g} \mathrm{L}^{-1}$ (IC50 value) and 3,000 $\mu \mathrm{g} \mathrm{L}^{-1}\left(\mathrm{IC}_{75}\right)$ against the experimental control $\left(0 \mu \mathrm{g} \mathrm{L}{ }^{-1}\right)$. Error bars show \pm one standard deviation. 


\subsubsection{Chlorophyll Content}

D. lemmermannii was the only species in which chlorophyll content was significantly impacted by glyphosate addition (ANOVA; $\mathrm{F}=6.689, \mathrm{p}=0.03$ ). A $16 \%$ increase was detected between the control and the highest glyphosate concentration (Tukey HSD; $\mathrm{p}=0.037$ ), but no significant difference was detected between the control and intermediate glyphosate concentration (Tukey HSD; $p=0.947$ or between the middle and highest concentrations (Tukey HSD; $p=0.055$ ). No significant differences between means were detected for $N$. spumigena (ANOVA; F = 2.632, $\mathrm{p}=0.151$ ), M. aeruginosa (ANOVA; $\mathrm{F}=0.901, \mathrm{p}=0.482$ ), or $M$. wesenbergii (ANOVA; $\mathrm{F}=0.632, \mathrm{p}=0.615)$.

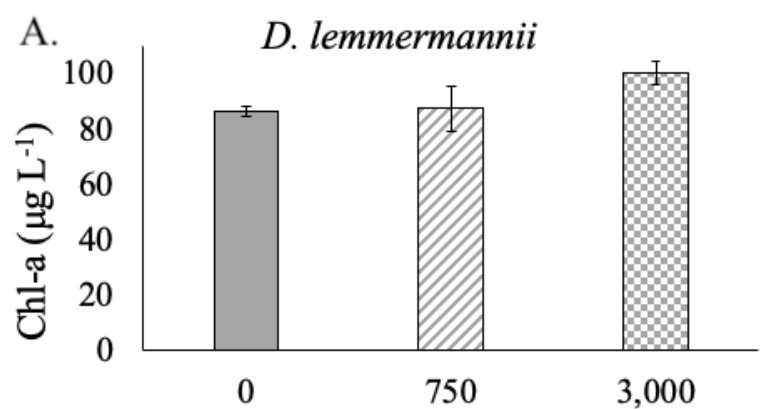

Glyphosate Concentration $\left(\mu \mathrm{g} \mathrm{L}^{-1}\right)$

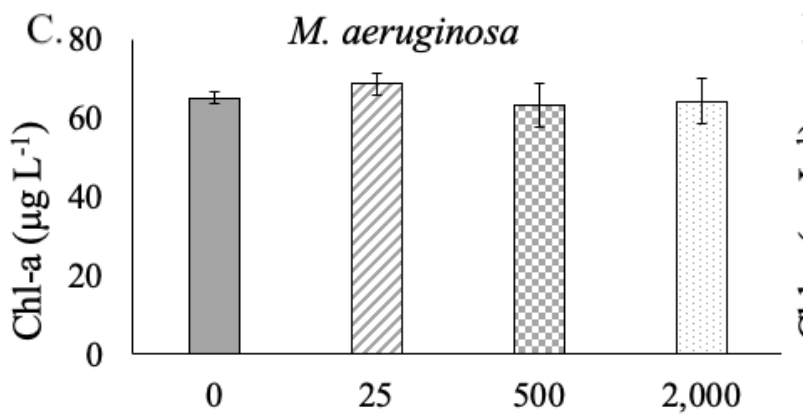

Glyphosate Concentration $\left(\mu \mathrm{g} \mathrm{L}^{-1}\right)$

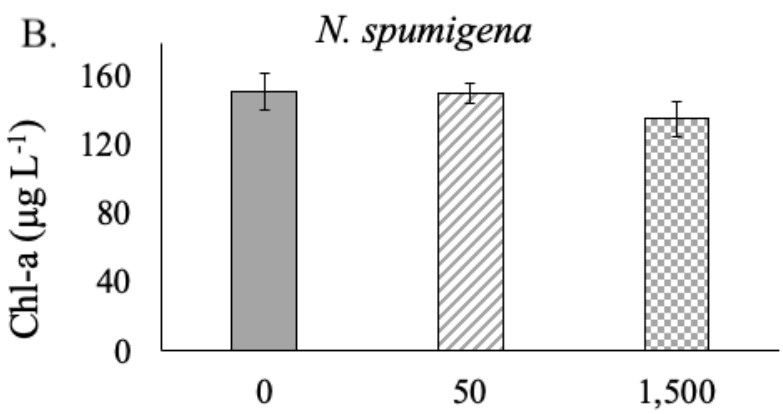

Glyphosate Concentration $\left(\mu \mathrm{g} \mathrm{L}^{-1}\right)$

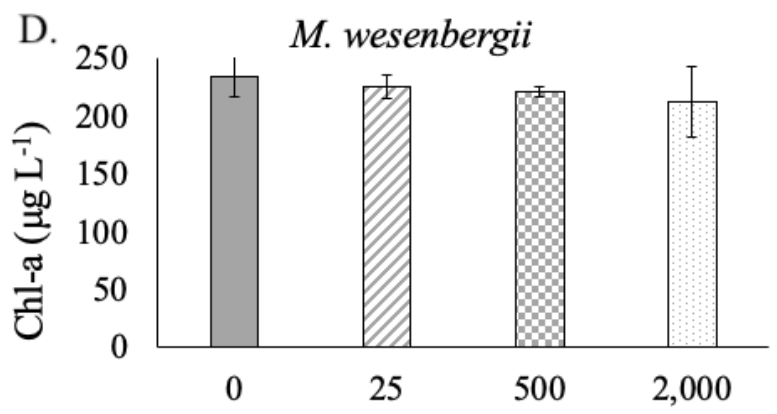

Glyphosate Concentration $\left(\mu \mathrm{g} \mathrm{L}^{-1}\right)$

Figure 3.3 A-D: Chlorophyll-a (Chl-a) concentrations for cyanobacteria treated with glyphosate at their $\mathrm{IC}_{50}$ and $\mathrm{IC}_{75}$ values, as well as the corresponding $\mathrm{IC}_{75}$ for the two Microcystis species. Note different scales on $y$-axes. Error bars show \pm one standard deviation. 


\subsubsection{Phycocyanin Content}

Glyphosate did not statistically significantly affect the phycocyanin content in D. lemmermannii (Kruskal-Wallis; $\mathrm{H}=3.583$, $\mathrm{p}=0.167$ ), N. spumigena (ANOVA; $\mathrm{F}=0.682$, $\mathrm{p}=0.547$ ), M. aeruginosa (Kruskal-Wallis; $\mathrm{H}=0.5, \mathrm{p}=0.48$ ), or $M$. wesenbergii (KruskalWallis; $\mathrm{H}=4.418, \mathrm{p}=0.22$ ). Some data is missing due to phycocyanin measurements being below the limit of detection. There is one missing data point from each $D$. lemmermannii concentration including the control, and one missing data point from the $N$. spumigena 1,500 $\mu \mathrm{g} \mathrm{L}^{-1}$ group. There is one missing data point from the control group in M. aeruginosa, two from the $25 \mu \mathrm{g} \mathrm{L}^{-1}$ group (which shows no error bars), and the other two concentrations had no phycocyanin measurements that were above the limit of detection.

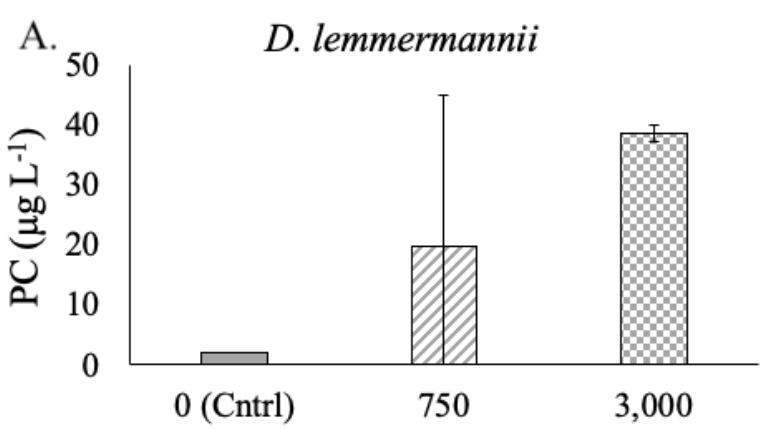

Glyphosate Concentration $\left(\mu \mathrm{g} \mathrm{L}^{-1}\right)$

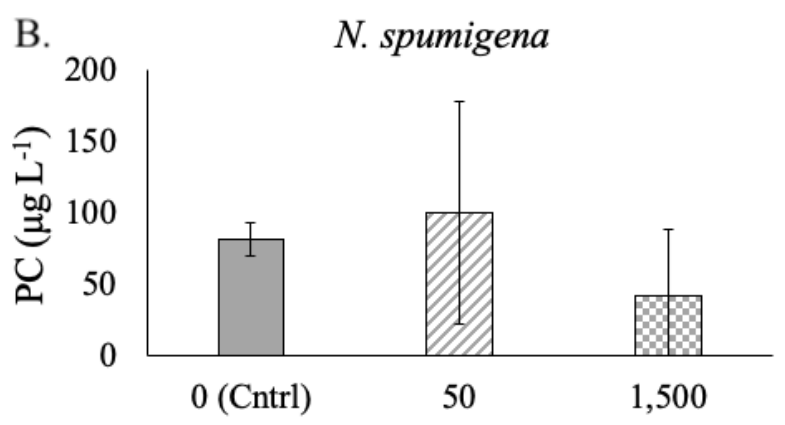

Glyphosate Concentration $\left(\mu \mathrm{g} \mathrm{L}^{-1}\right)$

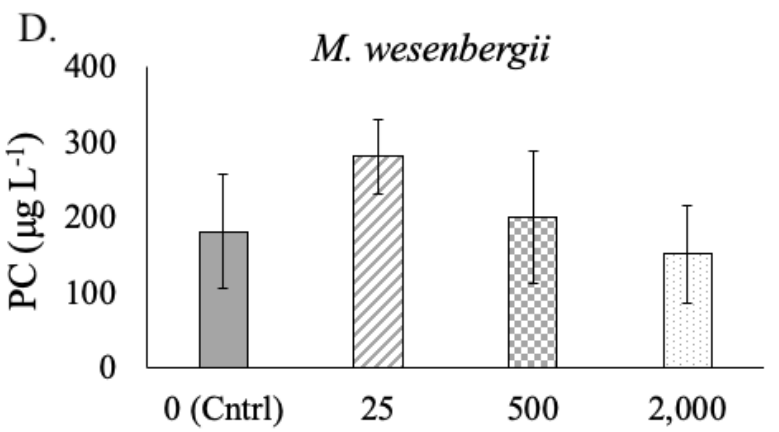

Glyphosate Concentration $\left(\mu \mathrm{g} \mathrm{L}^{-1}\right)$

Figure 3.4 A-D: Phycocyanin (PC) concentrations all four strains treated with glyphosate at their $\mathrm{IC}_{50}$ and $\mathrm{IC}_{75}$ values, as well as an additional treatment for the two Microcystis species as described in Chapter 3 (Section 3.2.2.2), Table 7. Error bars show \pm one standard deviation. 


\subsubsection{Photosynthetic Performance}

The photosynthetic data presented in the results shows readings from Channel 4 of the PAM fluorometer used (light excitation wavelength $665 \mathrm{~nm}$ ). This channel was chosen because it provided consistently high signals when being measured. The precision data (Section 2.3.1; Table 2.1) also shows that this channel had the lowest \% relative standard deviation (RSD). Photosynthetic performance results from Channels $2(520 \mathrm{~nm})$ and $3(645 \mathrm{~nm})$ can be found in Appendix Table A2.2, and Figures A2.1-A2.4.

Glyphosate supplementation decreased the maximum quantum yield of $D$. lemmermannii (ANOVA; $\mathrm{F}=33.3, \mathrm{p}=0.0006)$ and $M$. aeruginosa (ANOVA; $\mathrm{F}=5.571, \mathrm{p}=0.023$ ). Compared to the experimental control, the $750 \mu \mathrm{g} \mathrm{L}^{-1}$ treatment for D. lemmermannii resulted in a $48 \%$ decrease (Tukey HSD; $\mathrm{p}=0.0005$ ), and the $3,000 \mu \mathrm{g} \mathrm{L}^{-1}$ treatment resulted in a $32 \%$ decrease (Tukey HSD; $p=0.004$ ). There was no significant difference between the two different glyphosate concentrations for this species (Tukey HSD; $p=0.106$ ). The highest glyphosate concentration for $M$. aeruginosa $\left(2,000 \mu \mathrm{g} \mathrm{L}^{-1}\right)$ caused a maximum quantum yield that significantly differed from that of the other two glyphosate treatments. A $34 \%$ decrease was detected between both 25 and 2,000 $\mu \mathrm{g} \mathrm{L}^{-1}$ (Tukey HSD; p = 0.035), and 500 and 2,000 $\mu \mathrm{g} \mathrm{L}^{-1}$ (Tukey HSD; $\mathrm{p}=0.031$ ). The maximum quantum yield of cultures treated with the two medium concentrations were not significantly different from one another (Tukey HSD; $p=1$ ), and the control did not differ from any of the three glyphosate treatments (Tukey HSD; $\mathrm{p} \geq$ 0.087). No statistically significant differences were detected between glyphosate concentrations for $N$. spumigena and $M$. wesenbergii (Table 3.4). 


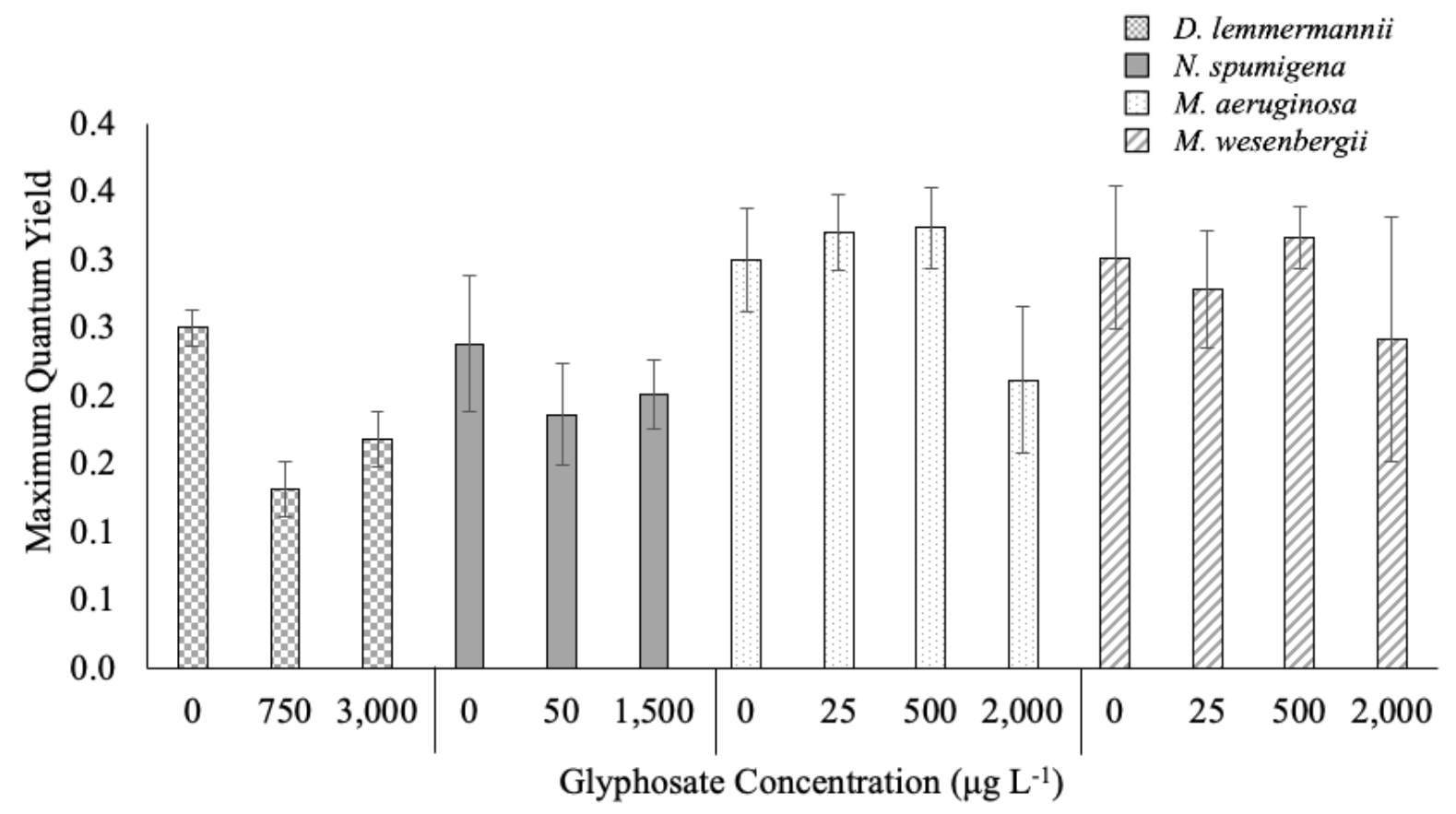

Figure 3.5: Mean maximum quantum yield for all glyphosate concentrations used (including the experimental control) for all four species. Error bars show \pm one standard deviation.

Alpha was not affected by glyphosate at any of the concentrations used, for all four species (ANOVA, $\mathrm{p} \geq 0.072$; Table 3.4).

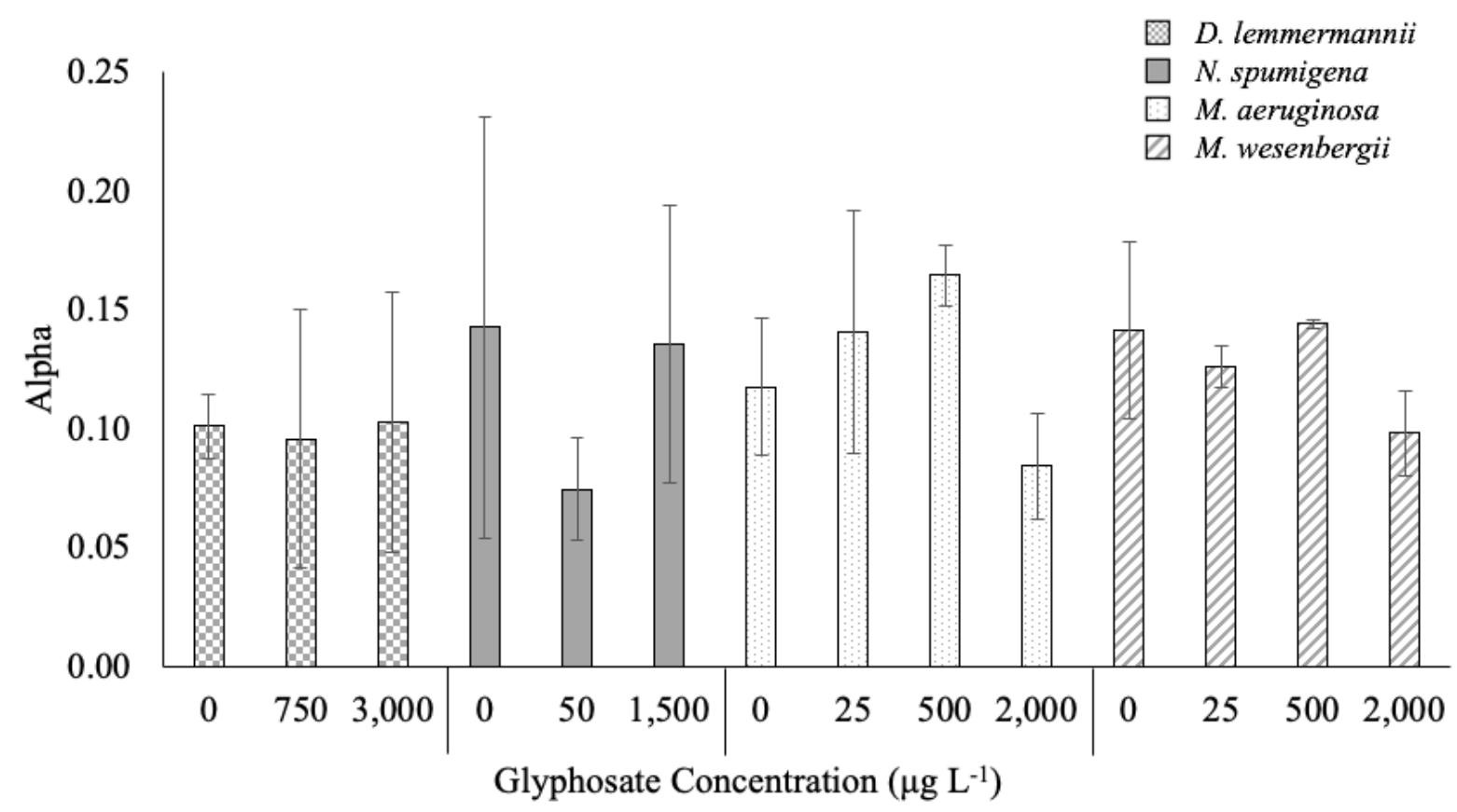

Figure 3.6: Mean alpha (slope of the initial linear range of the rapid light curve, photosynthetic efficiency) for all glyphosate concentrations used (including the experimental control) for all four species. Error bars show \pm one standard deviation. 
Glyphosate significantly impacted the ETR $\max$ in M. aeruginosa $($ ANOVA; $\mathrm{F}=10.35, \mathrm{p}=$ 0.004). A post-hoc Tukey HSD test revealed differences in means between the $500 \mu \mathrm{g} \mathrm{L}^{-1}$ treatment and every other concentration including the control. A nearly 300\% increase was detected between the experimental control $\left(0 \mu \mathrm{g} \mathrm{L}^{-1}\right)$ and $500 \mu \mathrm{g} \mathrm{L}^{-1}$ (Tukey HSD; $\left.\mathrm{p}=0.004\right)$, and a $117 \%$ increase between 25 and $500 \mu \mathrm{g} \mathrm{L}^{-1}$ glyphosate concentrations (Tukey HSD; $\mathrm{p}=$ 0.024), however there was a $62 \%$ decrease between 500 and 2,000 $\mu \mathrm{g} \mathrm{L}^{-1}$ (Tukey HSD; $\mathrm{p}=$ 0.011). There was no significant difference detected between the control and either of the other two glyphosate concentrations (Tukey HSD; $\mathrm{p} \geq 0.511$ ), or between 25 and 2,000 $\mu \mathrm{g} \mathrm{L}^{-1}$ themselves (Tukey HSD; $\mathrm{p}=0.933$ ). Glyphosate supplementation resulted in a similar pattern in both Microcystis species, with one of the middle concentrations giving the highest response (Figure 3.7), however, the herbicide did not significantly impact ETR $\max$ in D. lemmermannii, N. spumigena, or M. wesenbergii (Table 3.4).

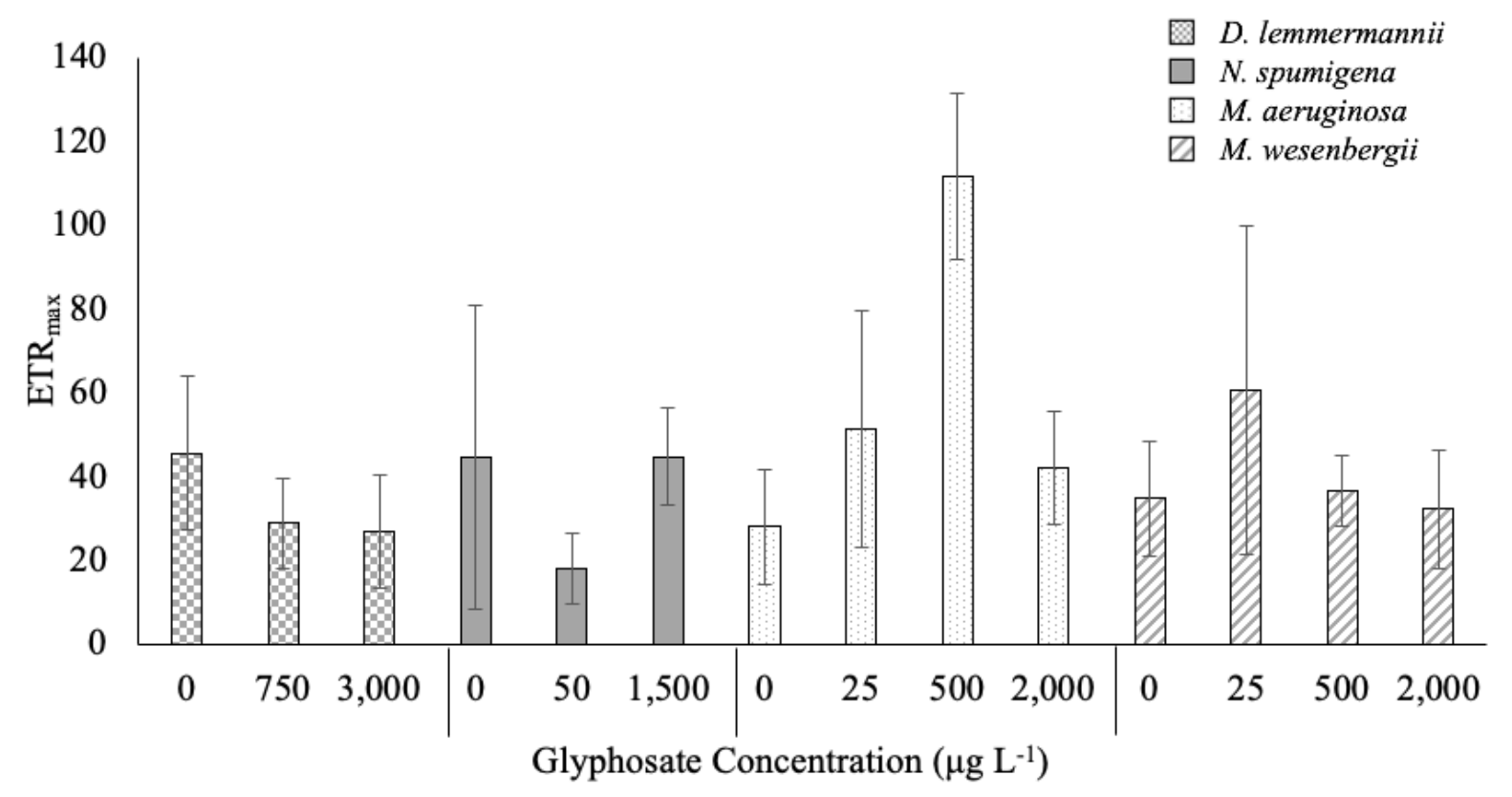

Figure 3.7: Mean ETR $\max$ (maximum electron transport capacity) for all glyphosate concentrations used (including the experimental control) for all four species. Error bars show \pm one standard deviation.

The light saturation parameter $\left(l_{\mathrm{k}}\right)$ was only significantly impacted by glyphosate in $M$. aeruginosa (ANOVA; F = 7.529, p = 0.01), and the $500 \mathrm{ug} / \mathrm{L}$ glyphosate treatment yielded the highest response similar to the trend in ETR max. A $242 \%$ increase in $l_{k}$ was seen between the control and the $500 \mu \mathrm{g} \mathrm{L}^{-1}$ treatment (Tukey HSD; $\mathrm{p}=0.008$ ), and a $111 \%$ increase between 
25 and $500 \mu \mathrm{g} \mathrm{L}^{-1}$ (Tukey HSD; $\mathrm{p}=0.038$ ). The highest glyphosate concentration did not significantly affect $l_{k}$ compared to any of the other concentrations (Tukey HSD; $p \geq 0.099$ ), and the $25 \mu \mathrm{g} \mathrm{L}{ }^{-1}$ treatment did not significantly impact $l_{\mathrm{k}}$ compared to the control (Tukey HSD; $p=0.66$ ). The light saturation parameter for the other three strains was not affected by glyphosate (Table 3.4 ).

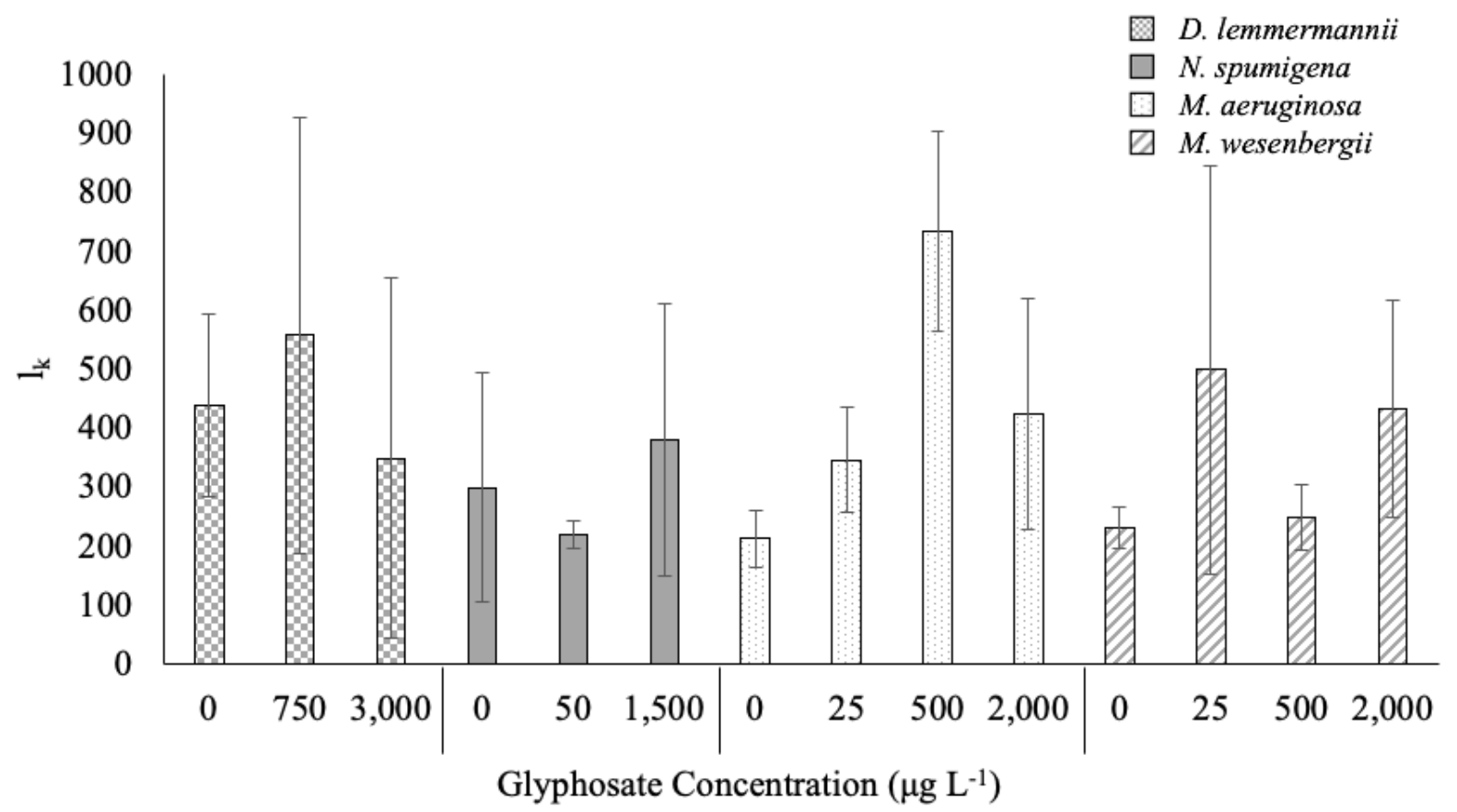

Figure 3.8: Mean $l_{k}$ (light saturation parameter) for all glyphosate concentrations used (including the experimental control; $0 \mu \mathrm{g} \mathrm{L}^{-1}$ ) for all four species. Error bars show \pm one standard deviation. 
Table 3.4: Statistical results (ANOVA) for determining significant differences in photosynthetic performance of four cyanobacteria species treated with glyphosate cells and the experimental control.

\begin{tabular}{|c|c|c|c|c|c|c|c|c|}
\hline \multirow[b]{2}{*}{ Species } & \multicolumn{2}{|c|}{$\mathbf{Y}$} & \multicolumn{2}{|c|}{ Alpha } & \multicolumn{2}{|c|}{ ETRmax $_{\text {max }}$} & \multicolumn{2}{|c|}{ lk } \\
\hline & F-statistic & p-value & F-statistic & p-value & F-statistic & p-value & F-statistic & p-value \\
\hline D. lemmermannii & 33.30 & $0.0006^{*}$ & 0.020 & 0.981 & 1.317 & 0.347 & 0.113 & 0.896 \\
\hline N. spumigena & 1.390 & 0.319 & 1.083 & 0.397 & 1.393 & 0.319 & 0.636 & 0.562 \\
\hline M. aeruginosa & 5.571 & $0.023^{*}$ & 3.435 & 0.072 & 10.35 & $0.004 *$ & 7.529 & $0.010^{*}$ \\
\hline M. wesenbergii & 0.973 & 0.452 & 2.987 & 0.096 & 0.868 & 0.501 & 1.102 & 0.410 \\
\hline
\end{tabular}




\subsection{Discussion}

\subsubsection{Screening for Cyanobacterial Growth Inhibition from Herbicides}

This is the first study investigating the inter-strain responses of an array of New Zealand cyanobacteria to herbicides. Glyphosate significantly inhibited growth in seven of the fourteen cyanobacterial strains tested in the preliminary screening experiment, including three of the four Dolichosermum strains assessed. Dolichospermum is one of the most common bloomforming genera of cyanobacteria globally (Capelli et al. 2017, Paerl and Otten 2015), including in New Zealand (Wood et al. 2017), and is found in lakes with good light penetration (Padisák et al. 2008). Because strains within a single species can look and behave differently, is important to investigate the effects of environmental drivers across not just species or genera, but across cyanobacteria strains too. For example, the optimal temperature for $D$. lemmermannii is mostly $13-18^{\circ} \mathrm{C}$, but some strains prefer $18-25^{\circ} \mathrm{C}$ (Zapomělová et al. 2010, Capelli et al. 2017). No toxin-producing members of this genus have been identified in New Zealand (Wood et al. 2017), thus growth inhibition of Dolichospermum may benefit competing toxic strains if they are unaffected by glyphosate. In other parts of the world Dolichospermum can produce toxins ( $\mathrm{Li}$ et al. 2016), which might lead to different impacts on phytoplankton community dynamics.

Microcystis, another common bloom-forming cyanobacterial genus (Harke et al. 2016, Paerl and Otten 2015), had three strains that were sensitive to glyphosate. Two of these were toxinproducing strains of M. aeruginosa, and one was the non-toxic M. wesenbergii. Global attention on the impacts of glyphosate on cyanobacteria has focused on Microcystis, as this genus commonly forms problematic blooms (Raps et al. 1983, Van Gremberghe et al. 2011, Harke et al. 2016). Microcystis strains that were unaffected by glyphosate tended to be those that have a colonial growth morphology, although M. aeruginosa CAWBG706, a colonial strain, was sensitive to glyphosate in the concentration range tested. The colonies for this strain were quite small compared to those of other colonial strains of the same species (CAWBG11, CAWBG563, CAWBG570) which were unaffected. Wu and Song (2008) suggested that colonial M. aeruginosa are able to tolerate enhanced stress conditions compared to unicellular M. aeruginosa, due to the high amount of carbohydrates in colonial cells. Microcystis colonies use a mucilaginous matrix to stay together (Wu and song 2008), which may make it more difficult for contaminants to reach cells. Interestingly, the homogenous $M$. aeruginosa CAWBG624 was not sensitive to glyphosate, whilst M. aeruginosa CAWBG617 was. These 
two strains are the same species, were isolated from the same lake, look similar when grown in culture and have similar cell size; but responded differently to this herbicide.

Nodularia spumigena also responded differently depending on the strain used. With N. spumigena CAWBG704 growth was significantly inhibited by glyphosate, whereas $N$. spumigena CAWBG021 was not significantly impacted. These two strains of $N$. spumigena were isolated from different locations in New Zealand (Wairewa/Lake Forsyth for CAWBG021 and Whakaki Lagoon for CAWBG704) and look different when grown in culture. Whilst the CAWBG704 filaments forms separate, small spherical colonies, the CAWBG021 filaments aggregate in scums at the surface. As observed for other traits, it appears that strain diversity and growth morphology contribute to the success of a single species or genus when responding to environmental contaminants.

Filamentous $C$. issatschenkoi was unaffected by glyphosate in the concentration range tested. This species produces anatoxin-a; a neurotoxin that causes convulsions, gasping, and death in vertebrates (Bownik 2010, Colas et al. 2020). The lack of growth inhibition for this strain may impact community dynamics in freshwater ecosystems, as cyanobacteria that are more resistant may outcompete those that are negatively affected when herbicides enter waterways. Some cyanobacteria strains have high degrees of tolerance to glyphosate. Powell et al (1991) found that growth of Synechocystis and Anabaena variabilis was minimally or not inhibited by the free acid of glyphosate, even though lower glyphosate concentrations can inhibit other bacteria (Schulz et al. 1984). Arunakumara et al (2013) also noted a species-dependent difference in tolerance to glyphosate is present in cyanobacteria, which is supported by the present study. However, individual strains within $C$. issatschenkoi could not be compared due to $C$. issatschenkoi CAWBG02 being the only Cuspidothrix strain available.

MCPA is highly mobile in soils and has been detected frequently in Australian storm waters from runoff (Allinson et al. 2017, Huang et al. 2017). Leaching into surface and groundwater bodies allows it to contaminate water and decrease water quality (Morton et al. 2019), and it frequently contaminates soil and water due to a slow degradation rate in winter (Sujetovienè et al. 2020). None of the fourteen cyanobacterial strains tested were significantly impacted by exposure to MCPA in the concentrations tested. Possible reasons for this could be that the MCPA concentrations used were too low, or that the active ingredient MCPA alone is not enough to alter the growth of cyanobacteria. Caux et al (1996) found that pesticide formulations can have a greater effect on phytoplankton than the active ingredient on its own. The green 
alga Selenastrum capricornutum had a high $\mathrm{IC}_{50}$ value of $18,400 \mu \mathrm{g} \mathrm{L}^{-1}$ for MCPA alone ( $\geq 96 \%$ active ingredient), but the $\mathrm{IC}_{50}$ value was reduced to $620 \mu \mathrm{g} \mathrm{L}^{-1}$ for the MCPAformulated solution Amine 500 (50\% MCPA). The different combinations of added ingredients are important to consider when testing the effects of environmental contaminants on phytoplankton, as these combinations are how the products are applied to the environment and how they enter waterways and could change how they are dispersed. Other ingredients added into commercial herbicides may even make them more toxic to non-target species.

MCPA may not be as toxic to phytoplankton as other herbicides at the same concentrations. Nagai (2019) found that the toxicity of MCPA to algal species (cyanobacteria, diatoms, green algae) is relatively weak compared to a range of other herbicides, and that the sensitivity to herbicides depended on the algal species. However, when combined with stressful conditions MCPA may have increased toxicity to cyanobacteria. Damage caused by exposure to UV-B radiation can be aggravated by the addition of MCPA to cyanobacteria (Chen et al. 2012). Microcystis viridis and Anabaena sp. exhibited decreased chlorophyll fluorescence yields, reduced photosynthetic pigment content, and DNA damage following exposure to the herbicide whilst UV-stressed (Chen et al. 2012).

\subsubsection{A Functional Analysis of Glyphosate Susceptibility on Selected Species}

Four strains of cyanobacteria that demonstrated susceptibility to glyphosate were selected from the screening trial for further investigation (two Microcystis species - one toxic and one nontoxic, the non-toxic Dolichospermum lemmermannii, and the toxic Nodularia spumigena).

Glyphosate treatment had the biggest impact on photosynthetic performance in $M$. aeruginosa CAWBG617. Glyphosate addition at the high-concentration treatment $\left(2,000 \mu \mathrm{g} \mathrm{L}^{-1}\right)$ resulted in a significantly lower maximum quantum yield compared to the other two glyphosate treatments (25 and $500 \mu \mathrm{g} \mathrm{L}^{-1}$ ). Overall, the intermediate concentration promoted photosynthetic performance and the high concentration inhibited it. Although high concentrations of glyphosate may negatively impact algal functioning, low concentrations can stimulate algal chlorophyll-a synthesis, growth, and photosynthesis (Zhu et al. 2012). Other studies have reported similar results with lower concentrations promoting or not affecting photosynthesis, and higher concentrations inhibiting it. Wong (2000) found that glyphosate at low concentrations $\left(20 \mu \mathrm{g} \mathrm{L}^{-1}\right)$ increased the photosynthetic rate of the green alga Scenedesmus quadricauda. For this alga, glyphosate at $200 \mu \mathrm{g} \mathrm{\textrm {L } ^ { - 1 }}$ did not affect the photosynthetic rate 
compared to the control, and 2,000 $\mu \mathrm{g} \mathrm{L}^{-1}$ caused inhibition. The same trends were seen for growth and chlorophyll-a content. My study also found that the high glyphosate treatment $\left(2,000 \mu \mathrm{g} \mathrm{L}^{-1}\right)$ inhibited photosynthetic performance, however, the opposite was true for the intermediate and low glyphosate treatments. The intermediate treatment $\left(500 \mu \mathrm{g} \mathrm{L}^{-1}\right)$ promoted photosynthetic performance and the low treatment $\left(25 \mu \mathrm{g} \mathrm{L}^{-1}\right)$ had no effect compared to the control in $M$. aeruginosa. Although the high concentration inhibited photosynthesis in my study, Zhang et al (2016) found that Microcystis aeruginosa growth was stimulated at glyphosate concentrations from $100-2,000 \mathrm{~L}^{-1}$. It would have been interesting to compare the cell concentrations of $M$. aeruginosa in my study to these results, however, based on the lack of impact on chlorophyll-a and negative effects on photosynthesis at the highest glyphosate concentration, it is unlikely that promoted growth would have been seen for this strain.

D. lemmermannii was the only other strain in the functional analysis to have a statistically significant PAM response to glyphosate. Compared to the experimental control, a $32-48 \%$ decrease in maximum quantum yield was seen across the two glyphosate treatments.

Chlorophyll concentration in D. lemmermannii treated with the highest dose of glyphosate was $16 \%$ higher than the control after four days. The chlorophyll-a concentrations in N. spumigena, $M$. aeruginosa, and $M$. wesenbergii in the functional analysis were slightly lower when treated with the higher glyphosate concentrations, although none of the results were significantly different to the control. Phycocyanin content in the four cyanobacteria species was unaffected by the glyphosate treatment at the concentrations used. The large variability in $D$. lemmermannii and $N$. spumigena phycocyanin samples may account for the lack of significant differences between groups. Pigment content in both Microcystis species was unaffected by glyphosate at the concentrations used, although, $M$. aeruginosa had nine phycocyanin samples that were below the limit of detection across all treatment concentrations (including all three from both the intermediate and high glyphosate treatments). Starting with a higher cell density for this strain or running the experiment for a shorter time period may provide more meaningful data in the future.

Neither of the glyphosate treatments stimulated or inhibited cell proliferation compared to the control however, cell concentration was significantly different between the low and high dose glyphosate treatments in D. lemmermannii, with an $83 \%$ increase in cell density observed. As cell enumeration could not be completed for the other three species, I was unable to compare the response of D. lemmermannii with the other cyanobacterial strains. Glyphosate at 
$750 \mu \mathrm{g} \mathrm{L}^{-1}$ resulted in the lowest cell concentration of the three treatments including the experimental control, and the highest glyphosate treatment resulted in the highest cell concentration. It would have been interesting to see if this trend was present in the other strains too. Wong (2000) found contradicting results for a green alga, with the lower glyphosate concentration promoting growth or having no effect, and the higher concentration inhibiting growth. Chlorophyll-a is often used as a proxy for growth, and because high glyphosate concentrations increased both cell concentration and chlorophyll-a content in D. lemmermannii, it is possible the growth trends of the strains unable to be completed followed their respective chlorophyll-a trend, though no significant difference were detected in chlorophyll-a content for N. spumigena, M. aeruginosa, and M. wesenbergii.

Drzyzga and Lipok (2018) used total chlorophyll content as a proxy for growth of cyanobacteria in different species treated with glyphosate. They found low and high concentrations of the herbicide did not have a substantial effect (approximately 10-20\% decrease in growth) on Fischerella cf. maior, but an intermediate concentration resulted in a nearly 2-fold increase in growth compared to the control. Growth of Anabaena variabilis and Nostoc cf. muscorum increased after treatment with all glyphosate concentrations and for both of these species, the highest glyphosate concentration yielded the highest growth. Growth of $N$. cf. muscorum increased with increasing glyphosate concentration, however, A. variabilis had slightly less growth when treated with the intermediate glyphosate concentration compared to the other two treatments.

Whilst the 3,000 $\mu \mathrm{g} \mathrm{L}^{-1}$ glyphosate treatment resulted in an increased cell concentration in the present study (compared to the low glyphosate treatment) and an increased chlorophyll-a concentration (compared to the control) for D. lemmermannii, it decreased the photosynthetic maximum quantum yield compared to the control. The decrease in quantum yield indicates photosynthetic stress, which explains the increase in chlorophyll-a as compensation for reduced photosynthesis. The $750 \mu \mathrm{g} \mathrm{L}^{-1}$ glyphosate treatment resulted in the lowest cell concentration (significant compared to the high glyphosate treatment) and the lowest maximum quantum yield (compared to the control) for this species. Interestingly, the high concentration of glyphosate seemed to be less inhibitory to D. lemmermannii than lower concentrations. If low concentrations of glyphosate negatively affect this strain more than the high concentration, this contrasts with the response of $M$. aeruginosa, for which photosynthetic performance was most inhibited by high concentrations $\left(2,000 \mu \mathrm{g} \mathrm{L}^{-1}\right)$. The photosynthetic response of $N$. spumigena 
loosely follows the trends of $D$. lemmermannii, although no conclusive statements can be made for N. spumigena due to the lack of significant results. Research is currently lacking on the effects of glyphosate on Dolichospermum and Nodularia.

Nodularia spumigena and $M$. wesenbergii were not significantly affected by glyphosate in this study. Both strains had growth impacted by the herbicide in the screening assay, but no effects on pigment content and photosynthetic performance were seen at the concentrations used in the functional analysis. This could be due to the lower concentrations used (max 1,500 $\mu \mathrm{g} \mathrm{L}^{-1}$ for $N$. spumigena and $2,000 \mu \mathrm{g} \mathrm{L}^{-1}$ for $M$. wesenbergii) compared to the comprehensive range up to $5,000 \mu \mathrm{g} \mathrm{L}^{-1}$ in the screening assay. Some cyanobacteria species have the ability to degrade glyphosate, and some can metabolise it (Forlani et al. 2008, Arunakumara et al. 2013, Drzyzga and Lipok 2018). Some species also naturally have a higher tolerance to herbicides and other contaminants (Powell et al. 1991), and this could be why these two species were not affected by glyphosate. Although most studies on Microcystis tend to focus on the toxic $M$. aeruginosa, previous work has shown that growth of $M$. wesenbergii is inhibited by isopropyl ammonium salt of glyphosate (Sun et al. 2013). Little research has been performed on the response of Nodularia to glyphosate, but Nodularia has been shown to be more tolerant to other herbicides (bensulfuron-methyl) than other cyanobacteria including Dolichospermum (Okmen et al. 2007). The results from the present study suggest that M. wesenbergii and $N$ spumigena are naturally more tolerant to glyphosate than D. lemmermannii and $M$. aeruginosa.

\subsection{Conclusions}

The global use of herbicides results in frequent contamination of waterways and can change phytoplankton community dynamics. I hypothesised that both glyphosate and MCPA would have a negative impact on growth and PSII functioning on the cyanobacteria used in this study.

Glyphosate treatment in this study resulted in an increase in photosynthetic efficiency in $M$. aeruginosa, indicating that this species utilises the herbicide. Increased photosynthetic functioning may lead to increased proliferation of toxic cells and therefore increased occurrence of toxic blooms. The lack of significant impacts on $M$. wesenbergii and $N$. spumigena, as well as negative effects of quantum yield of D. lemmermannii, suggest that glyphosate contamination in freshwaters may benefit toxic $M$. aeruginosa by inhibiting growth and functioning of competitors. This is the first study investigating the susceptibility to both 
MCPA and glyphosate on a range of New Zealand cyanobacteria. Not only were there interspecies differences in tolerance to glyphosate, but inter-strain differences too. Growth strategy may play a role in how individual cyanobacteria strains respond to herbicides and other contaminants, as colonial growth forms may be a trait to protect against stressors (Gan et al. 2012). 


\section{Chapter 4: General Discussion}

\subsection{Summary and Synthesis of Findings}

Chapter 2 of this thesis investigated the impact of the cyanotoxin microcystin on the nonmicrocystin-producing cyanobacterium Cuspidothrix issatschenkoi. This species can sequester microcystin, and the effects of microcystin supplementation on growth, pigment content (chlorophyll-a and phycocyanin), and PSII functioning were determined under nine different environmental conditions (temperature and light intensity combinations). As previous studies have shown inhibitory effects of microcystin on growth and photosynthesis (Phelan and Downing 2014, Chia et al. 2019), I hypothesised that growth and functioning of $C$. issatschenkoi would be negatively affected by microcystin supplementation. Because this species grows well in low light (Cirés and Ballot 2016) and high light has been shown to increase the negative effects of microcystin ( $\mathrm{Hu}$ et al. 2004), I also hypothesised that microcystin supplementation is more likely to have inhibitory effects under high light intensities. Microcystin supplementation at a concentration of $25 \mu \mathrm{g} \mathrm{L}^{-1}$ did not have an effect on growth or pigment content in C. issatschenkoi. Photosynthetic performance was also largely unaffected. Microcystin supplementation decreased maximum quantum yield and alpha in cells kept in low temperature and intermediate light intensity $\left(15^{\circ} \mathrm{C}, 60 \mu \mathrm{mol} \mathrm{m} \mathrm{m}^{-2} \mathrm{~s}^{-1}\right)$, indicating reduced photosynthetic efficiency and increased stress. In high temperature and high light intensity $\left(25^{\circ} \mathrm{C}, 100 \mu \mathrm{mol} \mathrm{m} \mathrm{m}^{-2} \mathrm{~s}^{-1}\right)$, microcystin supplementation resulted in an increased alpha (photosynthetic efficiency) and decreased $l_{k}$ (light saturation). Overall, competitive advantages of microcystin sequestration cannot be assumed for Cuspidothrix issatschenkoi due to the lack of significant differences in growth and functioning between supplemented cells and the control. Microcystin sequestration may be more beneficial to other non-microcystin-producing cyanobacteria strains within a species that has microcystin producers (e.g. M. wesenbergii or non-toxic $M$. aeruginosa if strains from these species were found to have the ability to sequester the toxin). The production of anatoxin-a may play a role in protecting $C$. issatschenkoi against other toxins, however, research on the interactions of anatoxin-a and microcystin is currently lacking. Exposure to anatoxin-a $\left(25 \mu \mathrm{g} \mathrm{L}^{-1}\right)$ significantly decreases chlorophyll-a in Microcystis aeruginosa Kützing, although growth is not inhibited (Chia et al. 2015). In this study, anatoxin-a exposure also resulted in a decrease in total microcystin and suggests that there may be interactions between cyanotoxins with one toxin inhibiting production or modifying toxicity of another. 
The reason cyanobacteria produce microcystins is still unknown, although many ideas have been suggested, including iron transport for respiration, photosynthesis, and metabolite biosynthesis (Klein et al. 2013), protein modulation (Zilliges et al. 2011), and as a response to part of a population dying off, possibly as a defence mechanism (Schatz et al. 2007). It is possible that cyanotoxin production has many benefits that work together to ensure the growth and survival of a producing species, which outweigh the cost of toxin production (Codd 1995, Ouellette and Wilhelm 2003).

The aim of Chapter 3 was to determine the effects of two herbicides commonly used in New Zealand and globally, MCPA and glyphosate (Manktelow et al. 2005). Fourteen strains of toxic and non-toxic cyanobacteria found in New Zealand, spanning seven species and four genera, were used in a screening assay to determine which were impacted by the herbicides. I hypothesised that both herbicides would negatively impact growth and photosynthetic functioning in the cyanobacteria strains used, as previous research has found that high concentrations of glyphosate have inhibitory effects on cyanobacteria (Ruan and Brown 2008), and MCPA causes abnormal growth and death in some photosynthetic organisms (Nielson and Dahllof 2007). MCPA did not have a significant effect of the growth rate of any of the fourteen strains at the concentrations used. The growth rates of seven strains were impacted by glyphosate, and response was strain specific. Of the four genera included in the screening assay (Cuspidothrix, Dolichospermum, Microcystis, Nodularia), all except Cuspidothrix had at least one strain effected; three of four Dolichospermum strains, three of seven Microcystis strains, and one of two Nodularia strains. Some strains (notably M. aeruginosa CAWBG011, 563, 570, 706) employed a colonial growth strategy in which cells accumulated in clumps. M. aeruginosa CAWBG706 was the only strain from that group of four that was significantly impacted by glyphosate. Colonies seem to provide some protection from the herbicide. However, $M$. aeruginosa CAWBG617 and CAWBG624 are both very homogenous and are closely related, but the former was affected, and the latter was not - suggesting there are other factors contributing to the tolerance of cyanobacteria to glyphosate.

Of the seven strains impacted by glyphosate in the screening assay, four were investigated further in a functional analysis. At least one strain from each genus (Dolichospermum, Nodularia, and Microcystis) was selected, with two chosen from Microcystis which allowed for comparison between a toxic (M. aeruginosa) and non-toxic (M. wesenbergii) strain from the same genus. Effects of glyphosate on growth, photosynthetic performance, and pigment 
content (chlorophyll-a and phycocyanin) were measured for all four strains. Cell enumeration could only be completed for $D$. lemmermannii, and the highest glyphosate concentration $(3,000$ $\mu \mathrm{g} \mathrm{L}^{-1}$ ) resulted in the highest cell concentration, whereas the lower glyphosate treatment (750 $\mu \mathrm{g} \mathrm{L}^{-1}$ ) resulted in the lowest cell concentration. Glyphosate treatment also caused a decrease in maximum quantum yield, and the high concentration glyphosate treatment caused an increase in chlorophyll-a. The increase in chlorophyll-a content may have been compensation for the decrease in photosynthetic performance, however these results have not been reported in the literature. The only other strain to be significantly impacted by glyphosate in the functional analysis was the toxic $M$. aeruginosa. The highest concentration used on this strain $\left(2,000 \mu \mathrm{g} \mathrm{L}^{-1}\right)$ decreased maximum quantum yield, but the intermediate glyphosate treatment $\left(500 \mu \mathrm{g} \mathrm{L}^{-1}\right)$ promoted both ETR $\max$ and $\mathrm{l}_{\mathrm{k}}$. Not only does glyphosate susceptibility differ among species, but the screening assay revealed that response is also strain-dependent. Singh and Singh (2004) found that two Anabaena doliolum strains responded in the same way to glyphosate, with both exhibiting initial stimulation of $\mathrm{O}_{2}$ evolution and photosynthetic electron transport at low-medium concentrations and photosynthetic activity inhibition at very high concentrations. However, my results show that strain diversity also contributes to individual response to contaminants. Glyphosate concentration also influenced the effect on PSII functioning in the present study and could impact how toxic and non-toxic cyanobacteria respond when in competition. The stimulation of $M$. aeruginos $a$ at intermediate concentrations was likely due to the species' ability to utilize glyphosate as a phosphorous source (Qiu et al. 2013).

Colonial growth strategies may provide protection to cyanobacteria from contaminants. With Microcystis aeruginosa used in the screening experiment, most of the strains that did not have growth rate negatively impacted by glyphosate employed a colonial growth strategy. This genus has extracellular mucilage that holds cells together, and this may have prevented uptake of glyphosate into cells like it provides protection from zooplankton grazing, viruses, and bacteria (Ma et al. 2014). Xiao et al (2018) suggested that colony formation provides protection from chemical stressors, and Microcystis may change to a colonial growth form under changing abiotic and biotic factors. Colonial Microcystis has a higher tolerance to copper than unicellular Microcystis, with ETR $\mathrm{max}_{\text {ax }}$ and maximum quantum yield decreasing more rapidly in unicellular phenotypes when exposed to the heavy metal (Wu et al. 2007). Microcystins also promote and contribute to the maintenance of cell aggregations in Microcystis (Gan et al. 2012). Cultures 
treated with low concentrations of microcystin-RR $\left(1 \mu \mathrm{g} \mathrm{L}{ }^{-1}\right)$ had increased colony size, and colony size decreased with extracellular microcystin depletion.

From a management perspective, there are two scenarios to avoid. The first is promotion of environmental conditions in which toxin-producing cyanobacteria flourish, and this could be from anthropogenic-induced changes to the environment that promote growth and functioning (e.g., increased surface water temperatures, increased nutrient inputs, elimination or inhibition of competing organisms). The second is the promotion of environmental conditions where toxins themselves are more readily produced. Unlike eukaryotic algae, many cyanobacteria have adaptations that allow them to thrive in high temperatures and nutrient-rich waters (Shan et al. 2019) - conditions that are increasing due to climate change and contamination of waterways (McGregor 2000, Sinang et al. 2015). If conditions are more favorable for cyanobacteria, then their ability to outcompete other phytoplankton may increase leading to higher rates of toxin production. Unfortunately, the planned toxin analysis from the glyphosate experiment could not be completed so the effect of glyphosate on toxin production was not determined and the response of $N$. spumigena and $M$. aeruginosa could not be compared. Toxic and non-toxic strains can react differently to environmental conditions and contaminants (Rapala et al. 1993, Van de Waal et al. 2011), however, little has been done on how response to herbicides differs between strains.

Differing susceptibility to glyphosate among cyanobacteria strains within a species was found in the screening assay, and physiological responses in the detailed functional study differed between species. As cyanobacteria in this study have responded differently depending on glyphosate concentration and species, it is important to consider multiple contributors to cyanobacterial blooms and phytoplankton communities including both abiotic and biotic influences, as well as species and strain-specific traits like growth strategy. I hypothesised that both MCPA and glyphosate would negatively impact cyanobacteria. Based on the screening assay, MCPA does not have a positive or negative impact on New Zealand cyanobacteria species at the concentrations used and will not contribute to increased harmful algal blooms. Glyphosate has little effect on colonial cyanobacteria, possibly due to the protective mucilage that holds cells together or inability to access all cells.

Photosynthetic performance of toxic $M$. aeruginosa increased from glyphosate treatment at $500 \mu \mathrm{g} \mathrm{L}^{-1}$, and whilst most reported measurements of glyphosate in waterways are much lower, these concentrations and higher have been measured in the natural environment. A 
decrease in maximum quantum yield for non-toxic D. lemmermannii and increased chlorophyll-a (likely in response to decrease photosynthetic functioning), shows how non-toxic strains can be negatively impacted by glyphosate. Thus, glyphosate at high concentrations may promote the occurrence of toxic Microcystis aeruginosa blooms and suppress growth of nontoxic cyanobacterial species. Because current environmental concentrations rarely get high enough to cause this effect, widespread use of glyphosate is unlikely to affect the occurrence of microcystin-producing taxa.

\subsection{Future Research}

It would be interesting to investigate the utilisation of microcystin in other species, especially in cyanobacteria strains which are closely related to microcystin-producers. An example of this would be a non-toxic $M$. aeruginosa strain if it had the ability to sequester microcystin. If competitive advantages are conferred to non-toxic strains within a single species, toxin production and sequestration may be beneficial within a species or genus. Further research into possible modifications of a cyanotoxin by another (e.g. microcystin by anatoxin-a or vice versa) would also help us to understand interactions of toxic cyanobacteria and cyanotoxins in the environment.

The effects of MCPA combined with other ingredients found in commercial herbicide products would also be worth investigating, as well as in different environmental conditions where cyanobacteria may already be stressed as this could influence the toxicity of MCPA. With predicted changes to the environment from anthropogenic impacts, cyanobacteria may respond differently to contaminants and shift phytoplankton community compositions. The effects of glyphosate on toxin production in N. spumigena and M. aeruginosa should also be studied and compared between the two species for a better understanding of cyanobacteria response to the herbicide. Previous studies have focused on the influence of a single herbicide or multiple herbicides on one species of cyanobacteria. However, research on the impacts of commonly used anthropogenic contaminants on cyanobacteria communities in New Zealand is currently lacking, particularly on inter-strain differences. 


\section{References}

Alexova, R., Fujii, M., Birch, D., Cheng, J., Waite, T.D., Ferrari, B.C., \& Neilan, B.A. (2011). Iron uptake and toxin synthesis in the bloom-forming Microcystis aeruginosa under iron limitation. Environmental Microbiology, 13, 1064-1077.

Allen, M. R., Stott, P. A., Mitchell, J. F. B., Schnur, R., \& Delworth, T. L. (2000). Quantifying the uncertainty in forecasts of anthropogenic climate change. Nature, 407, 617-620.

Allinson, M., Zhang, P., Bui, A., Myers, J. H., Pettigrove, V., Rose, G., Salzan, S. A., Walters, R., Allinson, G. (2017). Herbicides and trace metals in urban waters in Melbourne, Australia (2011-2012): Concentrations and potential impact. Environmental Science and Pollution Research, 24, 7274-7284.

Aparicio, V. C., De Gerónimo, E., Marino, D., Primost, J., Carriquiriborde, P., \& Costa, J. L. (2013). Environmental fate of glyphosate and aminomethylphosphonic acid in surface waters and soil of agricultural basins. Chemosphere, 93, 1866-1873.

Arunakumara, K. K. I. U, Walpola, B. C., \& Yoon, M-H. (2013). Metabolism and degradation of glyphosate in aquatic cyanobacteria: A review. African Journal of Microbiology Research, 7, 4084-4090.

Azevedo, S., Carmichael, W., Jochimsen, E., Rinehart, K., Lau, S., Shaw, G., \& Eaglesham, G. (2002). Human intoxication by microcystins during renal dialysis treatment in CaruaruBrazil. Toxicology, 181-182, 441-446.

Baillie, B. R. (2016). Herbicide concentrations in waterways following aerial application in a steepland planted forest in New Zealand. New Zealand Journal Of Forestry Science, 46, 16.

Baillie, B. R., \& Neary, D. G. (2015). Water quality in New Zealand's planted forests: A review. New Zealand Journal Of Forestry Science, 45, 7.

Baker, N. R. (2008). Chlorophyll fluorescence: a probe of photosynthesis in vivo. Annual Review of Plant Biology, 59, 89-113.

Baker, N., R., \& Rosenqvist, E. (2004). Applications of chlorophyll fluorescence can improve crop production strategies: an examination of future possibilities. Journal of Experimental Botany, 55, 1607-1621. 
Ballot, A., Fastner, J., Lentz, M., \& Wiedner, C. (2010). First report of anatoxin-a-producing cyanobacterium Aphanizomenon issatschenkoi in northeastern Germany. Toxicon, 56, 964971.

Battaglin, W. A., Meyer, M. T., Kuivila, K. M., \& Dietze, J. E. (2014). Glyphosate and its degradation product AMPA occur frequently and widely in U.S. soils, surface water, groundwater, and precipitation. JAWRA Journal of the American Water Resources Association, 50, 275-290.

Benbrook, C. (2016). Trends in glyphosate herbicide use in the United States and globally. Environmental Sciences Europe, 28, 3.

Bennett, A., and Bogorad, L. (1973). Complementary chromatic adaptation in a filamentous blue-green alga. The Journal Of Cell Biology, 58, 419-435.

Berdalet, E., Kudela, R., Urban, E., Enevoldsen, H., Banas, N. S., Bresnan, E., Burford, M., Davidson, K., Gobler, C. J., Karlson, B., Lim, P. T., Mackenzie, L., Montresor, M., Trainer. V. L., Usup, G., \& Yin, K. (2017). GlobalHAB: A new program to promote international research, observations, and modelling of harmful algal blooms in aquatic systems. Oceanography, 30, 70-81.

Bhandari, R., \& Sharma, P. K. (2006). High-light-induced changes on photosynthesis, pigments, sugars, lipids and antioxidant enzymes in freshwater (Nostoc spongiaeforme) and marine (Phormidium corium) cyanobacteria. Photochemistry and Photobiology, 82, 702-710.

Biessy, L., Atalah, J., Beuzenberg, V., Kuhajek, J., \& Wood, S. (2016). Measuring the influence of nutrients and river water on the photosynthetic efficiency of Didymosphenia geminatausing pulse amplitude modulated fluorometry. Diatom Research, 31, 149-160.

Biggs, B. J. F., Kilroy, C. (2000). Stream periphyton monitoring manual, prepared for the New Zealand Ministry for the Environment. Christchurch: NIWA.

Blank, C., \& Sãnchez-Baracaldo, P. (2010). Timing of morphological and ecological innovations in the cyanobacteria - a key to understanding the rise in atmospheric oxygen. Geobiology, 8, 1-23.

Blankenship, R. (1992). Origin and early evolution of photosynthesis. Photosynthesis Research, 33, 91-111.

Bolch, C. J. S., and Blackburn S. I. (1996). Isolation and purification of Australian isolates of the toxic cyanobacterium Microcystis aeruginosa Kütz. Journal of Applied Phycology 8, 5-13. 
Boopathi, T., \& Ki, J-S. Impact of environmental factors on the regulation of cyanotoxin production. Toxins, 6, 1951-1978.

Bourdot, G. W., Saville, D. J., \& Hurrell, G. A. (1996). Ecological fitness and the decline of resistance to the herbicide MCPA in a population of Ranunculus acris. The Journal of Applied Ecology, 33, 151-160.

Bownik, A. (2010). Harmful algae: Effects of alkaloid cyanotoxins on animal and human health. Toxin Reviews, 29, 99-114.

Briand, E., Yéprémian, C., Humbert, J., \& Quiblier, C. (2008). Competition between microcystin- and non-microcystin-producing Planktothrix agardhii (cyanobacteria) strains under different environmental conditions. Environmental Microbiology, 10, 3337-3348.

Burkill, P. H., Leakey, R. J. G., Owens, N. J. P., \& Mantoura, R. F. C. (1993). Synechococcus and its importance to the microbial foodweb of the northwestern Indian Ocean. Deep Sea Research Part II: Topical Studies in Oceanography, 40, 773-782.

Capelli, C., Ballot, A., Cerasino, L., Papini, A., \& Salmaso, N. (2017). Biogeography of bloomforming microcystin producing and non-toxigenic populations of Dolichospermum lemmermannii (Cyanobacteria). Harmful Algae, 67, 1-12.

Castro Berman, M., Marino, D. J. G., Quiroga, M. V., \& Zagarese, H. (2018). Occurrence and levels of glyphosate and AMPA in shallow lakes from the Pampean and Patagonian regions of Argentina. Chemosphere, 200, 513-522.

Caux, P-Y., Ménard, L., Kent, R. A. (1996). Comparitive study of the effects of MCPA, butylate, atrazine, and cyanazine on Selenastrum capricornutum. Environmental Pollution, 92, 219-225.

Chapra, S.C., Boehlert, B., Fant, Ch., Bierman, V.J., Henderson, J., Mills, D., Mas, D.M.L., Rennels, L., Jantarasami, L., Martinich, J., Strzepek, K.M., Paerl, H.W. (2017). Climate change impacts on harmful algal blooms in U.S. freshwaters: A screening-level assessment. Environmental Science and Technology, 51, 8933-8943.

Chaturvedi, P., Kumar Agrawal, M., \& Nath Bagchi, S. (2015). Microcystin-producing and non-producing cyanobacterial blooms collected from the Central India harbor potentially pathogenic Vibrio cholerae. Ecotoxicology and Environmental Safety, 115, 67-74. 
Chen, J., Song, L., Dai, J., Gan, N., \& Liu, Z. (2004). Effects of microcystins on the growth and the activity of superoxide dismutase and peroxidase of rape (Brassica napus L.) and rice (Oryza sativa L.). Toxicon, 43, 393-400.

Chen, L., Xie, M., Bi, Y., Wang, G., Deng, S., Liu, Y. (2012). The combined effects of UV-B radiation and herbicides on photosynthesis, antioxidant enzymes and DNA damage in two bloom-forming cyanobacteria. Ecotoxicology and Environmental Safety, 80, 224-230.

Chen, S., Zhang, L., Chen, H., Chen, Z., \& Wen, Y. (2019). Enantioselective toxicity of chiral herbicide Metolachlor to Microcystis aeruginosa. Journal of Agricultural and Food Chemistry, 67, 1631-1637.

Chia, M. A., Cordeiro-Araújo, M. K., \& Bittencourt-Oliveira, M. do C. (2015). Growth and antioxidant response of Microcystis aeruginosa (Cyanobacteria) exposed to anatoxin-a. Harmful Algae, 49, 135-146.

Chia, M., Kramer, B., Jankowiak, J., Bittencourt-Oliveira, M., \& Gobler, C. (2019). The individual and combined effects of the cyanotoxins, anatoxin-a and microcystin-LR, on the growth, toxin production, and nitrogen fixation of prokaryotic and eukaryotic algae. Toxins, $11,43$.

Chouhan, D., Bello-Mendoza, R., \& Wareham, D. G. (2016). MCPA biodegradation in an anoxic sequencing batch reactor (SBR). International Journal of Environmental Science and Technology, 14, 365-374.

Cirés, S., \& Ballot, A. (2016). A review of the phylogeny, ecology and toxin production of bloom-forming Aphanizomenon spp. and related species within the Nostocales (cyanobacteria). Harmful Algae, 54, 21-43.

Codd, G. A. (1995). Cyanobacterial toxins: Occurrence, properties and biological significance. Water Science and Technology, 32, 149-156.

Cohen, Y., Jørgensen, B.B., Revsbech, N.P., Poplawski, R. (1986). Adaptation to hydrogen sulfide of oxygenic and anoxygenic photosynthesis among cyanobacteria. Applied Environmental Microbiology, 51, 398-407.

Colas, S., Duval, C., \& Marie, B. (2020). Toxicity, transfer and depuration of anatoxin-a (cyanobacterial neurotoxin) in medaka fish exposed by single-dose gavage. Aquatic Toxicology, 222, 105422. 
Coupe, R. H., Kalkhoff, S. J., Capel, P. D., \& Gregoire, C. (2011). Fate and transport of glyphosate and aminomethylphosphonic acid in surface waters of agricultural basins. Pest Management Science, 68, 16-30.

Crowe, A. S., Leclerc, N., Struger, J., \& Brown, S. (2011). Application of a glyphosate-based herbicide to Phragmites australis: Impact on groundwater and near-shore lake water at a beach on Georgian Bay. Journal of Great Lakes Research, 37, 616-624.

Daouk, S., Copin, P.-J., Rossi, L., Chèvre, N., \& Pfeifer, H.-R. (2013). Dynamics and environmental risk assessment of the herbicide glyphosate and its metabolite AMPA in a small vineyard river of the Lake Geneva catchment. Environmental Toxicology and Chemistry, 32, 2035-2044.

Davis, T., Berry, D., Boyer, G., \& Gobler, C. (2009). The effects of temperature and nutrients on the growth and dynamics of toxic and non-toxic strains of Microcystis during cyanobacteria blooms. Harmful Algae, 8, 715-725.

Davis, T., Harke, M., Marcoval, M., Goleski, J., Orano-Dawson, C., Berry, D., \& Gobler, C. (2010). Effects of nitrogenous compounds and phosphorus on the growth of toxic and nontoxic strains of Microcystis during cyanobacterial blooms. Aquatic Microbial Ecology, 61, 149162.

Délye, C., Jasieniuk, M., \& Le Corre, V. (2013). Deciphering the evolution of herbicide resistance in weeds. Trends in Genetics, 29, 649-658.

Dias, E., Pereira, P., \& Franca, S. (2002). Production of paralytic shellfish toxins by Aphanizomenon sp LMECYA 31 (cyanobacteria). Journal of Phycology, 38, 705-712.

Dittmann, E., Börner, T., von Döhren, H., Kaebernick, M., Erhard, M., Neilan, B., \& Scheler, C. (2001). Altered expression of two light-dependent genes in a microcystin-lacking mutant of Microcystis aeruginosa PCC 7806. Microbiology, 147, 3113-3119.

Drzyzga, D., \& Lipok, J. (2017). Glyphosate dose modulates the uptake of inorganic phosphate by freshwater cyanobacteria. Journal of Applied Phycology, 30, 299-309.

Du, Y., Ye, J., Wu, L., Yang, C., Wang, L., \& Hu, X. (2017). Physiological effects and toxin release in Microcystis aeruginosa and Microcystis viridis exposed to herbicide fenoxaprop-pethyl. Environmental Science and Pollution Research, 24, 7752-7763. 
Dubinin A.V., Gerasimenko L.M., Gusev, M.V. (1992). Physiological features of a strain of Microcoleus chthonoplastes from a hypersaline reservoir. Mikrobiologiya (English translation), 61, 47-51.

Dubinsky, Z., \& Stambler, N. (2009). Photoacclimation processes in phytoplankton: Mechanisms, consequences, and applications. Aquatic Microbial Ecology, 56, 163-176.

Duke, S. O. (1990). Overview of herbicide mechanisms of action. Environmental Health Perspectives, 87, 263-271.

Edwards, W. M., Triplett, G. B., \& Kramer, R. M. (1980). A watershed study of glyphosate transport in runoff. Journal of Environment Quality, 9, 661-665.

Forlani, G., Pavan, M., Gramek, M., Kafarski, P., \& Lipok, J. (2008). Biochemical bases for a widespread tolerance of cyanobacteria to the phosphonate herbicide glyphosate. Plant And Cell Physiology, 49, 443-456.

Foy, R. H., \& Gibson, C. E. (1982). Photosynthetic characteristics of planktonic blue-green algae: Changes in photosynthetic capacity and pigmentation of Oscillatoria redekei van Goor under high and low light. British Phycology Journal, 17, 183-193.

Fujii, M., Dang, T. C., Rose, A. L., Omura, T., Waite, T. D. (2011). Effect of light on iron uptake by the freshwater cyanobacterium Microcystis aeruginosa. Environmental Science and Technology, 45, 1391-1398.

Gan, N., Xiao, Y., Zhu, L., Wu, Z., Liu, J., Hu, C., \& Song, L. (2012). The role of microcystins in maintaining colonies of bloom-forming Microcystis spp. Environmental Microbiology, 14, 730-742.

Garcia-Pichel, F., Belnap, J., Neuer, S., \& Schanz, F. (2003). Estimates of global cyanobacterial biomass and its distribution. Algological Studies, 109, 213-227.

Gehringer, M. M., Kewada, V., Coates, N., \& Downing, T. G. (2003). The use of Lepidium sativum in a plant bioassay system for the detection of microcystin-LR. Toxicon, 41, 871-876.

Gomez, I., \& Huovinen, P. (2011). Morpho-functional patterns and zonation of South Chilean seaweeds: The importance of photosynthetic and bio-optical traits. Marine Ecology Progress Series, 422, 77-91.

Gunarathna, S., Gunawardana, B., Jayaweera, M., Manatunge, J., \& Zoysa, K. (2018). Glyphosate and AMPA of agricultural soil, surface water, groundwater and sediments 
in areas prevalent with chronic kidney disease of unknown etiology, Sri Lanka. Journal of Environmental Science and Health Part B, 53, 729-737.

Hanelt, D. (2018). Photosynthesis assessed by chlorophyll fluorescence. In: Bioassays: Advanced Methods and Applications (1 edition). Amsterdam, Netherlands: Elsevier.

Harke, M. J., Steffen, M. M., Gobler, C. J., Otten, T. G., Wilhelm, S. W., Wood, S. A., \& Paerl, H. W. (2016). A review of the global ecology, genomics, and biogeography of the toxic cyanobacterium, Microcystis spp. Harmful Algae, 54, 4-20.

Harris, T., \& Smith, V. (2016). Do persistent organic pollutants stimulate cyanobacterial blooms? Inland Waters, 6(2), 124-130.

Havens, K., Ji, G., Beaver, J., Fulton, R., \& Teacher, C. (2019). Dynamics of cyanobacteria blooms are linked to the hydrology of shallow Florida lakes and provide insight into possible impacts of climate change. Hydrobiologia, 829, 43-59.

Hawes, I. (2001). Absorption and utilization of irradiance by cyanobacterial mats in two icecovered Antarctic lakes with contrasting light climates. Journal of Phycology, 37, 5-15.

Hébert, M.-P., Fugère, V., \& Gonzalez, A. (2018). The overlooked impact of rising glyphosate use on phosphorus loading in agricultural watersheds. Frontiers in Ecology and the Environment, 17, 48-56.

Helander, M., Saloniemi, I., \& Saikkonen, K. (2012). Glyphosate in northern ecosystems. Trends In Plant Science, 17, 569-574.

Holland, A., \& Kinnear, S. (2013). Interpreting the possible ecological role(s) of cyanotoxins: Compounds for competitive advantage and/or physiological aide? Marine Drugs, 11, 2239-2258.

Hostraat J. W., Peeters, J. C. H., Snel, J. F. H. \& Geel, C. (1994). Simple determination of photosynthetic efficiency and photoinhibition of Dunaliella tertiolecta by saturating pulse fluorescence measurements. Marine Ecology Progress Series, 103, 187-196.

Hove-Jensen, B., Zechel, D. L., \& Jochimsen, B. (2014). Utilization of glyphosate as phosphate source: Biochemistry and genetics of bacterial carbon-phosphorus lyase. Microbiology and Molecular Biology Reviews, 78, 176-197. 
Hu, Z., Liu, Y., \& Li, D. (2004). Physiological and biochemical analyses of microcystin-RR toxicity to the cyanobacterium Synechococcus elongatus. Environmental Toxicology, 19, 571577.

Huang, X., He, J., Yan, X., Hong, Q., Chen, K., He, Q., Zhang, L., Liu, X., Chuang, S., Li, S., \& Jiang, J. (2017). Microbial metabolism of chemical herbicides: Microbial resources, metabolic pathways and catabolic genes. Pesticide biochemistry and Physiology, 143, 272-297. Humpage, A.R. (2008). Toxin types, toxicokinetics and toxicodynamics. Advances in Experimental Medicine and Biology, 619, 383-415.

Ihnken, S., Eggert, A., \& Beardall, J. (2010). Exposure times in rapid light curves affect photosynthetic parameters in algae. Aquatic Botany, 93, 185-194.

Jöhnk, K., Huisman, J., Sharples, J., Sommeijer, B., Visser, P., \& Stroom, J. (2008). Summer heatwaves promote blooms of harmful cyanobacteria. Global Change Biology, 14, 495-512.

Kaebernick, M., \& Neilan, B. A. (2001). Ecological and molecular investigations of cyanotoxin production. FEMS Microbiology Ecology, 35, 1-9.

Kardinaal, W. E. A., Janse, I., Kamst-van Agterveld, M., Meima, M., Snoek, J., Mur, L.R., Huisman, J., Zwart, G., \& Visser, P. (2007a). Microcystis genotype succession in relation to microcystin concentrations in freshwater lakes. Aquatic Microbial Ecology, 48, 1-12.

Kardinaal, W. E. A., Tonk, L., Janse, I., Hol, S., Slot, P., Huisman, J., \& Visser, P. (2007b). Competition for light between toxic and nontoxic strains of the harmful cyanobacterium Microcystis. Applied and Environmental Microbiology, 73, 2939-2946.

Karlsson-Elfgren, I., Rengefors, K., \& Gustafsson, S. (2004). Factors regulating recruitment from the sediment to the water column in the bloom-forming cyanobacterium Gloeotrichia echinulata. Freshwater Biology, 49, 265-273.

Kim Tiam, S., Laviale, M., Feurtet-Mazel, A., Jan, G., Gonzalez, P., Mazzella, N., \& Morin, S. (2015). Herbicide toxicity on river biofilms assessed by pulse amplitude modulated (PAM) fluorometry. Aquatic Toxicology, 165, 160-171.

Klein, A.R., Baldwin, D.S., Silvester, E. (2013). Proton and iron binding by the cyanobacterial toxin microcystin-LR. Environmental Science \& Technology, 47, 5178-5184.

Konopka, A., \& Brock, T. (1978). Effect of temperature on blue-green algae (cyanobacteria) in Lake Mendota. Applied and Environmental Microbiology, 36. 572-576. 
Kosten S., Huszar V.L.M., Bécares E., Costa L.S., Van Donk E., Hansson L-A., Jeppesen E., Kruk C., Lacerot G, Mazzeo N, D.E Meester L., Moss B., Lürling M., Nöges T., Romo S., Scheffer M. (2012). Warmer climates boost cyanobacterial dominance in shallow lakes. Global Change Biology, 18, 118-126.

Kuster, T., Metsamaa, L., \& Dekker, A. G. (2008). Influence of the vertical distribution of cyanobacteria in the water column on the remote sensing signal. Estuarine, Coastal and Shelf Science, 78, 649-654.

Li, J., Parkefelt, L., Persson, K., \& Pekar, H. (2017). Improving cyanobacteria and cyanotoxins monitoring in surface waters for drinking water supply. Journal of Water Security, 3, jws2017005.

Li, W. (1994). Primary production of prochlorophytes, cyanobacteria, and eukaryotic ultra phytoplankton: Measurements from flow cytometric sorting. Limnology and Oceanography, 39, 169-175.

Li, X., Dreher, T. W., \& Li, R. (2016). An overview of diversity, occurrence, genetics and toxin production of bloom-forming Dolichospermum (Anabaena) species. Harmful Algae, 54, 5468.

Lorenzen, C. (1967). Determination of chlorophyll and pheo-pigments: Spectrophotometric equations. Limnology and Oceanography, 12, 343-346.

Ma, J., Brookes, J. D., Qin, B., Paerl, H. W., Gao, G., Wu, P., Zhang, W., Deng, J., Zhu, G., Zhang, Y., Xu, H., \& Niu, H. (2014). Environmental factors controlling colony formation in blooms of the cyanobacteria Microcystis spp. in Lake Taihu, China. Harmful Algae, 31, 136142.

MacLeod, C., \& Moller, H. (2006). Intensification and diversification of New Zealand agriculture since 1960: An evaluation of current indicators of land use change. Agriculture, Ecosystems \& Environment, 115, 201-218.

Malmqvist, B., \& Rundle, S. (2002). Threats to the running water ecosystems of the world. Environmental Conservation, 29, 134-153.

Manktelow, D., Stevens, P., Walker, J., Gurnsey, S., Park, N., Zabkiewicz J., Teulon, D., \& Rahman, A. (2005). Trends in pesticide use in New Zealand: 2004, report to the Ministry for the Environment (Project SMF4193). HortResearch client report no. 17962. 
Mantzouki, E., Visser, P., Bormans, M., \& Ibelings, B. (2015). Understanding the key ecological traits of cyanobacteria as a basis for their management and control in changing lakes. Aquatic Ecology, 50, 333-350.

Martínez-Ruiz, E. B., \& Martínez-Jerónimo, F. (2018). Exposure to the herbicide 2,4-D produces different toxic effects in two different phytoplankters: A green microalga (Ankistrodesmus falcatus) and a toxigenic cyanobacterium (Microcystis aeruginosa). Science of The Total Environment, 619-620, 1566-1578.

Maule, A., \& Wright, S. (1984). Herbicide effects on the population growth of some green algae and cyanobacteria. Journal Of Applied Bacteriology, 57, 369-379.

Maxwell, K., \& Johnson, G. N. (2000). Chlorophyll fluorescence - a practical guide. Journal of Experimental Botany, 51, 659-668.

McGregor, D. (2000). Reducing nutrient enrichment of waterways through public education: A tale of two cities. Environmental Conservation, 27, 351-358.

Mishra, A., \& Pandey, A. (1989). Toxicity of three herbicides to some nitrogen-fixing cyanobacteria. Ecotoxicology And Environmental Safety, 17, 236-246.

Morton, P. A., Fennell, C., Cassidy, R., Doody, D., Fenton, O., Mellander, P-E., Jordan, P. (2019). A review of the pesticide MCPA in the land-water environment and emerging research needs. WIREs Water, 7, e1402.

Mulkidjanian, A., Koonin, E., Makarova, K., Mekhedov, S., Sorokin, A., \& Wolf, Y. et al. (2006). The cyanobacterial genome core and the origin of photosynthesis. Proceedings Of The National Academy Of Sciences, 103, 13126-13131.

Nagai, T. (2019). Sensitivity differences among seven algal species to 12 herbicides with various modes of action. Journal of Pesticide Science, 44. 225-232.

Nagarkar, S., Williams, G. A., Subramanian, G., \& Saha, S. K. (2004). Cyanobacteriadominated biofilms: a high quality food resource for intertidal grazers. Hydrobiologia, 512, 89-95.

Nielsen, L., \& Dahllof, I. (2007). Direct and indirect effects of the herbicides Glyphosate, Bentazone and MCPA on eelgrass (Zostera marina). Aquatic Toxicology, 82, 47-54.

Nowicka, B., \& Kruk, J. (2016). Powered by light: Phototrophy and photosynthesis in prokaryotes and its evolution. Microbiological Research, 186-187, 99-118. 
Okmen, G., Donmez, G., Donmez, S. (2007). Influence of nitrate, phosphate and herbicide stresses on nitrogenase activity and growth of cyanobacteria isolated from paddy fields. Journal of Applied Biological Sciences, 1. 57-62.

Ouellette, A. J., \& Wilhelm, S. W. (2003). Toxic cyanobacteria: The evolving molecular toolbox. Frontiers in Ecology and the Environment, 1, 359-366.

Ozawa, K., Yokoyama, A., Ishikawa, K., Kumagai, M., Watanabe, M., \& Park, H. (2003). Accumulation and depuration of microcystin produced by the cyanobacterium Microcystis in a freshwater snail. Limnology, 4, 131-138.

Padisák, J., Crossetti, L. O., \& Naselli-Flores, L. (2008). Use and misuse in the application of the phytoplankton functional classification: A critical review with updates. Hydrobiologia, $621,1-19$.

Paerl, H. (2018). Mitigating toxic planktonic cyanobacterial blooms in aquatic ecosystems facing increasing anthropogenic and climatic pressures. Toxins, 10, 76.

Paerl, H., \& Huisman, J. (2008). CLIMATE: Blooms like it hot. Science, 320, 57-58.

Paerl, H., \& Otten, T. (2013). Harmful cyanobacterial blooms: Causes, consequences, and controls. Microbial Ecology, 65, 995-1010.

Paerl, H.W., \& Otten, T.G. (2015). Duelling 'CyanoHABs': Unravelling the environmental drivers controlling dominance and succession among diazotrophic and non-N2-fixing harmful cyanobacteria. Environmental Microbiology. 18, 316-324.

Peruzzo, P. J., Porta, A. A., \& Ronco, A. E. (2008). Levels of glyphosate in surface waters, sediments and soils associated with direct sowing soybean cultivation in north pampasic region of Argentina. Environmental Pollution, 156, 61-66.

Pflugmacher, S. (2002). Possible allelopathic effects of cyanotoxins, with reference to microcystin-LR, in aquatic ecosystems. Environmental Toxicology, 17, 407-413.

Phelan, R. R., \& Downing, T. G. (2014). The localization of exogenous microcystin-LR taken up by a non-microcystin producing cyanobacterium. Toxicon, 89, 87-90.

Powell, H., Kerbby, N., \& Rowell, P. (1991). Natural tolerance of cyanobacteria to the herbicide glyphosate. New Phytologist, 119, 421-426. 
Puddick, J., Biessy, L., Thomson-Laing, G., Smith, K. F., Ryan, K., Wood. S. A. (2020). Microcystins are sequestered by a range of non-microcystin-producing cyanobacteria and affects photosynthetic functioning. Manuscript in preparation.

Qiu, H., Geng, J., Ren, H., Xia, X., Wang, X., \& Yu, Y. (2013). Physiological and biochemical responses of Microcystis aeruginosa to glyphosate and its Roundup® formulation. Journal Of Hazardous Materials, 248-249, 172-176.

Quesada, A., \& Vincent, W. (1997). Strategies of adaptation by Antarctic cyanobacteria to ultraviolet radiation. European Journal Of Phycology, 32, 335-342.

Quiblier, C., Wood, S., Echenique-Subiabre, I., Heath, M., Villeneuve A., Humbert J-F. (2013). A review of current knowledge on toxic benthic freshwater cyanobacteria - Ecology, toxin production and risk management. Water Research, 47, 5464-5479.

Rantala, A., Fewer, D., Hisbergues, M., Rouhiainen, L., Vaitomaa, J., Borner, T., \& Sivonen, K. (2003). Phylogenetic evidence for the early evolution of microcystin synthesis. Proceedings of The National Academy Of Sciences, 101, 568-573.

Rapala, J., Sivonen,K., Luukkainen, R., \& Niemelä, S. I. (1993). Anatoxin-a concentration in Anabaena and Aphanizomenon under different environmental conditions and comparison of growth by toxic and non-toxic Anabaena-strains - A laboratory study. Journal of Applied Phycology, 5, 581-591.

Raps, S., Wyman, K., Siegelman, H. W., \& Falkowski, P. G. (1983). Adaptation of the cyanobacterium Microcystis aeruginosa to light intensity. Plant Physiology, 72, 829-832.

Rastogi, R. P., Sinha, R, P., \& Incharoensakdi, A. (2014). The cyanotoxin-microcystins: Current overview. Reviews in Environmental Science and Biotechnology, 13, 215-249.

Relyea, R. (2008). A cocktail of contaminants: how mixtures of pesticides at low concentrations affect aquatic communities. Oecologia, 159, 363-376.

Reynolds, C.S., Walsby, A.E. (1975). Water-blooms. Biological Reviews, 50, 437-481.

Richmond, M. E. (2018). Glyphosate: A review of its global use, environmental impact, and potential health effects on humans and other species. Journal of Environmental Studies and Sciences, 8, 416-434. 
Rippka, R., Stanier, R., Deruelles, J., Herdman, M., \& Waterbury, J. (1979). Generic assignments, strain histories and properties of pure cultures of cyanobacteria. Microbiology, $111,1-61$.

Ritz, C., Baty, F., Streibig, J.C., \& Gerhard, D. (2016). Dose-response analysis using R. PLoS ONE, 10, e0146021.

Robarts, R. D., \& Zohary, T. (1987). Temperature effects on photosynthetic capacity, respiration, and growth rates of bloom-forming cyanobacteria. New Zealand Journal of Marine and Freshwater Research, 21, 391-399.

Rolando, C., Garrett, L., Baillie, B., \& Watt, M. (2013). A survey of herbicide use and a review of environmental fate in New Zealand planted forests. New Zealand Journal Of Forestry Science, 43, 17.

Rouhiainen, L., Vakkilainen, T., Siemer, B. L., Buikema, W., Haselkorn, R., \& Sivonen, K. (2004). Genes coding for hepatotoxic heptapeptides (microcystins) in the cyanobacterium Anabaena strain 90. Applied and Environmental Microbiology, 70, 686-692.

Ruan, Z-X., \& Brown, M. T. (2008). Effects of acute glyphosate exposure on the growth and physiology of Nostoc sphaeroides, an edible cyanobacterium of paddy rice fields. Acta Hydrobiologica Sinica, 32, 462-467.

Runnegar, M., Gerdes, R., \& Falconer, I. (1991). The uptake of the cyanobacterial hepatotoxin microcystin by isolated rat hepatocytes. Toxicon, 29, 43-51.

Sakshaug, E., Bricaud, A., Dandonneau, Y., Falkowski, P. G., Kiefer, D. A., Legendre, L., Morel, A., Parslow, J., Takahashi, M. (1997). Parameters of photosynthesis: Definitions, theory and interpretation of results. Journal of Plankton Research, 19, 1637-1670.

Saoudi, A., Brient, L., Boucetta, S., Ouzrout, R., Bormans, M., \& Bensouilah, M. (2017). Management of toxic cyanobacteria for drinking water production of Ain Zada Dam. Environmental Monitoring and Assessment, 189, 361.

Saroussi, S., \& Beer, S. (2007). Alpha and quantum yield of aquatic plants derived from PAM fluorometry: Uses and misuses. Aquatic Botany, 86, 89-92.

Sato, N., \& Awai, K. (2016). Diversity in biosynthetic pathways of galactolipids in the light of endosymbiotic origin of chloroplasts. Frontiers In Plant Science, 7, 117. 
Schatz, D., Keren, Y., Vardi, A., Sukenik, A., Carmeli, S., Borner, T., Dittmann, E., \& Kaplan, A. (2007). Towards clarification of the biological role of microcystins, a family of cyanobacterial toxins. Environmental Microbiology, 9, 965-970.

Scholz, S., Esterhuizen-Londt, M., \& Pflugmacher, S. (2017). Rise of toxic cyanobacterial blooms in temperate freshwater lakes: Causes, correlations and possible countermeasures. Toxicological \& Environmental Chemistry, 99, 543-577.

Schreiber U. (1998). Chlorophyll fluorescence: New instruments for special applications. In: Garab G. (eds) Photosynthesis: Mechanisms and effects. Dordrecht, Netherlands: Springer.

Schulz, A., Sost, D., \& Amrhein, N. (1984). Insensitivity of 5-enolpyruvylshikimic acid-3phosphate synthase to glyphosate confers resistance to this herbicide in a strain of Aerobacter aerogenes. Archives of Microbiology, 137, 121-123.

Sedmak, B., \& Kosi, G. (1998). The role of microcystins in heavy cyanobacterial bloom formation. Journal of Plankton Research, 20, 691-708.

Sevilla, E., Martin-Luna, B., Bes, M., Fillat, M., \& Peleato, M. (2011). An active photosynthetic electron transfer chain required for $m c y D$ transcription and microcystin synthesis in Microcystis aeruginosa PCC 7806. Ecotoxicology, 21, 811-819.

Shan, K., Song, L., Chen, W., Li, L., Liu, L., Wu, Y., Jia, Y., Zhou, Q., Peng, L. (2019). Analysis of environmental drivers influencing interspecific variations and associations among bloom-forming cyanobacteria in large, shallow eutropic lakes. Harmful Algae, 84, 84-94.

Shih, P., Wu, D., Latifi, A., Axen, S., Fewer, D., \& Talla, E. et al. (2012). Improving the coverage of the cyanobacterial phylum using diversity-driven genome sequencing. Proceedings of The National Academy Of Sciences, 110, 1053-1058.

Sinang, S. C., Poh, K. B., Shamsudin, S., \& Sinden, A. (2015). Preliminary assessment of cyanobacteria diversity and toxin potential in ten freshwater lakes in Selangor, Malaysia. Bulletin for Environmental Contamination and Toxicology, 95, 542-547.

Singh, D.P., Tyagi, M., Kumar, A., Thakur, J., Kumar, A., 2001. Antialgal activity of a hepatotoxin-producing cyanobacterium, Microcystis aeruginosa. World Journal of Microbiology \& Biotechnology, 17, 15-22.

Singh, S,. \& Singh, D. P. (2004). Influence of glyphosate on photosynthetic properties of wild type and mutant strains of cyanobacterium Anabaena doliolum. Current Science, 86, 571-576. 
Struger, J., Thompson, D., Staznik, B., Martin, P., McDaniel, T., \& Marvin, C. (2008). Occurrence of glyphosate in surface waters of Southern Ontario. Bulletin of Environmental Contamination and Toxicology, 80, 378-384.

Sujetovienè, G., Gasauskaitė, K., \& Žaltauskaitè, J. (2020). Toxicity of phenoxy herbicide on the lichen Ramalina fraxinea. Toxicology \& Environmental Chemistry, 101, 497-507.

Sun, K., Liu, W., Liu, L., Wang, N., \& Duan, S. (2013). Ecological risks assessment of organophosphorus pesticides on bloom of Microcystis wesenbergii. International Biodeterioration \& Biodegradation, 77, 98-105.

Talbot, H. M., Summons, R. E., Jahnke, L. L., Cockell, C. S., Rohmer, M., \& Farrimond, P. (2008). Cyanobacterial bacteriohopanepolyol signatures from cultures and natural environmental settings. Organic Geochemistry, 39, 232-263.

Trenberth, K. (2011). Changes in precipitation with climate change. Climate Research, 47, 123-138.

Van de Waal, D. B., Verspagen, J. M., Finke, J. F., Vournazou, V., Immers, A. K., Kardinaal, W. E. A., Tonk, L., Becker, S., Van Donk, E., Visser, P. P., \& Huisman, J. (2011). Reversal in competitive dominance of a toxic versus non-toxic cyanobacterium in response to rising $\mathrm{CO}_{2}$. The ISME Journal, 5, 1438-1450.

Van Dolah, F. (2000). Marine algal toxins: origins, health effects, and their increased occurrence. Environmental Health Perspectives, 108, 133-141.

Van Gremberghe, I., Leliaert, F., Mergeay, J., Vanormelingen, P., Van der Gucht, K., Debeer, A.-E., Lacerot, G., Meester, L. D., \& Vyverman, W. (2011). Lack of phylogeographic structure in the freshwater cyanobacterium Microcystis aeruginosa suggests global dispersal. PLoS ONE, 6, e19561.

Vézie, C., Rapala, J., Vaitomaa, J., Seitsonen, J., \& Sivonen, K. (2002). Effect of nitrogen and phosphorus on growth of toxic and nontoxic Microcystis strains and on intracellular microcystin concentrations. Microbial Ecology, 43, 443-454.

Vivancos, P. D., Driscoll, S. P., Bulman, C. A., Ying, L., Emami, K., Treumann, A., Mauve, C., Noctor, G., Foyer, C. H. (2011). Perturbations of amino acid metabolism associated with glyphosate-dependent inhibition of shikimic acid metabolism affect cellular redox homeostasis and alter the abundance of proteins involved in photosynthesis and photorespiration. Plant Physiology, 157, 256-268. 
Wang, Q., Xie, P., Chen, J., Liang, G. (2008). Distribution of microcystins in various organs (heart, liver, intestine, gonad, brain, kidney and lung) of Wistar rat via intravenous injection. Toxicon, 52, 721-727.

Wang, Z., Li, D., Cao, X., Song, C., \& Zhou, Y. (2015). Photosynthesis regulates succession of toxic and nontoxic strains in blooms of Microcystis (Cyanobacteria). Phycologia, 54, 640648.

Wong, P. K. (2000). Effects of 2,4-D, glyphosate and paraquat on growth, photosynthesis and chlorophyll-a synthesis of Scenedesmus quadricauda Berb 614. Chemosphere, 41, 177-182.

Wood, S. A., Maier, M. Y., Puddick, J., Pochon, X., Zaiko, A., Dietrich, D. R., \& Hamilton, D. P. (2017). Trophic state and geographic gradients influence planktonic cyanobacterial diversity and distribution in New Zealand lakes. FEMS Microbiology Ecology, 93, fiw234.

Wood, S. A., Rasmussen, J. P., Holland, P. T., Campbell, R., \& Crowe, A. L. M. (2007). First report of the cyanotoxin anatoxin-a from Aphanizomenon issatschenkoi (cyanobacteria). Journal of Phycology, 43, 356-365.

Woodburn, A. T. (2000). Glyphosate: Production, pricing and use worldwide. Pest Management Science, 56, 309-312.

World Health Organization. (1999). Toxic cyanobacteria in water: A guide to their public health consequences, monitoring and management. Boca Raton, Florida, USA: CRC Press.

Wu, Z-X., \& Song, L-R. (2008). Physiological comparison between colonial and unicellular forms of Microcystis aeruginosa Kütz. (Cyanobacteria). Phycologia, 47, 98-104.

Wu, Z., Gan, N., Huang, Q., \& Song, L. (2007). Response of Microcystis to copper stress - Do phenotypes of Microcystis make a difference in stress tolerance? Environmental Pollution, 147, 324-330.

Xiao, M., Li, M., Reynolds, S. (2018). Colony formation in the cyanobacterium Microcystis. Biological Reviews, 93, 1399-1420.

Xie, J., Zhao, L., Liu, K., \& Liu, W. (2018). Enantiomeric environmental behavior, oxidative stress and toxin release of harmful cyanobacteria Microcystis aeruginosa in response to napropamide and acetochlor. Environmental Pollution, 246, 728-733. 
Yamamoto, Y., \& Nakahara, H. (2005). Competitive dominance of the cyanobacterium Microcystis aeruginosa in nutrient-rich culture conditions with special reference to dissolved inorganic carbon uptake. Phycological Research, 53, 201-208.

Young, F. M., Thomson, C., Metcalf, J. S., Lucocq, J. M., \& Codd, G. A. (2005). Immunogold localisation of microcystins in cryosectioned cells of Microcystis. Journal of Structural Biology, 151, 208-214.

Zapomělová, E., Řeháková, K., Jezberová, J., \& Komárková, J. (2009). Polyphasic characterization of eight planktonic Anabaena strains (cyanobacteria) with reference to the variability of 61 Anabaena populations observed in the field. Hydrobiologia, 639, 99-113.

Zehr, J., Bench, S., Carter, B., Hewson, I., Niazi, F., \& Shi, T. et al. (2008). Globally distributed uncultivated oceanic N2-Fixing cyanobacteria lack oxygenic photosystem II. Science, 322, 1110-1112.

Zhang, Q., Zhou, H., Li, Z., Zhu, J., Zhou, C., \& Zhao, M. (2016). Effects of glyphosate at environmentally relevant concentrations on the growth of and microcystin production by Microcystis aeruginosa. Environmental Monitoring and Assessment, 188, 632.

Zhao, Y., Xie, P., Tang, R., Zhang, X., Li, L., Li, D. (2008). In vivo studies on the toxic effects of microcystins on mitochondrial electron transport chain and ion regulation in liver and heart of rabbit. Comparative Biochemistry and Physiology Part C: Toxicology and Pharmacology, 148, 204-210.

Zhou, W., Juneau, P., \& Qiu, B. (2006). Growth and photosynthetic responses of the bloomforming cyanobacterium Microcystis aeruginosa to elevated levels of cadmium. Chemosphere, 65, 1738-1746.

Zhu, X., Kong, H., Gao, Y., Wu, M., \& Kong, F. (2012). Low concentrations of polycyclic aromatic hydrocarbons promote the growth of Microcystis aeruginosa. Journal of Hazardous Materials, 237-238, 371-375.

Zilliges, Y., Kehr, J-C., Meissner, S., Ishida, K., Mikkat, S., Hagemann,M., Kaplan, A., Börner, T., \& Dittmann, E. The cyanobacterial hepatotoxin microcystin binds to proteins and increases the fitness of Microcystis under oxidative stress conditions. PloS ONE, 6, e17615. 
Appendices:

Appendix 1: Data for additional PAM fluorometry at 520 and $645 \mathrm{~nm}$ from microcystin supplementation experiment described in Chapter 2.

Table A1.1: Statistical results (two sample t-test) for determining significant differences in photosynthetic performance of microcystinsupplemented cells and the experimental control at 520 and $645 \mathrm{~nm}$.

\begin{tabular}{|c|c|c|c|c|c|c|c|c|c|c|}
\hline & & dition & & & & & & & & \\
\hline & Temp $\left({ }^{\circ} \mathrm{C}\right)$ & 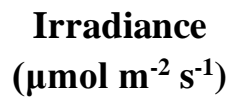 & t-statistic & p-value & t-statistic & p-value & t-statistic & p-value & t-statistic & p-value \\
\hline & & 20 & -0.694 & 0.526 & -1.036 & 0.359 & -0.241 & 0.822 & -0.264 & 0.805 \\
\hline & 15 & 60 & 0.463 & 0.667 & 0.950 & 0.396 & 4.287 & 0.013 & 2.331 & 0.080 \\
\hline$\Xi$ & & 100 & -0.501 & 0.643 & 0.043 & 0.968 & -2.140 & 0.099 & -1.659 & 0.173 \\
\hline ก & & 20 & 0.714 & 0.515 & -0.435 & 0.686 & -0.568 & 0.600 & -0.581 & 0.593 \\
\hline$\sim$ & 20 & 60 & -3.133 & 0.035 & 0.322 & 0.763 & -0.467 & 0.665 & -1.470 & 0.216 \\
\hline $\bar{\Xi}$ & & 100 & 1.319 & 0.258 & -1.450 & 0.221 & -0.866 & 0.435 & -0.722 & 0.510 \\
\hline జ్త్ర & & 20 & -0.482 & 0.655 & 0.594 & 0.585 & 0.069 & 0.948 & -0.109 & 0.919 \\
\hline & 25 & 60 & -0.621 & 0.568 & 0.378 & 0.725 & -0.159 & 0.881 & -0.384 & 0.720 \\
\hline & & 100 & 1.069 & 0.345 & 0.387 & 0.719 & -0.700 & 0.523 & -0.776 & 0.481 \\
\hline & & 20 & -1.482 & 0.213 & -3.318 & 0.029 & -3.442 & 0.026 & 1.373 & 0.242 \\
\hline & 15 & 60 & 4.226 & 0.013 & 0.476 & 0.659 & -0.846 & 0.445 & -0.784 & 0.477 \\
\hline$\Xi$ & & 100 & 0.169 & 0.874 & -0.159 & 0.882 & -1.111 & 0.329 & -1.066 & 0.347 \\
\hline 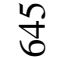 & & 20 & 0.369 & 0.731 & 0.383 & 0.721 & -0.508 & 0.638 & -1.058 & 0.350 \\
\hline$m$ & 20 & 60 & 1.225 & 0.288 & -0.413 & 0.701 & -0.735 & 0.503 & -0.818 & 0.460 \\
\hline $\bar{\Xi}$ & & 100 & $1.3 \mathrm{e}^{-15}$ & 1.000 & -2.192 & 0.093 & 1.458 & 0.219 & 0.685 & 0.531 \\
\hline త్ & & 20 & -0.873 & 0.432 & -1.279 & 0.270 & -1.195 & 0.298 & 0.708 & 0.518 \\
\hline$u$ & 25 & 60 & 0.000 & 1.000 & -4.696 & 0.009 & -0.940 & 0.401 & -0.641 & 0.557 \\
\hline & & 100 & -0.923 & 0.408 & -0.730 & 0.506 & -1.843 & 0.139 & -1.515 & 0.204 \\
\hline
\end{tabular}



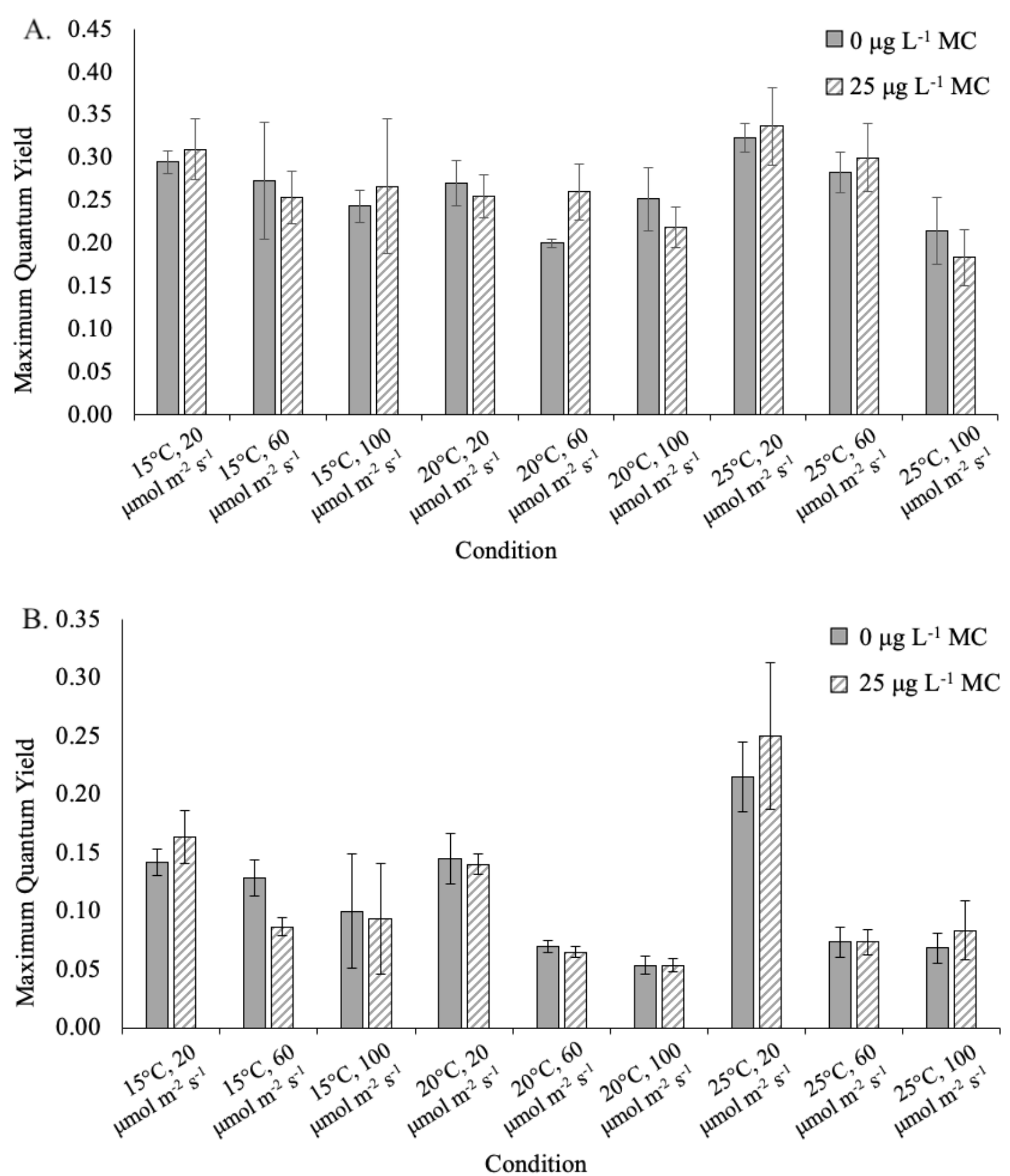

Figure A1.1 A-B: Mean maximum quantum yield at $520 \mathrm{~nm}$ (A) and $645 \mathrm{~nm}$ (B) for the experimental control $\left(0 \mu \mathrm{g} \mathrm{L}^{-1}\right)$ and microcystin-supplemented $\left(25 \mu \mathrm{g} \mathrm{L}^{-1}\right)$ Cuspidothrix issatschenkoi cultures in nine different combinations of light level $\left(20,60,100 \mu \mathrm{mol} \mathrm{m}^{-2} \mathrm{~s}^{-1}\right)$, and temperature $\left(15,20,25^{\circ} \mathrm{C}\right)$. Error bars show \pm one standard deviation. 


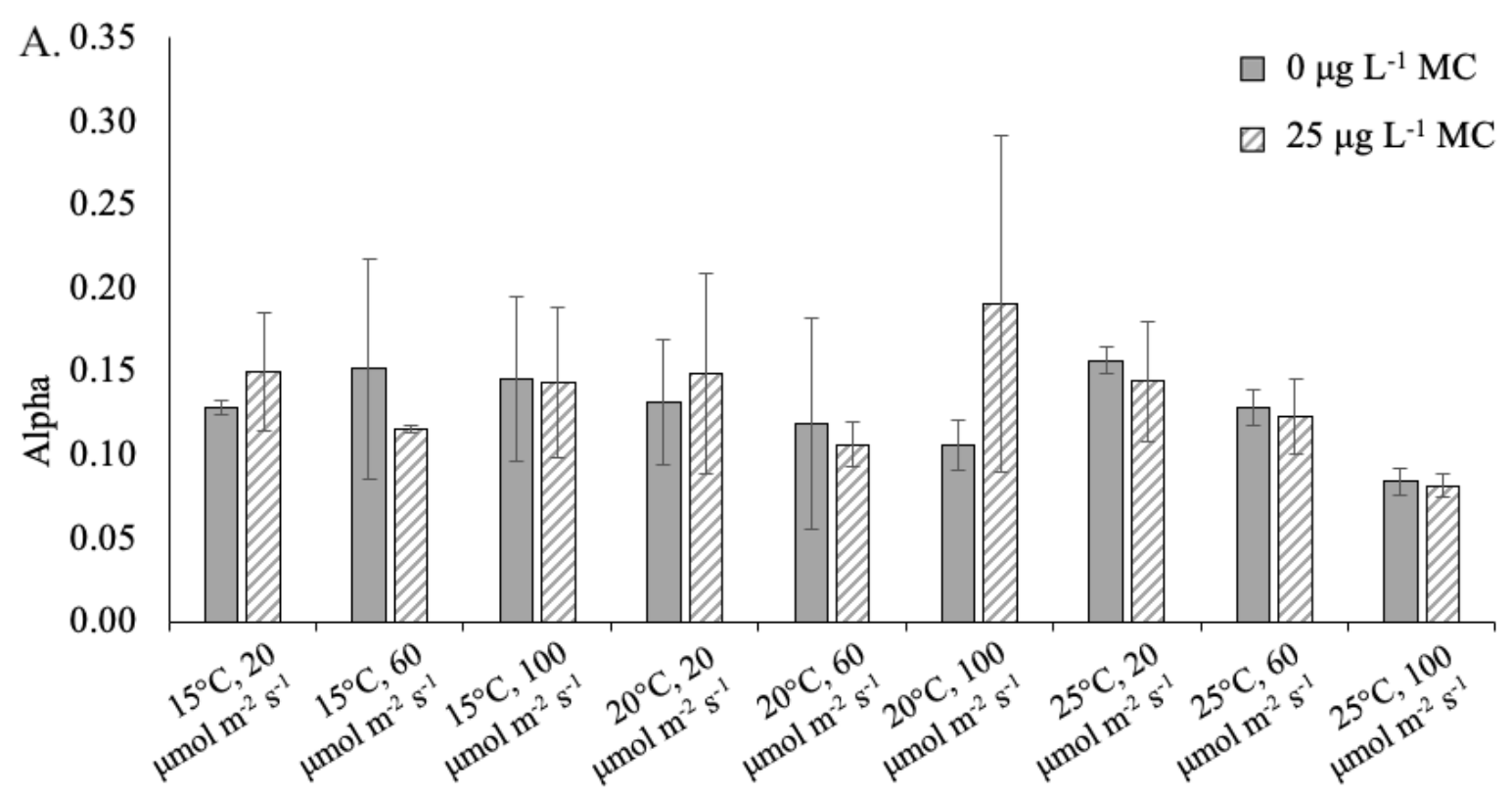

\section{Condition}

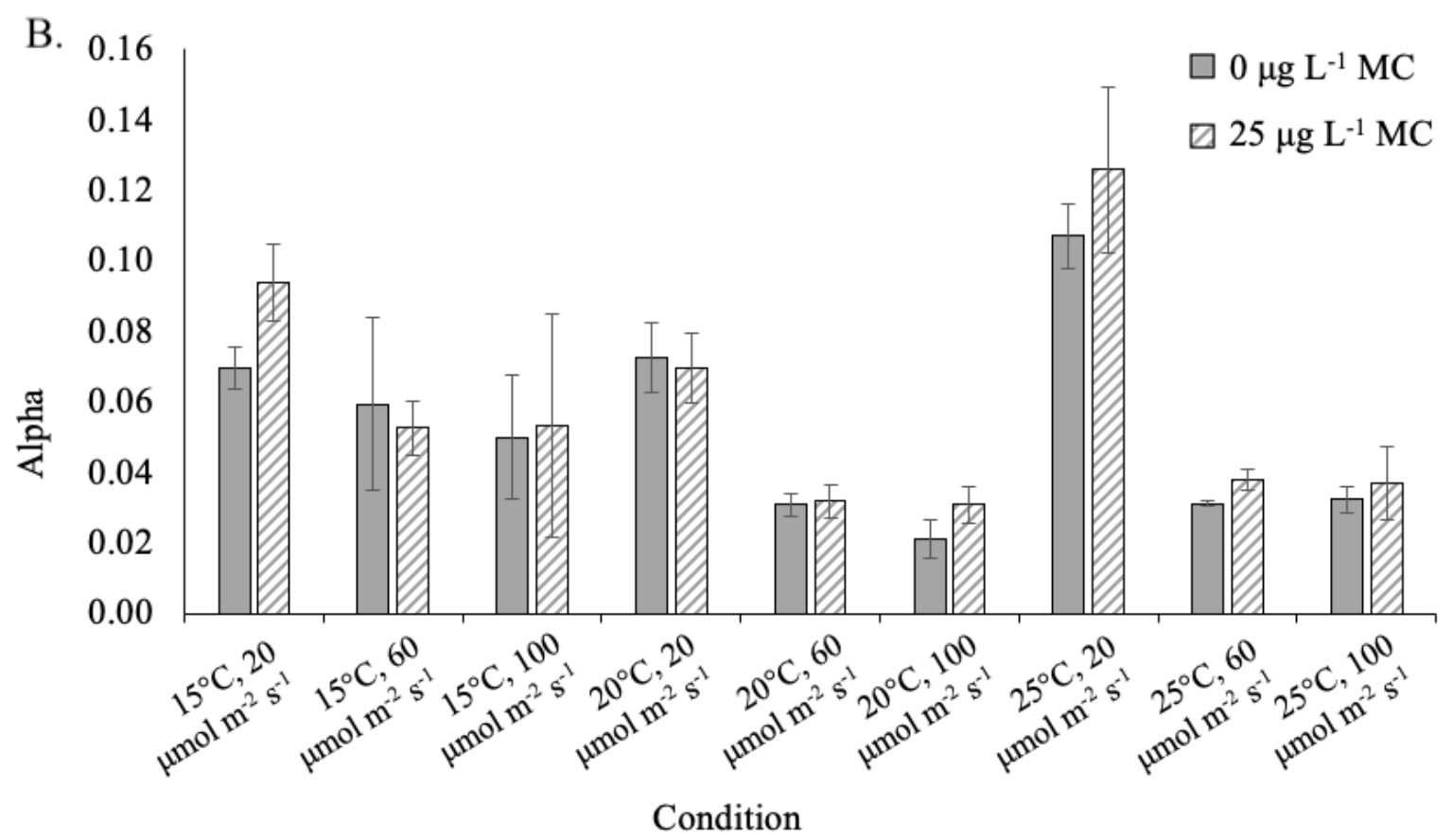

Figure A1.2 A-B: Mean alpha at $520 \mathrm{~nm}$ (A) and $645 \mathrm{~nm}$ (B) for the experimental control (0 $\left.\mu \mathrm{g} \mathrm{L}^{-1}\right)$ and microcystin-supplemented $\left(25 \mu \mathrm{g} \mathrm{L}^{-1}\right)$ Cuspidothrix issatschenkoi cultures in nine different combinations of light level $\left(20,60,100 \mu \mathrm{mol} \mathrm{m}^{-2} \mathrm{~s}^{-1}\right)$, and temperature $\left(15,20,25^{\circ} \mathrm{C}\right)$. Error bars show \pm one standard deviation. 


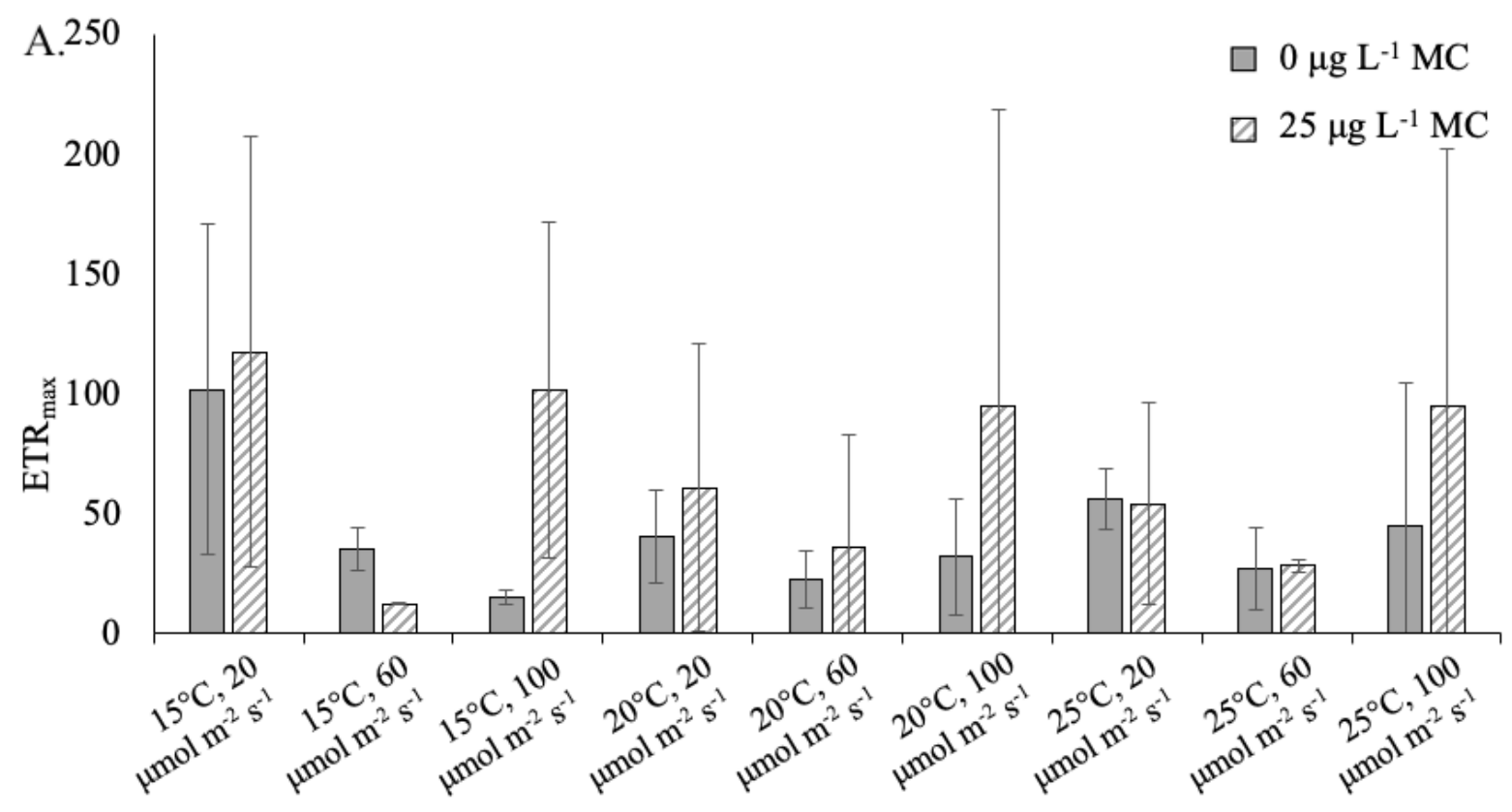

Condition

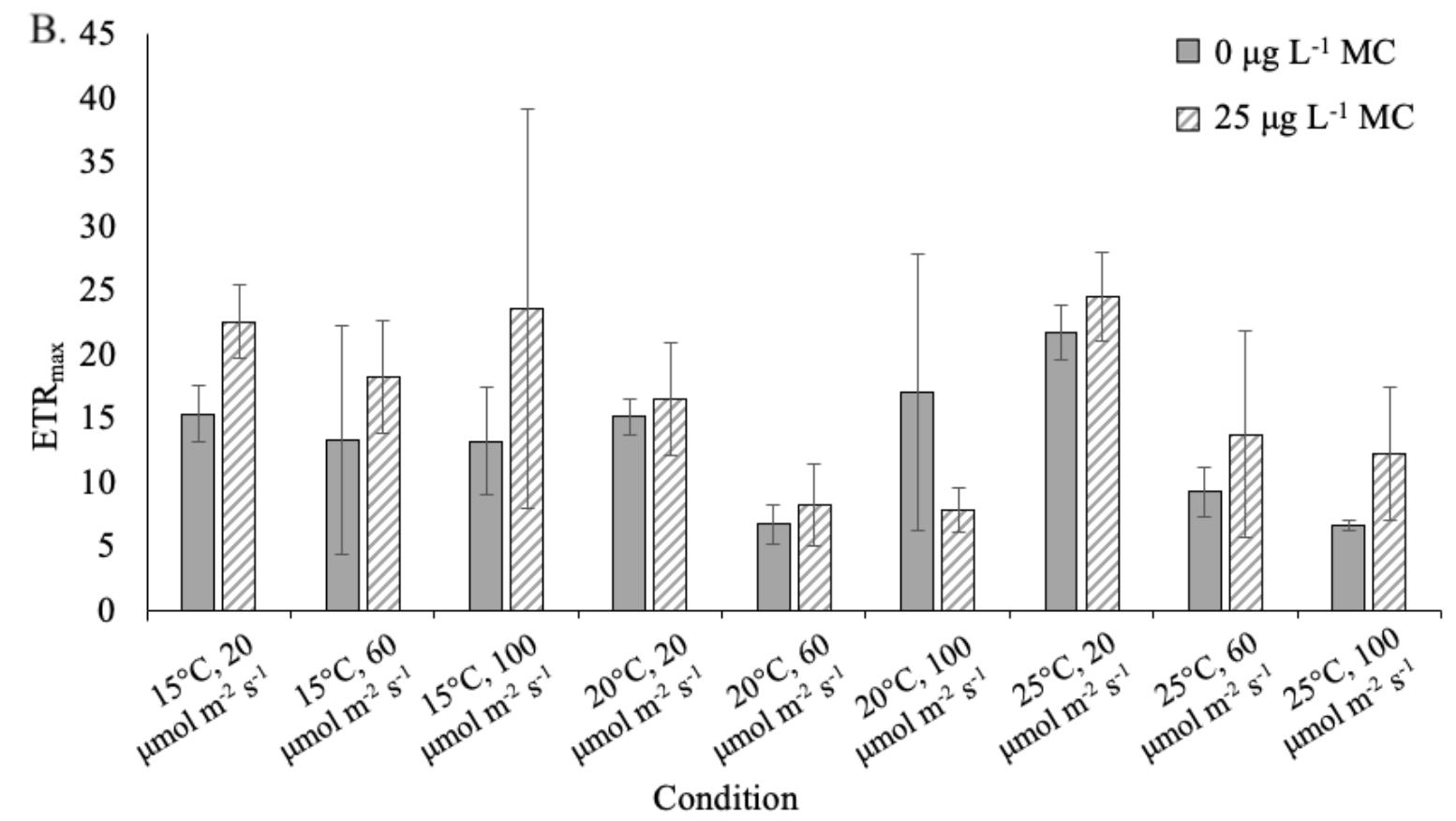

Figure A1.3 A-B: Mean ETR max $_{\text {at }} 520 \mathrm{~nm}(\mathrm{~A})$ and $645 \mathrm{~nm}$ (B) for the experimental control $\left(0 \mu \mathrm{g} \mathrm{L}^{-1}\right)$ and microcystin-supplemented $\left(25 \mu \mathrm{g} \mathrm{L}^{-1}\right)$ Cuspidothrix issatschenkoi cultures in nine different combinations of light level $\left(20,60,100 \mu \mathrm{mol} \mathrm{m}^{-2} \mathrm{~s}^{-1}\right)$, and temperature $(15,20$, $25^{\circ} \mathrm{C}$ ). Error bars show \pm one standard deviation. 

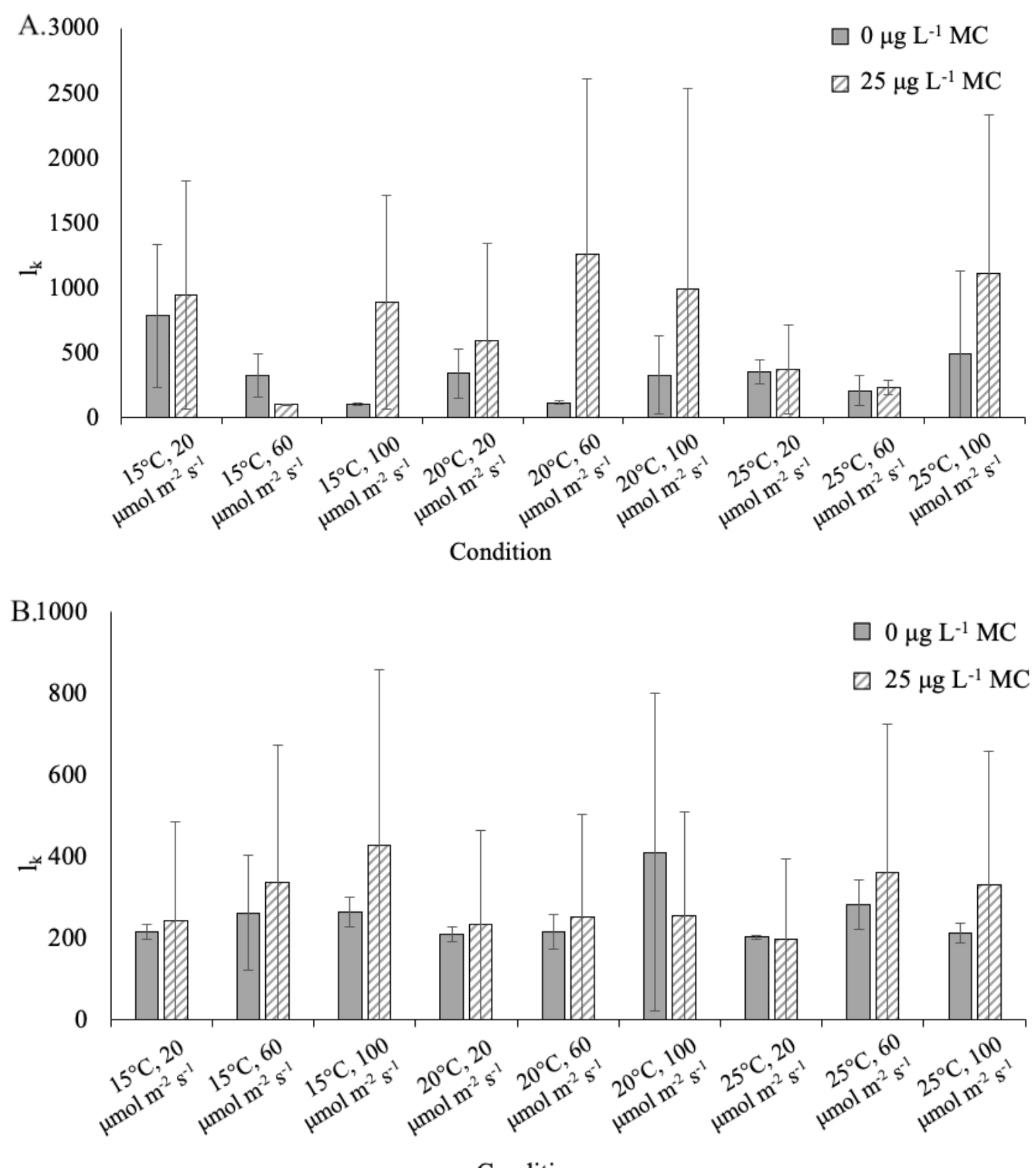

Condition

Figure A1.4 A-B: Mean $l_{\mathrm{K}}$ at $520 \mathrm{~nm}$ (A) and $645 \mathrm{~nm}$ (B) for the experimental control (0 $\mu \mathrm{g}$ $\left.\mathrm{L}^{-1}\right)$ and microcystin-supplemented $\left(25 \mu \mathrm{g} \mathrm{L}^{-1}\right)$ Cuspidothrix issatschenkoi cultures in nine different combinations of light level $\left(20,60,100 \mu \mathrm{mol} \mathrm{m}^{-2} \mathrm{~s}^{-1}\right)$, and temperature $\left(15,20,25^{\circ} \mathrm{C}\right)$. Error bars show \pm one standard deviation. 
Appendix 2: Screening experiment MCPA results, and data for additional PAM fluorometry at 520 and $645 \mathrm{~nm}$ from glyphosate functional analysis described in Chapter 3.

Table A2.1: Linear regression p-values for the relationship between MCPA concentration and growth rate, for all fourteen cyanobacteria strains that were tested in the screening experiment.

\begin{tabular}{lll}
\hline Species & Culture Code & p-value \\
\hline C. issatschenkoi & CAWBG02 & 0.510 \\
D. lemmermannii & CAWBG567 & 0.951 \\
D. lemmermannii & CAWBG680 & 0.957 \\
D. planctonicum & CAWBG651 & 0.258 \\
D. circinale & CAWBG663 & 0.074 \\
$M$. aeruginosa & CAWBG011 & 0.636 \\
$M$. aeruginosa & CAWBG563 & 0.980 \\
$M$. aeruginosa & CAWBG570 & 0.842 \\
$M$. aeruginosa & CAWBG617 & 0.064 \\
$M$. aeruginosa & CAWBG624 & 0.369 \\
$M$. aeruginosa & CAWBG706 & 0.457 \\
$M$. wesenbergii & CAWBG647 & 0.441 \\
N. spumigena & CAWBG021 & 0.716 \\
N. spumigena & CAWBG704 & 0.192 \\
\hline
\end{tabular}


Table A2.2: Statistical results (ANOVA) for determining significant differences in photosynthetic performance of four cyanobacteria species treated with glyphosate cells and the experimental control at 520 and $645 \mathrm{~nm}$.

\begin{tabular}{|c|c|c|c|c|c|c|c|c|c|c|}
\hline & & \multirow[b]{2}{*}{ Species } & \multicolumn{2}{|c|}{$\mathbf{Y}$} & \multicolumn{2}{|c|}{ Alpha } & \multicolumn{2}{|c|}{$\mathbf{E T R}_{\max }$} & \multicolumn{2}{|c|}{$l_{K}$} \\
\hline & & & F-statistic & p-value & F-statistic & p-value & F-statistic & p-value & F-statistic & p-value \\
\hline \multirow{4}{*}{$\begin{array}{l}\text { N } \\
\stackrel{\Xi}{\Xi} \\
\text { 芯 } \\
\text { త্ }\end{array}$} & \multirow{4}{*}{ 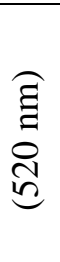 } & D. lemmermannii & 1.172 & 0.372 & 3.944 & 0.081 & 0.162 & 0.855 & 0.315 & 0.743 \\
\hline & & N. spumigena & 2.316 & 0.180 & 0.011 & 0.989 & 1.382 & 0.333 & 0.604 & 0.582 \\
\hline & & M. aeruginosa & 2.711 & 0.115 & 0.102 & 0.957 & 3.211 & 0.083 & 0.925 & 0.471 \\
\hline & & M. wesenbergii & 2.212 & 0.164 & 4.092 & 0.049 & 0.488 & 0.700 & 0.156 & 0.923 \\
\hline \multirow{4}{*}{ 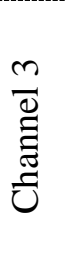 } & \multirow{4}{*}{ 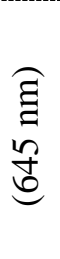 } & D. lemmermannii & 7.498 & 0.023 & 0.168 & 0.85 & 0.136 & 0.876 & 0.159 & 0.856 \\
\hline & & N. spumigena & 0.467 & 0.648 & 10.65 & 0.011 & 1.219 & 0.36 & 0.968 & 0.432 \\
\hline & & M. aeruginosa & 1.388 & 0.315 & 1.041 & 0.426 & 0.372 & 0.776 & 0.237 & 0.868 \\
\hline & & M. wesenbergii & 2.400 & 0.143 & 0.626 & 0.618 & 4.758 & 0.035 & 0.804 & 0.526 \\
\hline
\end{tabular}




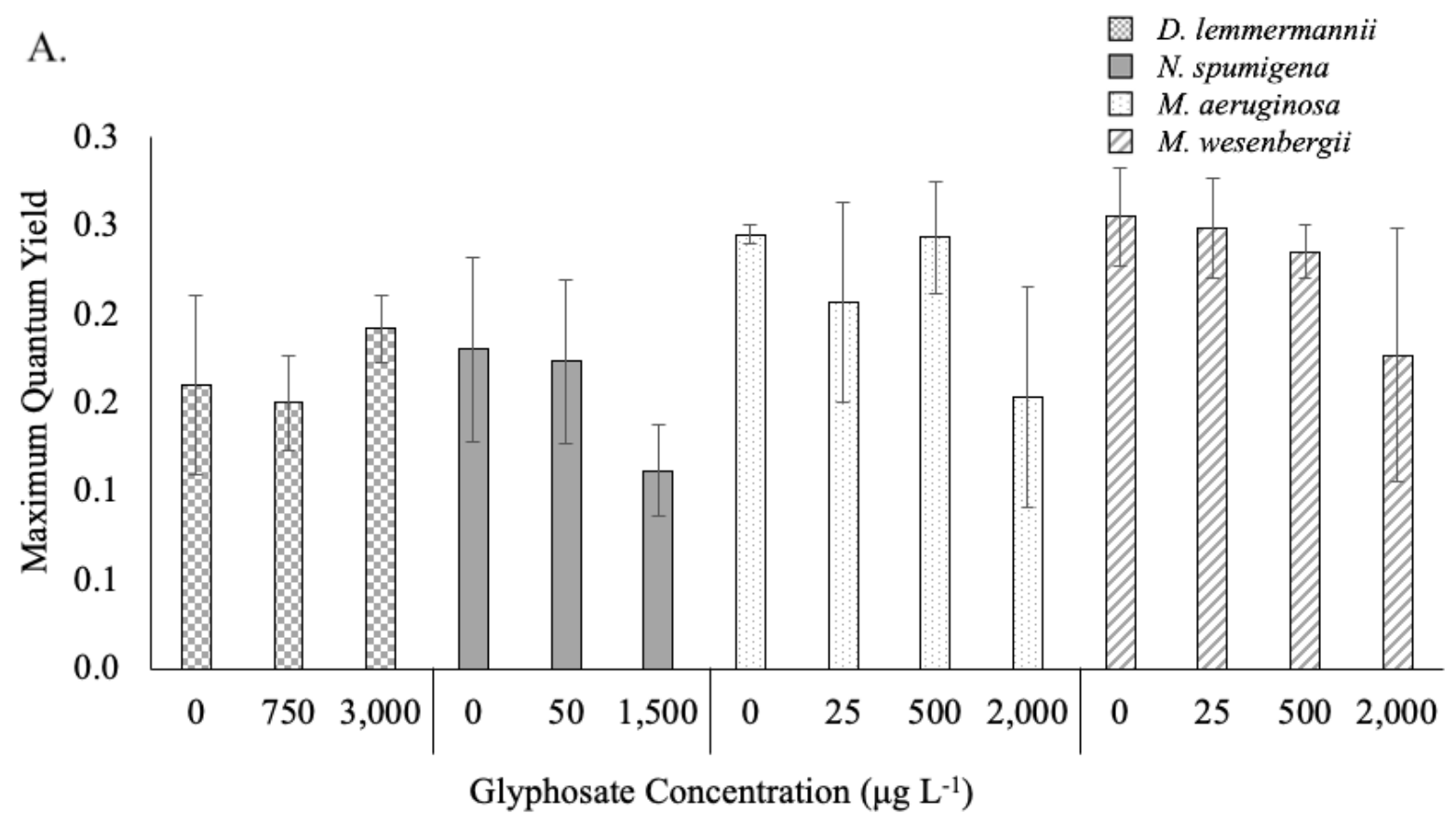

B.

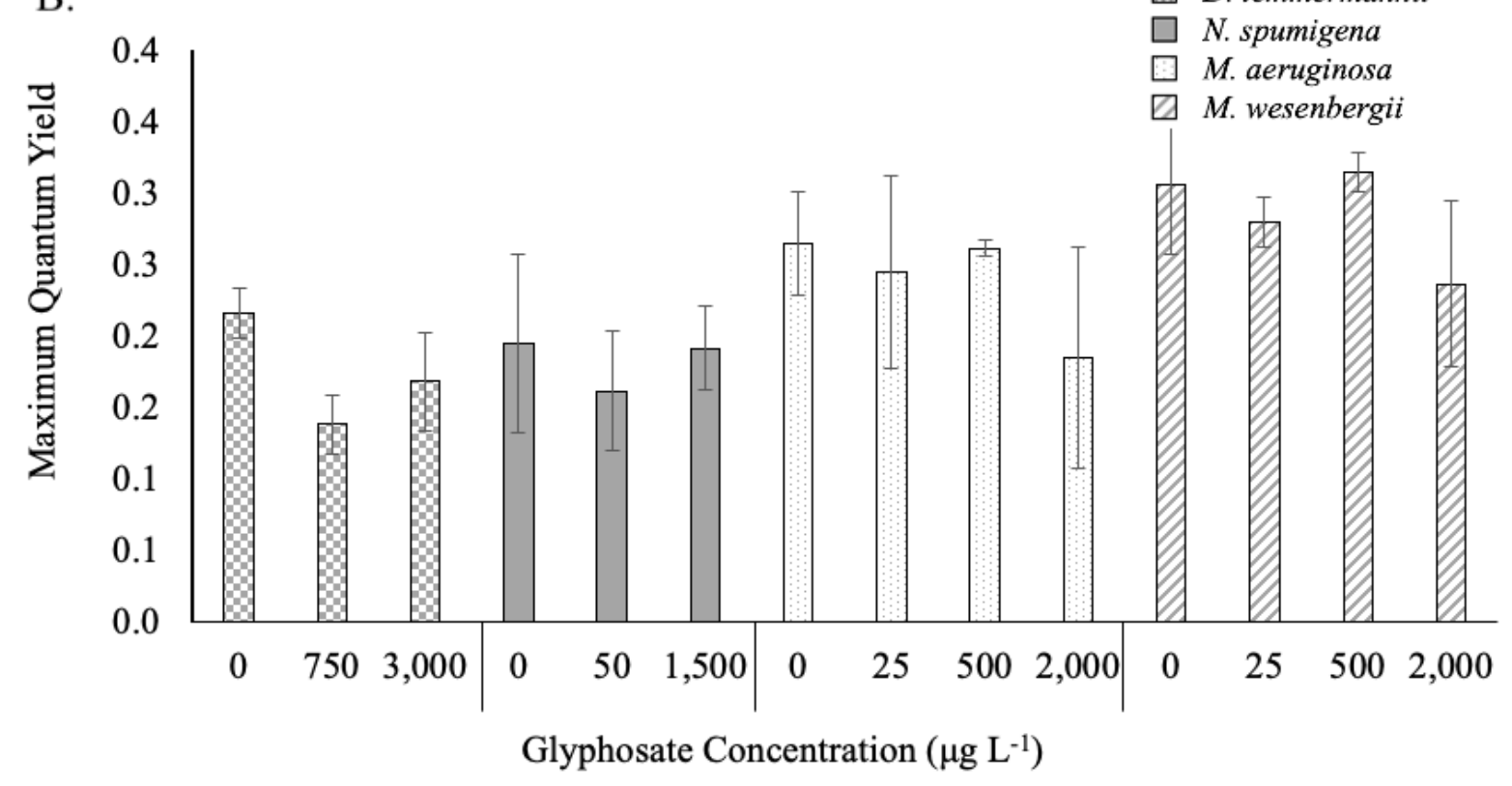

Figure A2.1 A-B: Mean maximum quantum yield at $520 \mathrm{~nm}$ (A) and $645 \mathrm{~nm}$ (B) for each glyphosate concentration (including the experimental control; $0 \mu \mathrm{g} \mathrm{L}^{-1}$ ) for Dolichospermum lemmermannii, Nodularia spumigena, Microcystis aeruginosa, and Microcystis wesenbergii. Error bars show \pm one standard deviation. 


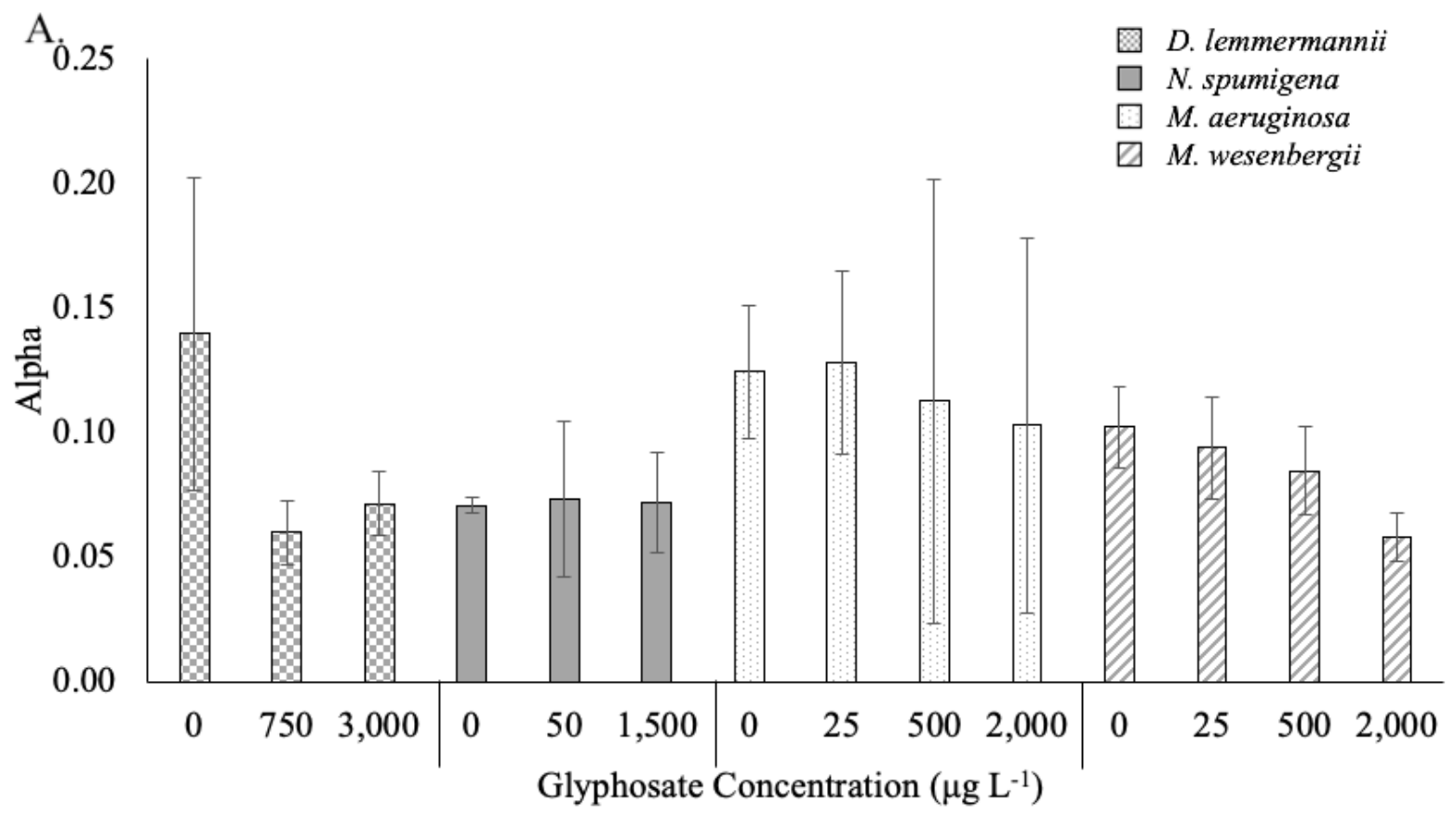

B.
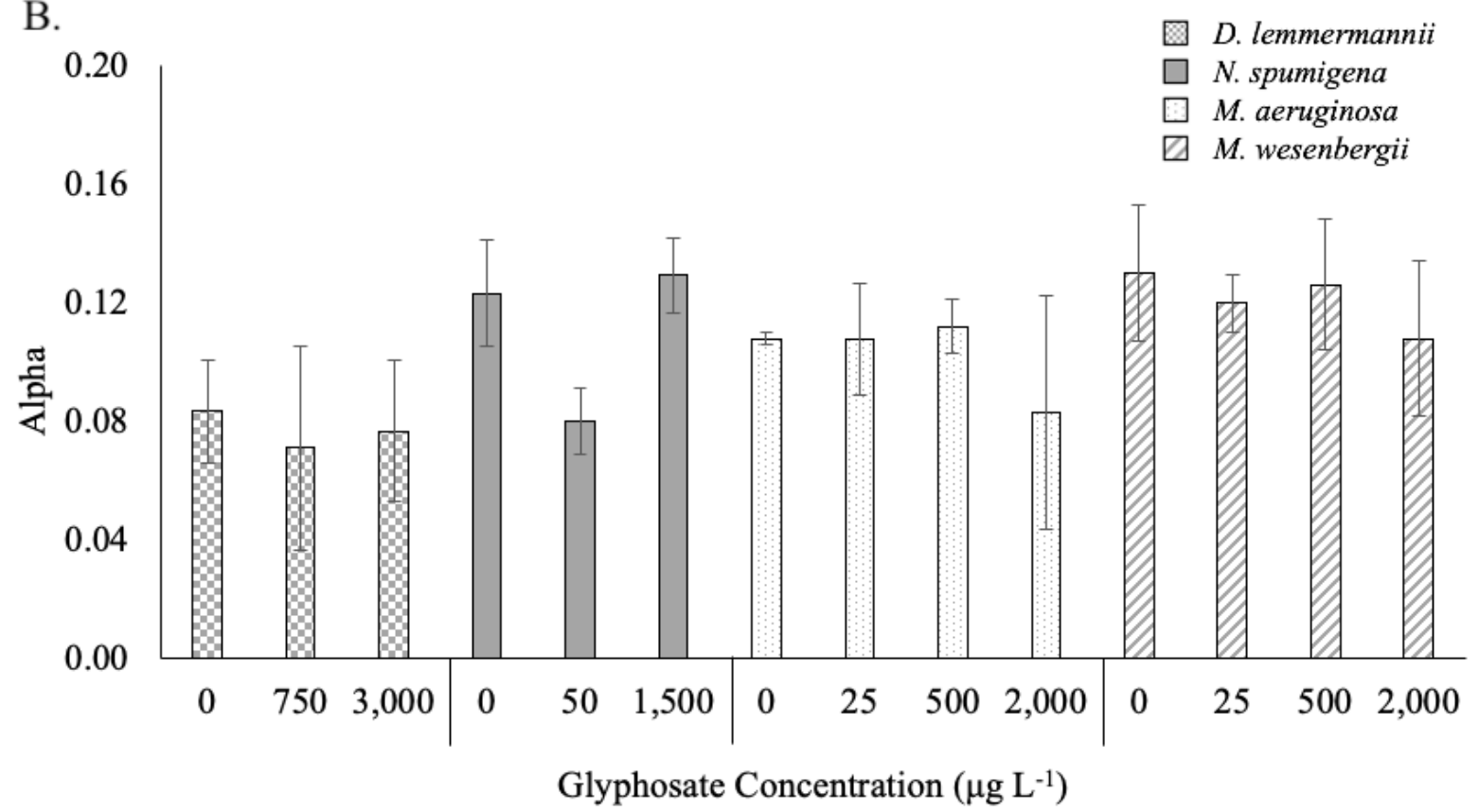

Figure A2.2 A-B: Mean alpha at $520 \mathrm{~nm}$ (A) and $645 \mathrm{~nm}$ (B) for each glyphosate concentration (including the experimental control; $0 \mu \mathrm{g} \mathrm{L}^{-1}$ ) for Dolichospermum lemmermannii, Nodularia spumigena, Microcystis aeruginosa, and Microcystis wesenbergii. Error bars show \pm one standard deviation. 

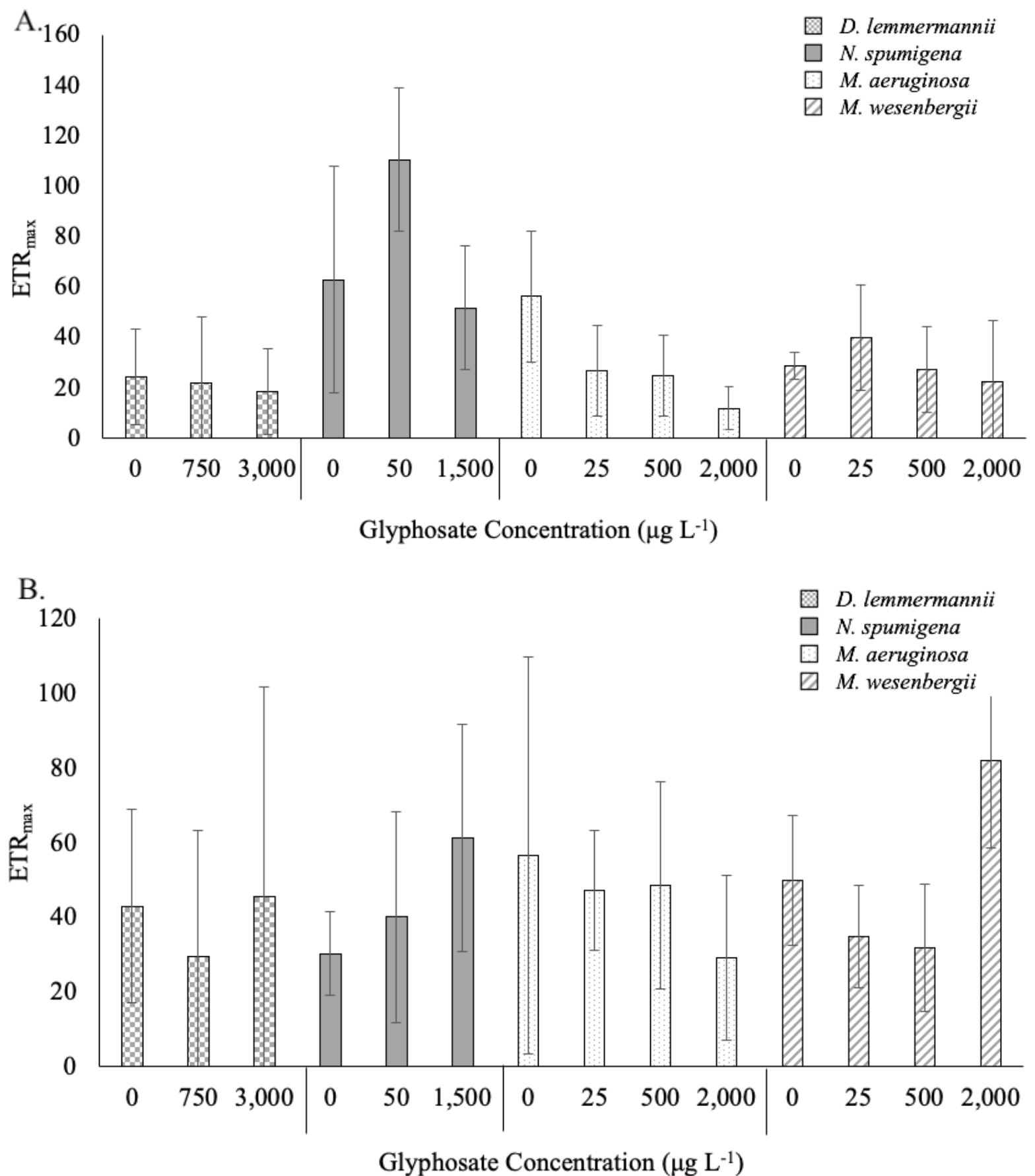

Figure A2.3 A-B: Mean ETR $\max$ at $520 \mathrm{~nm}$ (A) and $645 \mathrm{~nm}$ (B) for each glyphosate concentration (including the experimental control; $0 \mu \mathrm{g} \mathrm{L}^{-1}$ ) for Dolichospermum lemmermannii, Nodularia spumigena, Microcystis aeruginosa, and Microcystis wesenbergii. Error bars show \pm one standard deviation. 

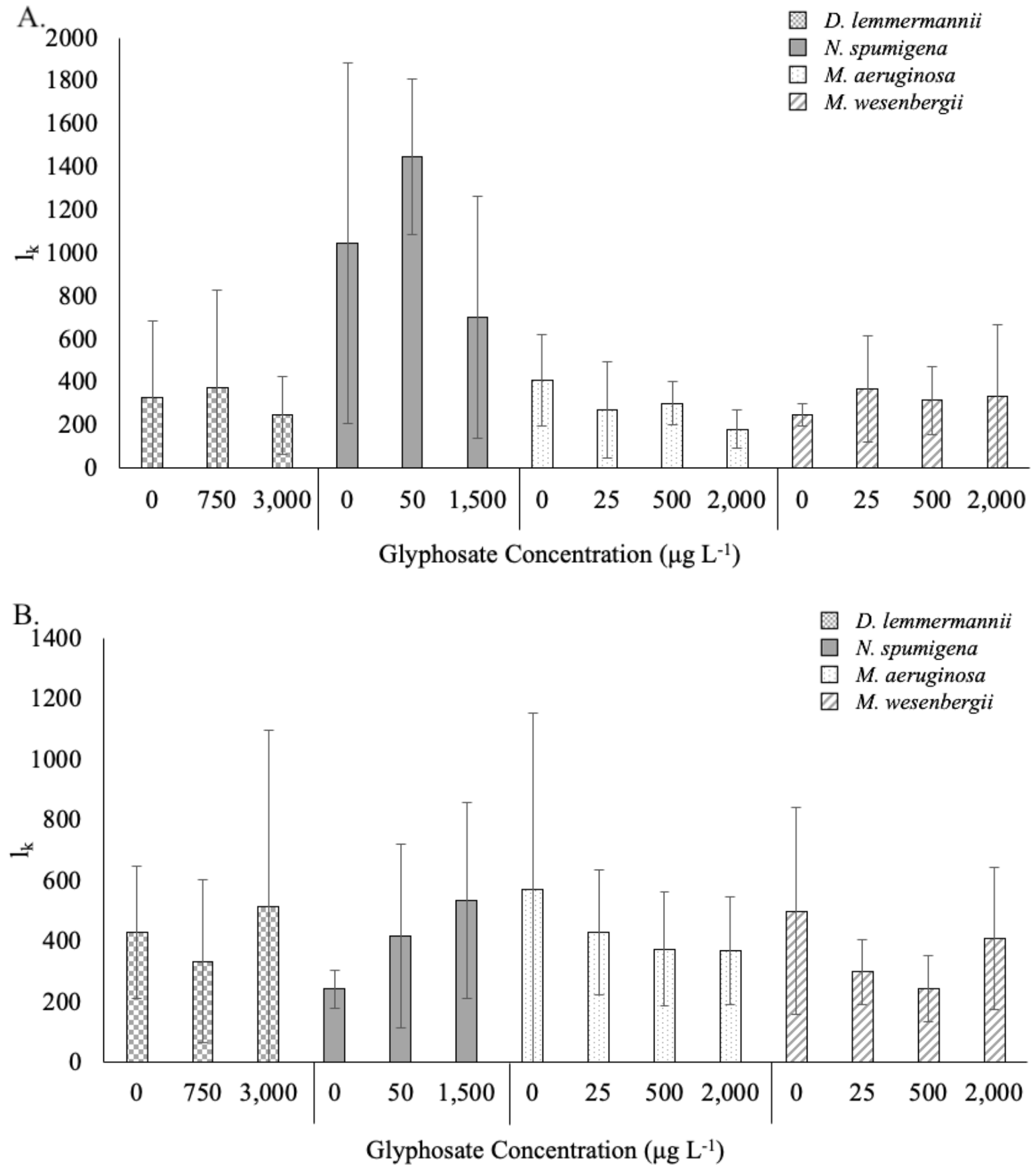

Figure A2.4 A-B: Mean $l_{k}$ at $520 \mathrm{~nm}(\mathrm{~A})$ and $645 \mathrm{~nm}$ (B) for each glyphosate concentration (including the experimental control; $0 \mu \mathrm{g} \mathrm{L}^{-1}$ ) for Dolichospermum lemmermannii, Nodularia spumigena, Microcystis aeruginosa, and Microcystis wesenbergii. Error bars show \pm one standard deviation. 